
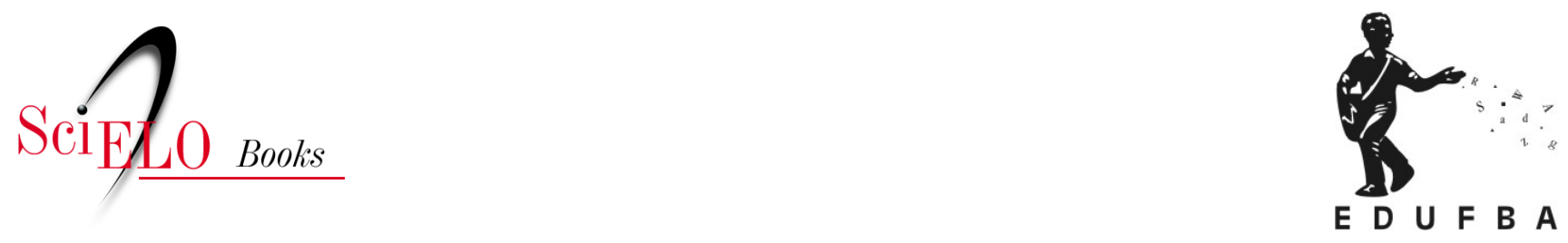

\title{
Avaliação nutricional
}

\author{
Lílian Ramos Sampaio (org.)
}

\section{SciELO Books / SciELO Livros / SciELO Libros}

SAMPAIO, L.R., org. Avaliação nutricional [online]. Salvador: EDUFBA, 2012, 158 p. Sala de aula collection. ISBN: 978-85-232-1874-4. https://doi.org/10.7476/9788523218744.

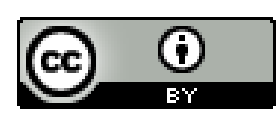

All the contents of this work, except where otherwise noted, is licensed under a Creative Commons Attribution $\underline{4.0 \text { International license. }}$

Todo o conteúdo deste trabalho, exceto quando houver ressalva, é publicado sob a licença Creative Commons Atribição 4.0.

Todo el contenido de esta obra, excepto donde se indique lo contrario, está bajo licencia de la licencia Creative Commons Reconocimento 4.0. 
Avaliação Nutricional 


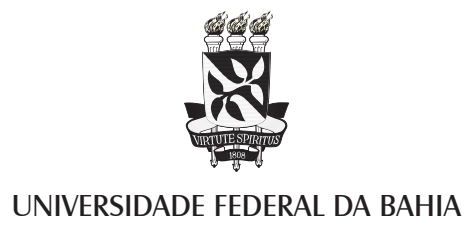

Reitora

Dora Leal Rosa

Vice-Reitor

Luiz Rogério Bastos Leal

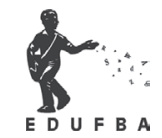

EDITORA DA UNIVERSIDADE FEDERAL DA BAHIA

\title{
Diretora
}

Flávia Goulart Mota Garcia Rosa

\author{
Conselho Editorial \\ Alberto Brum Novaes \\ Angelo Szaniecki Perret Serpa \\ Caiuby Alves da Costa \\ Charbel Ninõ El-Hani \\ Cleise Furtado Mendes \\ Dante Eustachio Lucchesi Ramacciotti \\ Evelina de Carvalho Sá Hoisel \\ José Teixeira Cavalcante Filho \\ Maria Vidal de Negreiros Camargo
}




\title{
Avaliação Nutricional
}

\author{
Lílian Ramos Sampaio \\ Organizadora
}

saladeaula 9

Salvador

EDUFBA, 2012 


\title{
2012, autores
}

Direitos para esta edição cedidos à EDUFBA.

Feito o depósito Legal.

\author{
Projeto gráfico \\ Alana Gonçalves de Carvalho Martins \\ Editoração eletrônica e capa \\ Victor França \\ Preparação de Originais e Revisão de Texto \\ Yasmine Spínola dos Santos \\ Normalização \\ Lucas M. Esperança Vieira
}

\section{Sistema de Bibliotecas - UFBA}

A945 Avaliação nutricional / Organizado por Lílian Ramos Sampaio. - Salvador: EDUFBA, 2012. 158 p. - Série Sala de aula, 9.

ISBN 978-85-232-0975-9

1. Nutrição - avaliação. I Sampaio, Lílian Ramos. II Título.

CDD - 612.39

\section{EDUFBA}

Rua Barão de Jeremoabo, s/n

Campus de Ondina, Salvador-BA

CEP 40170-115

Tel/fax: (71) 3283-6164

unw.edufba.ufba.br

edufba@ufba.br 
Dedico este livro aos alunos da Disciplina Avaliação Nutricional. 


\section{AGRADECIMENTOS}

Agradeço aos bolsistas e monitores que muito contribuíram com este trabalho: Tatiane Melo, Roberta Sá, Bartira Improta, Venusca Rocha, Pricilla Almeida, Valéria Brandão, Matheus Cortes, Taciana Andrade e Edneia Passos. 


\section{Sumário}

\section{Apresentação...11}

Sobre os Autores...13

Avaliação nutricional: conceitos e importância para a formação do nutricionista...15

Maria da Conceição Monteiro da Silva e Lílian Ramos Sampaio

Semiologia nutricional...23

Lílian Ramos Sampaio, Maria da Conceição Monteiro da Silva, Tatiane Oliveira e Venusca Rocha Leite

Avaliação bioquímica do estado nutricional...49

Lílian Ramos Sampaio, Maria da Conceição Monteiro da Silva, Andréia Nishiyamamoto de Oliveira e Catarina Lobo Santos de Souza

\section{Antropometria...73}

Lílian Ramos Sampaio, Maria da Conceição Monteiro da Silva, Tatiane Melo de Oliveira e Christiane Ishikawa Ramos

Técnicas de medidas antropométricas...89

Lílian Ramos Sampaio, Maria da Conceição Monteiro da Silva, Tatiane Melo de Oliveira e Christiane Ishikawa Ramos

Inquérito alimentar...103

Lílian Ramos Sampaio, Maria da Conceição Monteiro da Silva, Anna Karla Carneiro Roriz e Venusca Rocha Leite

Bioimpedância Elétrica...113

Lílian Ramos Sampaio, Michaela Eickembero,

Pricilla de Almeida Moreira e Carolina Cunha de Oliveira

Anexos...133 


\section{Apresentação}

O livro de apoio didático ora apresentado emerge como uma proposta de auxílio aos alunos na sistematização e apropriação do conhecimento sobre Avaliação Nutricional (disciplina da graduação em Nutrição - NUT 143). Trata-se de um componente curricular obrigatório de grande relevância para o processo de formação do nutricionista, uma vez que o conhecimento que dele se processa é utilizado nas diferentes áreas de atuação do profissional.

Inserido no projeto pedagógico do curso de Nutrição, da Universidade Federal da Bahia, do $6^{\circ}$ semestre do curso, o componente curricular NUT 143 - Avaliação Nutricional apresenta a seguinte ementa:

Métodos e técnicas de avaliaçāo direta e indireta do estado nutricional de indivíduos e populações. Processo de determinação do estado nutricional nos diferentes ciclos de vida. Planejamento, análise e acompanhamento de diagnóstico nutricional de indivíduos e grupos populacionais.

A pretensão é que este material se converta em um importante instrumento pedagógico, capaz de apoiar o professor no processo de ensino e estimular o aluno na busca do conhecimento, de forma organizada e ampliada, considerando que o conhecimento aqui sistematizado está longe de atender a real necessidade do aluno, em termos de aprofundamento, para o futuro exercício da profissão. Assim, a complementaridade deve ser feita com o aluno agregando outros referenciais bibliográficos, indicados pelo professor e por ele descobertos no decorrer das aulas.

Este material contempla os métodos e técnicas relacionados aos principais indicadores de avaliação nutricional de indivíduos e coletividades, ou seja: Semiologia, Marcadores bioquímicos, Antropometria, Inquérito Alimentar e Bioimpedância. 


\section{Sobre os Autores}

\section{Andréia Nishiyamamoto de Oliveira}

Graduada em Nutrição pela Universidade do Estado do Rio de Janeiro (UERJ) (2002 a 2005), pós-graduada em Nutrição Clínica pela Universidade Gama Filho (março/2007 a setembro/2008), pós-graduada em Nutrição Oncológica pelo Instituto Nacional de Câncer (INCA) (março a setembro 2009) tem residência em Nutrição Clínica pelo Hospital Universitário Pedro Ernesto (fevereiro/2007 a janeiro/2009) e é professora substituta da Escola de Nutrição da Universidade Federal da Bahia (desde março/2010).

\section{Anna Karla Carneiro Roriz}

Graduada em Nutrição pela Universidade Federal da Bahia (UFBA), doutoranda em Medicina e Saúde (UFBA), mestre em Alimentos Nutrição e Saúde (ENUFBA) e especialista em Nutrição Clínica (ENUFBA).

\section{Carolina Cunha de Oliveira}

Graduada em Nutrição pela Universidade Federal da Bahia (UFBA) (2009) e mestre em Alimentos, Nutrição e Saúde (UFBA).

\section{Christiane Ishikawa Ramos}

Graduada em Nutrição pela Universidade Federal da Bahia (UFBA) (2008). Aprimoranda em Nutrição Hospitalar - pelo Programa de Aprimoramento, no Hospital Universitário da Universidade de São Paulo (PAP-HU-USP).

\section{Lílian Ramos Sampaio}

Professora Adjunta da Escola de Nutrição da Universidade Federal da Bahia (UFBA). Possui graduação em Nutrição pela UFBA (1988), mestrado em Nutrição Humana Aplicada pela Universidade de São Paulo (1997) e doutorado em Ciência (Nutrição) pela Universidade Federal de São Paulo (2004). Possui título de Especialista em Gerontologia pela Sociedade Brasileira de Geriatria e Gerontologia. Os projetos de pesquisa, de extensão, as orientações e disciplinas que ministra têm como ênfase as áreas de Avaliação Nutricional e Nutrição e Envelhecimento. 
Michaela Eickemberg - Nutricionista e Mestre em Alimentos, Nutrição e Saúde pela Escola de Nutrição da UFBA e especialista em Nutrição Clínica pelo GANEP (2007).

\section{Maria da Conceição Monteiro da Silva}

Nutricionista, mestre em Saúde Comunitária pelo Instituto de Saúde Coletiva (UFBA), doutoranda no Programa de Pós-graduação de Medicina e Saúde pela Faculdade de Medicina da UFBA e professora adjunto III, lotada no Departamento da Ciência da Nutrição - Escola de Nutrição da UFBA.

\section{Pricilla de Almeida Moreira}

Graduada em Nutrição pela Universidade Federal da Bahia (UFBA) (2009) e mestranda em Alimentos, Nutrição e Saúde (UFBA).

\section{Tatiane Melo de Oliveira}

Graduanda em Nutrição pela Universidade Federal da Bahia (UFBA). Já atuou em pesquisas na área de segurança alimentar e higiene. Estágiária voluntária no ambulatório Magalhães Neto, na especialidade de geriatria, durante o ano de 2009. Monitora por dois semestres consecutivos na disciplina Avaliação Nutricional, oferecida pela Escola de Nutrição da UFBA. Atualmente, atua na área de Nutrição Clínica, com participação no desenvolvimento de pesquisas.

\section{Venusca Rocha Leite}

Graduada em Nutrição pela Universidade Federal da Bahia (UFBA) e bolsista do Programa Permanecer. 


\section{Avaliação nutricional: conceitos e importância para a formação do nutricionista}

Maria da Conceição Monteiro da Silva Lílian Ramos Sampaio

Ao iniciar o estudo da avaliação nutricional, faz-se necessário apropriar-se de alguns conceitos, começando pelo significado de avaliação, de estado nutricional e, por fim, de avaliação do estado nutricional. Assim, avaliar, de acordo com o dicionário de Aurélio Buarque, significa: "julgar"; "fazer apreciação", ou seja, comparar resultados com referências, parâmetros e valores cientificamente, tecnicamente ou politicamente aceitos.

Para o conceito de "estado nutricional", adotamos o proposto por Vasconcelos (2008), por incorporar a dimensão biológica (manifestação biológica sobre o corpo da relação entre consumo e as necessidades nutricionais) e social (manifestação biológica das relações que se operam sobre o corpo no interior 
da sociedade). Dessa forma, o autor conceitua estado nutricional como a síntese orgânica das relações entre o homem, a natureza e o alimento, as quais se estabelecem no interior de uma sociedade. Portanto, para a avaliação do estado nutricional de um individuo ou grupo populacional, é necessária a utilização de métodos de coleta e procedimentos diagnósticos que possibilitem determinar o estado nutricional, assim como as causas prováveis que deram origem ao(s) problema(s) nutricional(is), para que medidas de intervenção sejam planejadas, executadas e monitoradas nos âmbitos individual ou coletivo.

Em referência aos conceitos apresentados, a avaliação do estado nutricional tem como objetivo identificar distúrbios e riscos nutricionais, e também a gravidade desses, para então traçar condutas que possibilitem a recuperação ou manutenção adequada do estado de saúde. O monitoramento do paciente, através da avaliação nutricional, também é muito importante para acompanhar as respostas do indivíduo às intervenções nutricionais. Outros usos da avaliação nutricional de grande relevância: na vigilância alimentar e nutricional nos diferentes ciclos da vida; no diagnóstico da magnitude e distribuição geográfica dos problemas nutricionais; na tomada de decisão para intervenção nutricional no âmbito das políticas e dos programas públicos de combate aos problemas nutricionais mais relevantes considerados como sendo de saúde pública e no monitoramento dos efeitos da intervenção nutricional nos âmbitos individual e coletivo.

O conceito de estado nutricional aqui adotado implica na concepção de um modelo multicausal de determinação dos problemas nutricionais que aumenta sua complexidade na medida em que incorpora uma hierarquização no processo de causalidade. Este modelo parte de causas básicas/estruturais que expressam os processos econômicos, políticos e ideológicos da organização 
social, o desenvolvimento das forças produtivas e as relações de produção. Este, então, segue para um nível de determinação intermediário (mediato), que tem a ver com as relações de organização de produção e consumo de cada classe social, e, finalmente, atinge o nível de determinação mais imediato ou individual que se relaciona com a influência de fatores biológicos, ambientais, econômicos, sociais (quanto à saúde e à educação), culturais e ideológicos e com a forma como se organiza a produção e o consumo familiar e individual. Este último nível se relaciona mais diretamente com a dimensão biológica quando considera a relação entre ingestão alimentar e gasto energético. Assim, em ultima instância, é no desequilíbrio entre o consumo alimentar e o gasto energético que se observam as alterações no estado nutricional ao nível do corpo biológico.

O desequilíbrio entre consumo e necessidades nutricionais, em decorrência do consumo insuficiente para atender as necessidades nutricionais, pode ter como consequência doenças carenciais, a exemplo da desnutrição energético protéica, anemia ferropriva, hipovitaminose A, bócio, cárie dental, dentre outras carências nutricionais. No caso do excesso de consumo, tem-se a obesidade, excesso de algumas vitaminas e minerais, as dislipidemias e algumas doenças crônicas não transmissíveis, como a hipertensão, o diabetes não insulino dependente e alguns tipos de câncer. Pelo exposto, a definição dos métodos a serem utilizados na avaliação do estado nutricional tem relação com a identificação das manifestações orgânicas dos problemas nutricionais ao nível do corpo, denominados de métodos diretos, e com a identificação das causas desses problemas, denominados de indiretos. Os métodos diretos são classificados, ainda de acordo com o tipo de abordagem, em objetivos (abordagem quantitativa) e subjetivos (abordagem qualitativa). Os métodos objetivos compreen- 
dem os exames antropométricos (peso, altura, dobra cutânea etc); exames laboratoriais (hemoglobina, colesterol etc); exame clínico nutricional (sinais e sintomas clínicos nutricionais) e métodos sofisticados como a densitometria, bioimpedância etc. Quanto aos subjetivos, tem-se a semiologia nutricional, a avaliação subjetiva global e a avaliação muscular subjetiva.

Os métodos indiretos buscam identificar os fatores associados ao processo de determinação do estado nutricional, ou seja, aqueles que explicam a ocorrência do problema nutricional, além de identificarem indivíduos ou grupos em risco nutricional. São os demográficos (sexo, idade, faixa etária, morbidade, mortalidade etc); socioeconômicos (salário, ocupação, escolaridade, acesso ao serviço de saúde etc.); culturais (tabus alimentares, características locais específicas); estilo de vida (atividade física, hábito de fumar e consumir bebida alcoólica, etc.) e de inquérito de consumo alimentar (recordatório alimentar de 24 horas, frequência alimentar, pesada direta etc.). A associação de todos esses métodos é imprescindível para melhorar a acurácia e precisão do diagnóstico.

Com o apoio dos métodos diretos e indiretos podem ser construídos os indicadores do estado nutricional. A partir dessa premissa e de posse do conhecimento epidemiológico e clinico do processo de determinação dos problemas nutricionais, é possível direcionar e ampliar as informações a serem obtidas, considerando a queixa do paciente e fatores ambientais, com sua influência no acesso ao alimento, genéticos (hereditariedade, predisposição ao desenvolvimento de doenças etc) e psicológicos (anorexia, bulimia, ansiedade, etc). Dessa forma, durante o atendimento nutricional, o nutricionista deve estar atento a todas essas condições, no sentido de potencializar a eficácia da intervenção nutricional. Considerando a variabilidade dos métodos para avaliação do estado nutricional, é necessário saber escolhê-los. Para a escolha 
dos métodos adequados para aplicação em determinada situação é importante a apropriação de alguns conhecimentos, tais como: distinguir uma avaliação para coletividade (pesquisa) de uma avaliação nutricional individual, pois, apesar do mesmo objetivo - correção e/ou manutenção do estado nutricional adequado -, existem métodos que são possíveis de se desenvolver em uma avaliação individual, mas que não se aplicam em populações/ coletividades; a epidemiologia do problema a ser investigado e as formas de manifestações orgânicas dos problemas nutricionais, assim como o conhecimento sobre a validade dos métodos em termos de sensibilidade e especificidade para o diagnóstico do problema nutricional a ser investigado. Ou seja, a escolha do método a ser utilizado dependerá inicialmente do objetivo da avaliação e dos problemas a serem investigados.

Agrega-se ainda à diversidade de elementos a serem avaliados e considerados para escolha do método adequado à faixa etária em questão as condições do espaço físico para o exame e a disponibilidade dos instrumentos, dentre outros quesitos. A avaliação nutricional pode ser individual ou coletiva, a depender do método utilizado: clínico ou epidemiológico.

A avaliação de populações ou coletividades apresenta caráter mais abrangente, uma vez que aborda a questão com maior ênfase na dimensão social, possibilitando o diagnóstico e a explicação dos fatores de determinação para um dado grupo ou população, que conduz a ações de promoção e prevenção para a coletividade, e não para o indivíduo.

A avaliação nutricional de coletividades, mais utilizada por profissionais que atuam na área da saúde coletiva, será abordada em um capítulo específico no segundo volume desta série didática. 
A avaliação nutricional do indivíduo, ou avaliação nutricional no âmbito da clínica, é uma ação desenvolvida pelo nutricionista no seu processo de trabalho domiciliar, ambulatorial e hospitalar. Para a realização da avaliação nutricional, há a necessidade do uso do raciocínio clínico e investigativo para associar o conhecimento técnico e cientifico à habilidade na utilização de métodos e técnicas de diagnóstico e ao processo de determinação dos problemas nutricionais.

\section{Considerações Finais}

Em quase todas as áreas de atuação, o nutricionista terá que fundamentar a sua prática em informações sobre o perfil nutricional do indivíduo ou grupos populacionais. Assim, avaliar o estado nutricional de um indivíduo ou de uma coletividade é um instrumental importante no processo de trabalho do nutricionista nas diferentes áreas de atuação, a saber: i) $\mathrm{Na}$ área da alimentação coletiva, necessária para o planejamento dos cardápios, de acordo com as condições de saúde e nutrição da clientela; para o monitoramento do estado nutricional e para ações educativas ou outras intervenções necessárias para promoção da saúde, alimentação saudável e prevenção de problemas nutricionais; ii) No que se refere à nutrição e saúde pública, conhecer o estado nutricional da população é de fundamental importância para o planejamento de políticas públicas e programas na área da alimentação e nutrição; para o monitoramento e execução de ações de promoção da alimentação saudável e de prevenção dos distúrbios nutricionais; iii) $\mathrm{Na}$ nutrição clínica, em que a obtenção do diagnóstico nutricional e as causas a ele relacionadas é condição necessária para 
a elaboração do plano de atenção alimentar e nutricional para o paciente, incluindo a prescrição da dieta.

Diante de uma nova sociedade detentora de um conhecimento ampliado referente à alimentação, ciente dos muitos malefícios e benefícios trazidos por certos alimentos, somados à realidade de transição nutricional e às mudanças nos padrões alimentares, o nutricionista deve estar bem preparado, atualizado e possuir segurança tanto na utilização como na interpretação dos diversos métodos de avaliação nutricional.

\section{Referências}

GIBSON, R. S. Anthropometric assessment of growth. In: Gibson R. S. Principles of nutritional assessment. New York: Oxford University Press, 1990. p. 163-186.

UNIVERSIDADE FEDERAL DA BAHIA. Escola de Nutrição Avaliação nutricional: componente curricular NUT 143. Salvador, 200-?.

VASCONCELOS, Francisco de Assis Guedes. Avaliação nutricional de coletividades. 4. ed. rev. e amp. Florianópolis: Ed. UFSC, 2008. 186 p. 


\title{
Semiologia nutricional
}

\author{
Lílian Ramos Sampaio \\ Maria da Conceição Monteiro da Silva \\ Tatiane Melo de Oliveira \\ Venusca Rocha Leite
}

O termo semiologia, criado a partir do grego sèmeion (sinal) e logos (estudo, ciência), designa a ciência dos sinais, isto é, a ciência que estuda a organização dos sistemas significantes.

$\mathrm{Na}$ área da saúde, a semiologia compreende o estudo dos sinais e sintomas do indivíduo, no qual os sinais representam as manifestações clínicas de uma doença observadas pelo examinador por meio da inspeção, palpação ou ausculta. Os sintomas são sensações subjetivas, sentidas pelo indivíduo e não visualizada pelo examinador. E, para avaliação dessas alterações e/ou manifestações semiológicas, no que se refere aos problemas nutricionais, o nutricionista dispõe da anamnese nutricional para a identificação dos sintomas clínicos nutricionais e do exame físico na avaliação dos sinais clínicos nutricionais.

O exame clínico nutricional consiste em avaliar as alterações orgânicas expressas nos tecidos externos 
do indivíduo, ou mesmo a evolução de patologias já existentes no organismo. Estas situações possivelmente podem associar-se à inadequação alimentar, seja por deficiência ou excesso na ingestão. Assim, por meio da semiologia nutricional, busca-se determinar as condições nutricionais do paciente, identificar os sinais e sintomas de carência ou excesso de nutrientes e correlacioná-los com os hábitos alimentares. É um indicador subjetivo, uma vez que sua avaliação não resulta em um valor, e sim nas impressões individuais do avaliador e do avaliado.

É importante lembrar que para o sinal clínico ser considerado consequência de problemas nutricionais ele deve ser primordialmente bilateral. Sendo assim, a avaliação é realizada minuciosamente, sendo priorizados, no momento do exame, aqueles sinais referentes aos problemas de maior prevalência nas diferentes faixas etárias e considerando as informações obtidas a partir da avaliação da anamnese e do consumo alimentar.

Apesar da facilidade de aplicação desse método, a semiologia nutricional apresenta como principais limitações o fato de que as manifestações clínicas são evidenciadas apenas nos estados mais avançados de excesso e/ou carência nutricional, e para adequada identificação é necessário treinamento para melhorar a habilidade no reconhecimento dos sinais clínicos nutricionais.

\section{Anamnese Nutricional}

A palavra anamnese vem do grego anmnesis e significa recordar. $\mathrm{Na}$ prática clínica, significa a rememoração dos eventos relacionados à saúde e à identificação dos sintomas e sinais atuais, com o intuito principal de possibilitar entender, com a maior precisão possível, a história dos motivos que traz o paciente à 
consulta. Dessa forma, a anamnese ou história clínica é de grande relevância para se reconhecer e entender as três dimensões do diagnóstico: o paciente, a moléstia e as circunstâncias associadas. Além disso, a anamnese é indispensável para o alcance de uma relação entre paciente e profissional adequada. A importância deste tipo de relacionamento é evidente, já que dele dependerá, em sua maior parte, o grau de confiança que o paciente irá depositar nesse profissional, a qualidade das informações que serão transmitidas ou mesmo a colaboração que o paciente oferecerá em relação à adesão da conduta terapêutica. Na nutrição, o sucesso da conduta é, em maior parte, dependente de mudanças nos hábitos alimentares, estes que, na maioria das vezes, representam um desafio, sendo imprescindível uma relação harmônica do binômio paciente-nutricionista.

$\mathrm{Na}$ avaliação nutricional, a história clínica é direcionada para identificação da situação nutricional e de fatores de determinação associados. O paciente deve então ser interrogado sobre fatores que interferem direta ou indiretamente no estado nutricional: perda ou ganho ponderal recente; sinais de doenças gastrointestinais, como náuseas, vômitos, diarreia; uso de medicamentos que interferem na absorção e na utilização dos nutrientes; presença de fatores limitantes na ingestão adequada, como anorexia, lesões bucais, dificuldades de mastigação; presença de doenças crônicas ou intervenções cirúrgicas e etilismo e tabagismo, além de fatores psíquicos que possam interferir na ingestão alimentar.

Apesar de importante, a história clínica nutricional não deve ser usada isoladamente, uma vez que a capacidade desse método depende de variáveis como: condição clínica e tipo de informante (em geral, o paciente ou acompanhante) e de entrevistador (no caso, o nutricionista) - situações estas que, quando não se apresentam de maneira positiva, podem comprometer a eficácia da 
anamnese. Na maioria das vezes, as dificuldades existentes estão na deficiência de comunicação entre o paciente e o profissional de saúde. Sendo assim, este último deve estar preparado e saber como irá atuar nas diversas situações listadas no quadro 1.

- Deficiência na fonação ou audição

- Diferenças de linguagem

- Depressão do estado de consciência

- Distúrbios mentais

- Crianças - Falta de objetividade - Incoerência

- Deficiência de memória e observação

- Concepções errôneas sobre a moléstia

- Falta de confiança na nutrição

- Inibição e/ou distração causadas pela presença de outras pessoas

Quadro 1 - Limitações da anamnese decorrentes do paciente Fonte: Adaptado de López e Medeiros (2001).

Além da anamnese geral, na avaliação nutricional temos a anamnese alimentar. Esta representa o ponto de partida para a avaliação da ingestão alimentar. Feita com base nos inquéritos alimentares, busca-se fazer com que o paciente relate como é o seu padrão alimentar e os fatores relacionados.

\section{Exame Físico}

A realização do exame físico, tanto geral como específico, é importante, pois irá complementar a história clínica, alimentar e 
nutricional e proporcionar elementos capazes de apoiar hipóteses sobre o diagnóstico nutricional. O exame físico geral pode avaliar uma série de dados do paciente, incluindo os antropométricos e sinais clínicos. O exame físico engloba observações dos diversos tecidos de proliferação rápida, os quais refletem precocemente problemas nutricionais, quando comparados a outros tecidos, sistemas corporais (cardiovascular, respiratório, neurológico e gastrointestinal) dos tecidos adiposo e muscular e da condição hídrica do paciente, buscando sempre investigar a presença de alterações específicas.

Inicialmente, deve-se registrar a impressão sobre o estado geral do paciente por meio da observação e relato deste. Ânimo, depressão, fraqueza, tipo físico, estado de consciência, discurso e movimentos corporais devem ser investigados.

O exame deve ser realizado de forma sistemática e progressiva, a partir da cabeça até a região plantar. Inicia-se pelo cabelo, seguido dos olhos, narinas, face, boca (lábios, dentes, língua), pescoço (tireóide), tórax (abdome), membros superiores (unhas, região palmar) e inferiores (quadríceps, joelho, tornozelo, região plantar), pele e sistemas (cardiovascular, neurológico, respiratório e gastrointestinal), de acordo com quadro 2.

No caso do adolescente, deve-se examinar também o desenvolvimento das mamas, pelos pubianos e genitália. A fase da pubescência pode ser avaliada através da observação do paciente sobre o seu próprio corpo e utilizando os estágios de Tanner.

Cada parte do corpo deve ser examinada de forma cuidadosa, para que, associada ao relato dos sintomas e de outras informações, seja possível a definição ou suspeita diagnóstica para subsidiar a solicitação dos exames laboratoriais. 


\begin{tabular}{|c|c|c|}
\hline $\begin{array}{l}\text { Região/ } \\
\text { situação exa- } \\
\text { minada }\end{array}$ & $\begin{array}{l}\text { Característica(s) a ser(em) } \\
\text { avaliada(s) }\end{array}$ & $\begin{array}{l}\text { Características em } \\
\text { condições normais }\end{array}$ \\
\hline Cabelo & $\begin{array}{l}\text { Coloração, brilho, quantidade, espessu- } \\
\text { ra, hidratação, ocorrência de alopecia. }\end{array}$ & $\begin{array}{l}\text { Brilhantes, firmes e } \\
\text { difíceis de arrancar, } \\
\text { aparência normal e } \\
\text { espessa, crescimento } \\
\text { normal, macios ao } \\
\text { tato e coloração } \\
\text { adequada. }\end{array}$ \\
\hline Face & $\begin{array}{l}\text { Estado geral, condição físico. Presença } \\
\text { de edema ou depleção (sinal de chave } \\
\text { - exposição do arco zigomático). Apre- } \\
\text { sentação de: palidez, atrofia unilateral } \\
\text { ou bitemporal. Fácies agudo: exausto, } \\
\text { cansado, não consegue manter os olhos } \\
\text { abertos por muito tempo; Fácies crôni- } \\
\text { co: aparência deprimida, triste, pouco } \\
\text { diálogo. }\end{array}$ & $\begin{array}{l}\text { Bom Estado Geral, } \\
\text { sem sinais de deple- } \\
\text { ção ou edema. }\end{array}$ \\
\hline Olhos & $\begin{array}{l}\text { Aspecto, cor das mucosas e membranas, } \\
\text { sinais de excesso de nutrientes - xan- } \\
\text { telasma, arco córneo lipídico, sinais de } \\
\text { deficiência de nutrientes: desnutrição } \\
\text { - olhos escavados, escuros e flacidez ao } \\
\text { redor, hipovitaminoses - xeroftalmia, } \\
\text { nictalopia, etc. }\end{array}$ & $\begin{array}{l}\text { Brilhantes, membra- } \\
\text { nas róseas e úmidas, } \\
\text { sem manchas e boa } \\
\text { adaptação visual no } \\
\text { escuro. }\end{array}$ \\
\hline Lábios & $\begin{array}{l}\text { Coloração da mucosa, presença de } \\
\text { lesões decorrentes de hipovitaminoses. }\end{array}$ & $\begin{array}{l}\text { Lábios macios e sem } \\
\text { inflamações. }\end{array}$ \\
\hline Língua & $\begin{array}{l}\text { Coloração, integridade papilar, edema, } \\
\text { espessamento. }\end{array}$ & $\begin{array}{l}\text { Língua vermelha, } \\
\text { sem edema, com } \\
\text { superfície normal e } \\
\text { paladar preservado. }\end{array}$ \\
\hline Gengivas & Edema, porosidade e sangramento & $\begin{array}{l}\text { Ausência de sangra- } \\
\text { mentos e edema. }\end{array}$ \\
\hline Peças dentárias & $\begin{array}{l}\text { Presença de cáries, ausência de peças } \\
\text { dentárias, uso de prótese (bem adaptada } \\
\text { ou não), alterações em função de exces- } \\
\text { so ou escassez de nutrientes. }\end{array}$ & $\begin{array}{l}\text { Arcada dentária ín- } \\
\text { tegra, sem ausência } \\
\text { de peças dentárias } \\
\text { ou uso de prótese } \\
\text { bem adaptada - não } \\
\text { ocasionar compro- } \\
\text { metimento da mas- } \\
\text { tigação. }\end{array}$ \\
\hline
\end{tabular}




\begin{tabular}{|c|c|c|}
\hline $\begin{array}{l}\text { Região/ } \\
\text { situação exa- } \\
\text { minada }\end{array}$ & $\begin{array}{l}\text { Característica(s) a ser(em) } \\
\text { avaliada(s) }\end{array}$ & $\begin{array}{l}\text { Características em } \\
\text { condições normais }\end{array}$ \\
\hline Pele & $\begin{array}{l}\text { Cor, pigmentação, integridade, turgor, } \\
\text { presença de edema, brilho e temperatu- } \\
\text { ra, manifestações decorrentes de defici- } \\
\text { ência ou excesso de nutrientes. }\end{array}$ & $\begin{array}{l}\text { Cor uniforme, lisa, } \\
\text { aparência saudável, } \\
\text { turgor preservados } \\
\text { ou compatíveis com } \\
\text { a idade (no caso de } \\
\text { idosos). }\end{array}$ \\
\hline Unhas & $\begin{array}{l}\text { Forma, ângulo, coloração, contorno, } \\
\text { rigidez e presença de micoses. }\end{array}$ & $\begin{array}{l}\text { Uniformes, arre- } \\
\text { dondadas, lisas e } \\
\text { firmes. }\end{array}$ \\
\hline Abdôme & $\begin{array}{l}\text { Quanto à rigidez: flácido ou tenso; } \\
\text { quanto ao volume: distendido, plano, } \\
\text { globoso ou escavado; quanto à presença } \\
\text { de gases: poucos gazes (normal), maciez } \\
\text { (quando há tumor) ou timpânico. }\end{array}$ & $\begin{array}{l}\text { Ausência das altera- } \\
\text { ções referidas. }\end{array}$ \\
\hline $\begin{array}{l}\text { Tecido } \\
\text { subcultâneo }\end{array}$ & $\begin{array}{l}\text { Excesso de tecido adiposo, ou déficit de } \\
\text { tecido subcutâneo - flacidez; presença } \\
\text { de edema }\end{array}$ & $\begin{array}{l}\text { Ausência das altera- } \\
\text { ções referidas. }\end{array}$ \\
\hline $\begin{array}{l}\text { Tecido Muscular } \\
\text { esquelético }\end{array}$ & Retração ou atrofia & $\begin{array}{l}\text { Ausência das altera- } \\
\text { ções referidas. }\end{array}$ \\
\hline Sistema nervoso & $\begin{array}{l}\text { Perdas do controle na contração ou } \\
\text { parestesias }\end{array}$ & $\begin{array}{l}\text { Ausência das altera- } \\
\text { ções referidas. }\end{array}$ \\
\hline $\begin{array}{l}\text { Condição hí- } \\
\text { drica }\end{array}$ & Desidratação ou edema* & $\begin{array}{l}\text { Ausência das altera- } \\
\text { ções referidas. }\end{array}$ \\
\hline
\end{tabular}

Quadro 2 - Região do corpo a ser examinada e características específicas a serem avaliadas

$\star$ O edema de causa nutricional deve ser: frio, mole, indolor, geralmente não forma cacifo e é bilateral

Fonte: Adaptado de Bevilacqua (1997); Martins (2008).

Antes de dar início à realização do exame, deve-se ter atenção aos critérios de preparação e organização:

- $\quad$ O profissional deve ter cuidado com a contaminação pessoal e ao paciente: deve-se ter uma higiene criteriosa, tanto das mãos do avaliador, quanto dos equipamentos que serão utilizados. Lembrando que essa higiene deve sempre 
acontecer antes do início da avaliação e entre um paciente e outro. Caso seja necessário, o profissional deve fazer uso de EPI's (equipamentos de proteção): luvas, máscaras, jaleco, etc. Isso irá garantir uma maior segurança, tanto para o avaliador como para o paciente;

- $\quad$ O paciente deve ser preparado previamente para a realização do exame; o avaliador deve explicar todos os procedimentos a serem realizados, os equipamentos utilizados, as posições necessárias e dar uma prévia do tempo de duração. Assim, o paciente melhor informado poderá colaborar com a avaliação e evitar situações constrangedoras;

- $\quad$ A vestimenta deve ser adequada, tanto para o profissional como para o paciente, procurando sempre manter o corpo do avaliado o mais coberto possível, deixando descobertas somente as áreas a serem avaliadas;

- Realizar os procedimentos sempre em locais adequados: o paciente deve se sentir à vontade; é importante a privacidade, um ambiente silencioso, suficientemente iluminado e com temperatura confortável;

- $\quad$ Para avaliação do abdome, o paciente deve estar com a bexiga vazia. Os procedimentos como aferição do peso devem ser feitos, de preferência, antes das refeições. Em pacientes hospitalizados, recomenda-se que sejam feitas as aferições de peso com o paciente em jejum;

- $\quad \mathrm{Na}$ aferição da tensão arterial, o paciente não deve estar agitado. A mensuração deve ser realizada quando o paciente estiver tranquilo, preferencialmente do meio para o final da consulta. Deve ser questionada ao paciente a realização de atividade física antes da consulta, bem como a ingestão de medicamentos e de alimentos energéticos e/ou estimu- 
lantes, uma vez que estes elevam a tensão arterial durante um período determinado de tempo, podendo influenciar na aferição da real pressão arterial desse paciente;

- $\quad$ Expressar sempre interesse e respeito pelo problema do paciente, por uma questão humanista e ética e pela contribuição que pode dar para a definição do estabelecimento do diagnóstico;

- Nunca manifestar tristeza ou formular julgamento a respeito do relato da história do paciente. Lembre-se: você não é um juiz, além de que esse comportamento induz à omissão ou exacerbação das respostas.

Existem várias técnicas e procedimentos para a realização do exame físico. Dentre essas, abordaremos aqui as que são direcionadas para a avaliação nutricional:

- Inspeção: para esta técnica, o avaliador irá usar de sua visão, olfato e audição na avaliação do paciente. Por exemplo: verificar a presença de obesidade, caquexia, condição hídrica, integridade da pele, cicatrização de feridas, icterícia, ascite, capacidade funcional, estado mental etc.

- $\quad$ Palpação: trata-se de uma avaliação táctil, onde seu uso tem como objetivo sentir pulsações e vibrações. Através desta técnica, o nutricionista pode avaliar as estruturas corporais como: textura, tamanho, temperatura, consistência e mobilidade. O Turgor, a elasticidade da pele, integridade da derme, tamanho de órgãos, edema periférico, massas abdominais, ascite, perda de peso, entre outros, são exemplos de situações que podem ser detectadas pela técnica de palpação.

- Percussão: consiste na avaliação de "sons", para determinar o contorno, formato e posição destes. Permite avaliar 
também se o órgão está sólido ou se há presença de líquido ou gases. Essa técnica não é sempre necessária no exame clínico nutricional.

- Ausculta: nesta técnica, serão avaliados os sons corpóreos que podem ser ouvidos com ou sem estetoscópio (ex.: sons do coração, dos pulmões - presença de líquidos, intestinais -, ruídos hidroaéreos e dos vasos sanguíneos).

Para algumas carências, este tipo de exame torna-se específico, como no raquitismo (vitamina $\mathrm{D}$ ), bócio endêmico (iodo), mancha de Bitot/xerose da conjuntiva (vitamina A), bem como no excesso de tecido adiposo, em que é possível diagnosticar obesidade etc. Outros sinais e sintomas de alterações específicas encontrados no exame físico são apresentados na tabela 1 .

Apesar de o exame físico ser de baixo custo, de simples execução e importante no reconhecimento da gravidade dos problemas nutricionais, ele necessita de treinamento e do olhar clínico do avaliador. Importante lembrar também a baixa sensibilidade e especificidade dos sinais e sintomas clínicos nutricionais para o diagnóstico nutricional, uma vez que outras situações que não a carência ou excesso de nutrientes podem manifestar-se da mesma forma. A identificação dos desequilíbrios nutricionais por este método é tardia, já que muitas manifestações exteriores só são perceptíveis quando as alterações internas já se encontram graves.

\section{Avaliação muscular subjetiva - AMS}

A AMS visa observar a atrofia de determinados grupamentos musculares, correlacionando-a com a atividade do músculo afetado. Esta é uma técnica facilmente aplicada por observadores treinados, pois não requer o uso de equipamentos e pode ser 
complementada pela história clínica. É de grande utilidade para a avaliação e o acompanhamento clínico da atenção nutricional, por sua capacidade de detectar alterações morfológicas na musculatura responsável pela mastigação, deambulação e vida laborativa. Trata-se, portanto, de um exame físico orientado para quatro grupamentos musculares, envolvidos obrigatoriamente nas atividades rotineiras diárias:

1. Músculo temporal superficial e masseter, relacionados com a mastigação:

a. Atrofia leve: sem exposição do arco zigomático;

b. Atrofia moderada: exposição do arco zigomático;

c. Atrofia grave: quando é possível a visualização do contorno ósseo, envolvendo a órbita, o arco zigomático e o ramo ascendente da mandíbula, sugerindo o desenho de uma "chave".

2. Músculo adutor do polegar, relacionado com a vida laborativa e déficit muscular.

a. Atrofia leve e moderada: depressão em graus variados do relevo muscular;

b. Atrofia grave: possibilidade de visualização de um contorno ósseo do indicador e do polegar, formando uma concha.

3. Músculos interósseos da mão, relacionados com a vida laborativa e déficit muscular.

a. Tróficos: ausência de depleção;

b. Não tróficos: visualização de depleção (perda importante da musculatura). 
4. Músculos da panturrilha, relacionados com a deambulação e déficit muscular.

a. Tróficos: ausência de depleção;

b. Não tróficos: visualização de depleção (perda importante da musculatura).

Os estudos realizados com AMS sugerem complementação deste método com outras técnicas de avaliação nutricional. Sugere-se também a utilização e/ou criação de índices múltiplos, com o objetivo de aumentar a sensibilidade e a especificidade no diagnóstico das alterações nutricionais, uma vez que, até o momento, não existe parâmetro tradicional isolado capaz de estabelecer diagnóstico nutricional fidedigno para o paciente hospitalizado. 


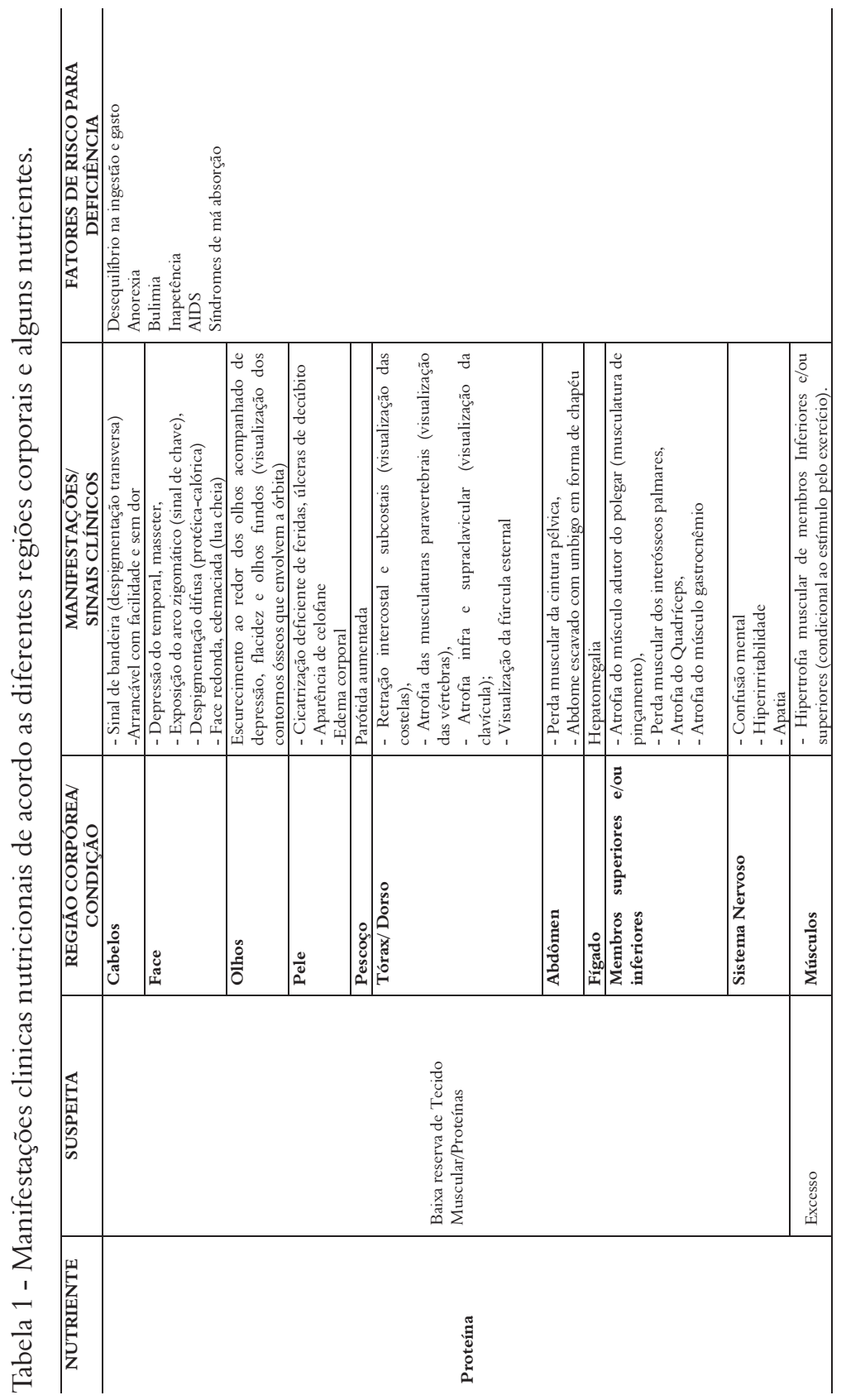

Lílian Sampaio, Maria Silva, Tatiane Oliveira e Venusca Leite 35 


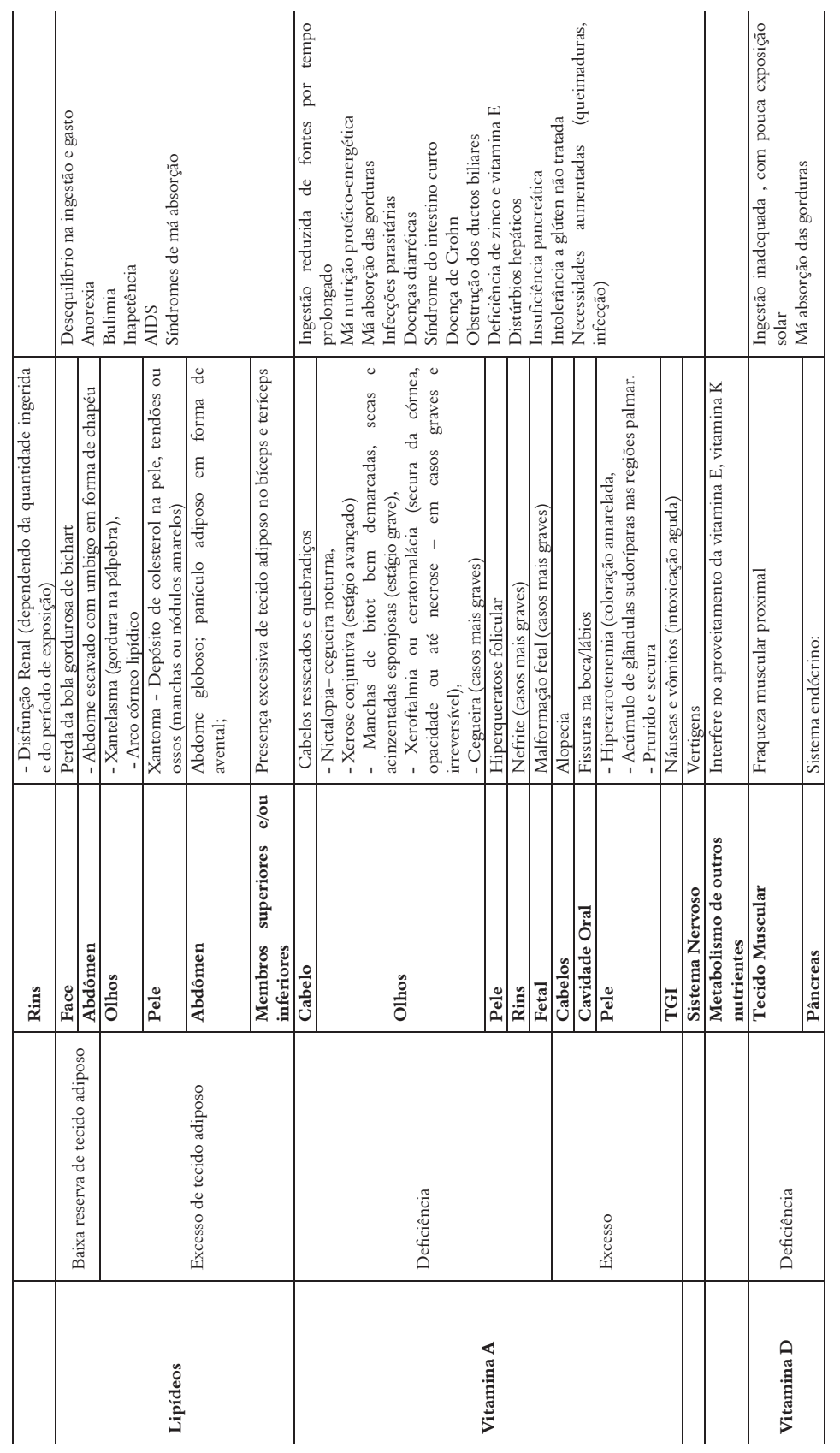

36 Semiologia nutricional 


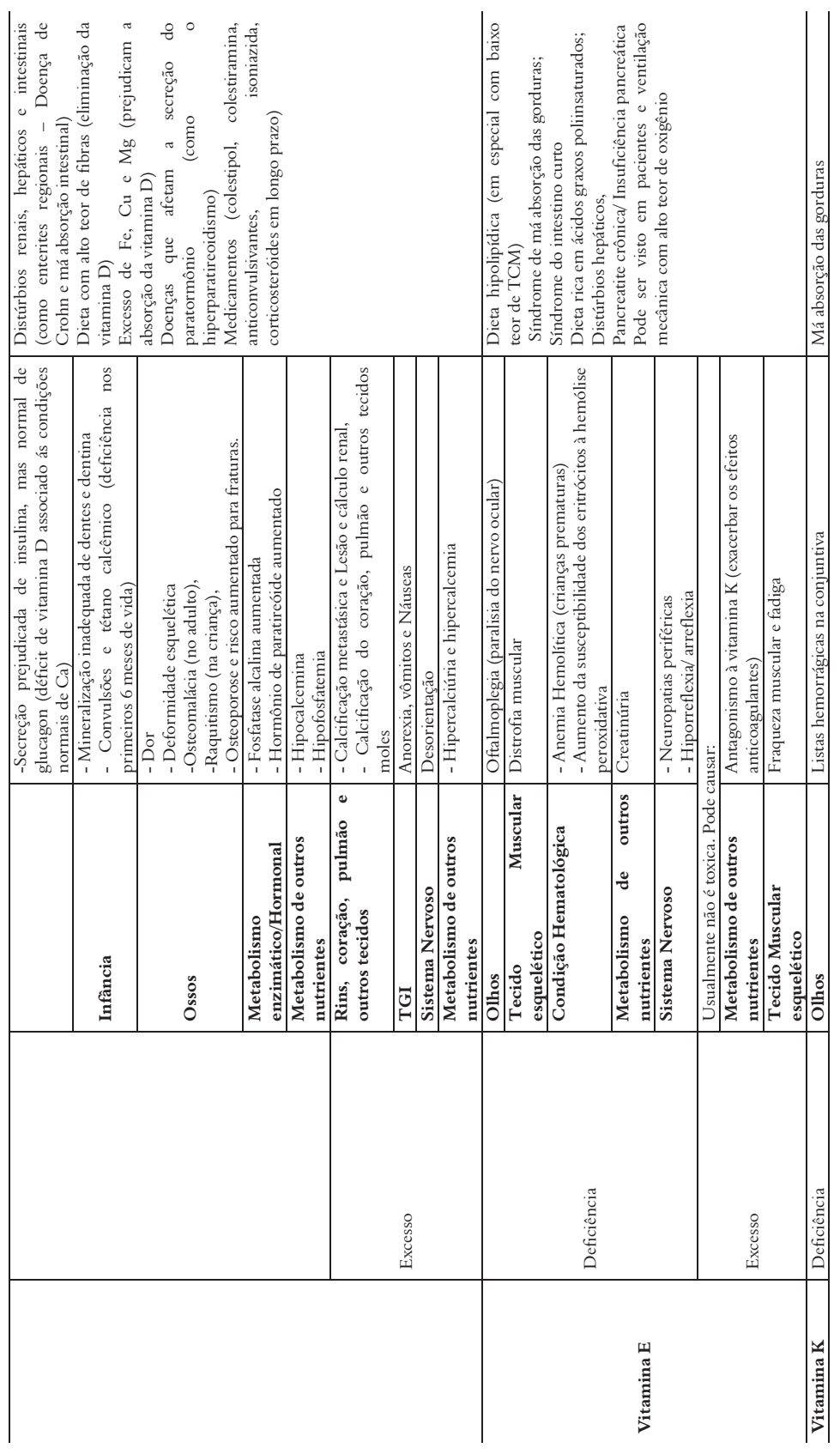




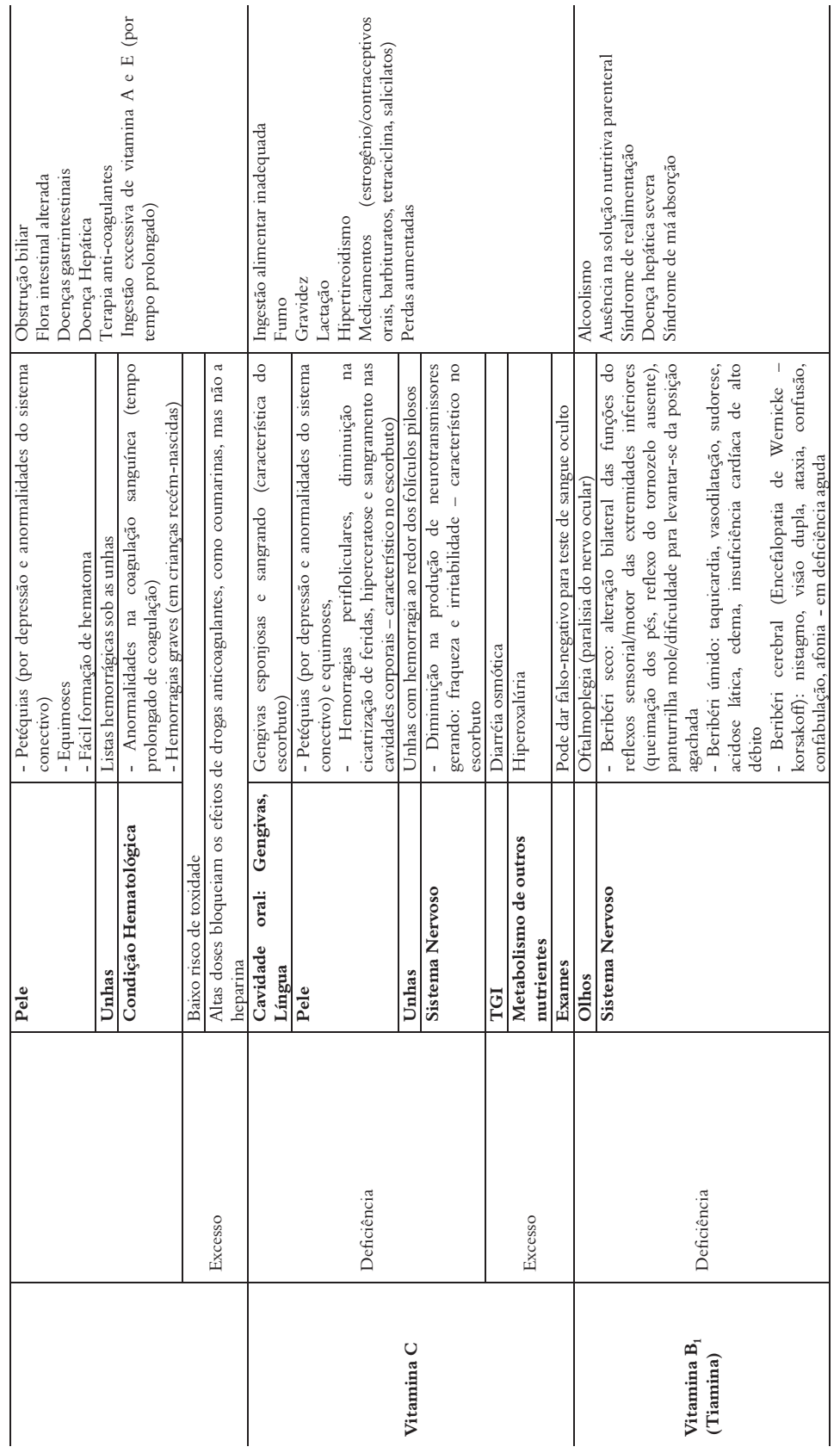

38 Semiologia nutricional 


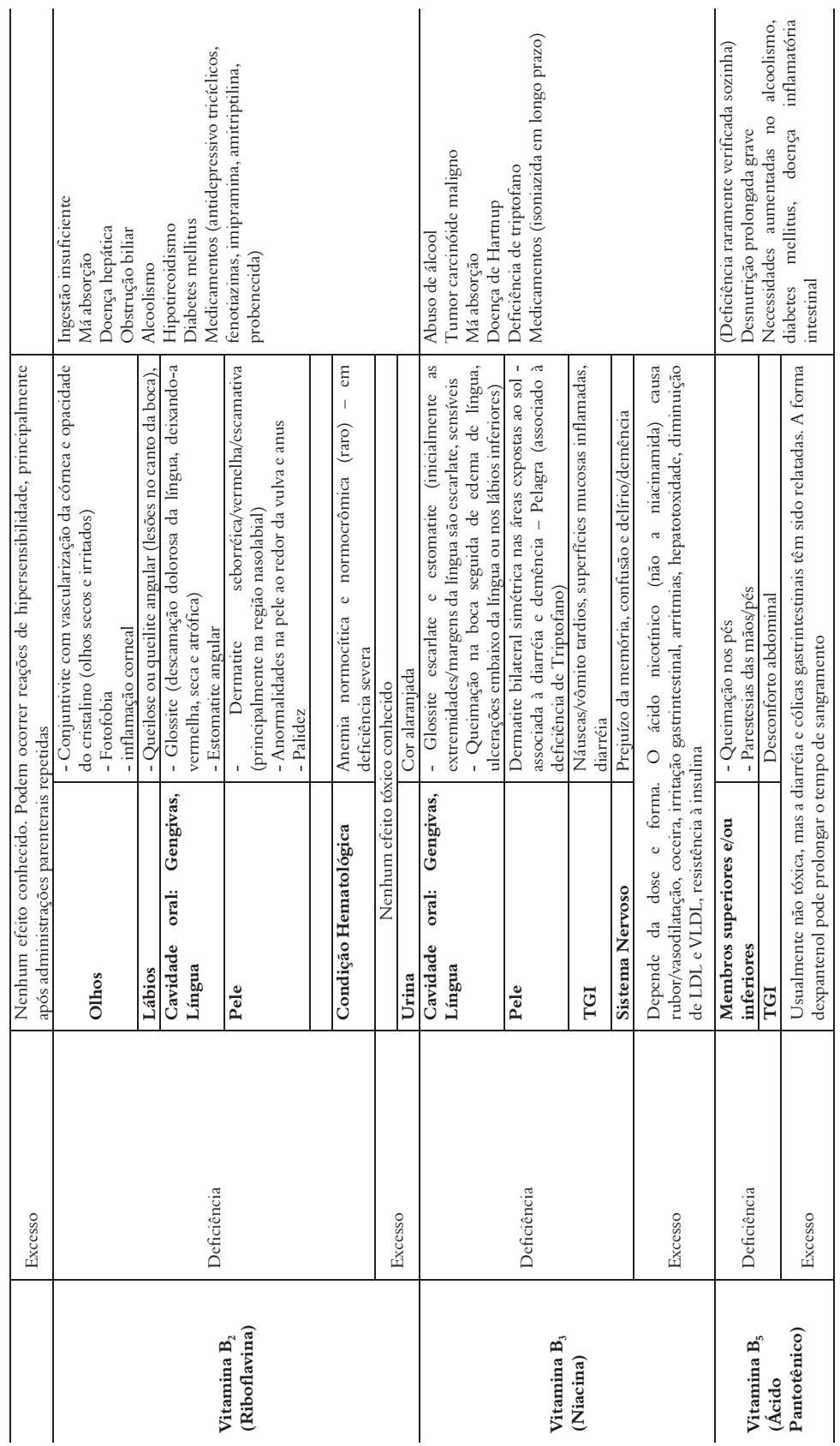




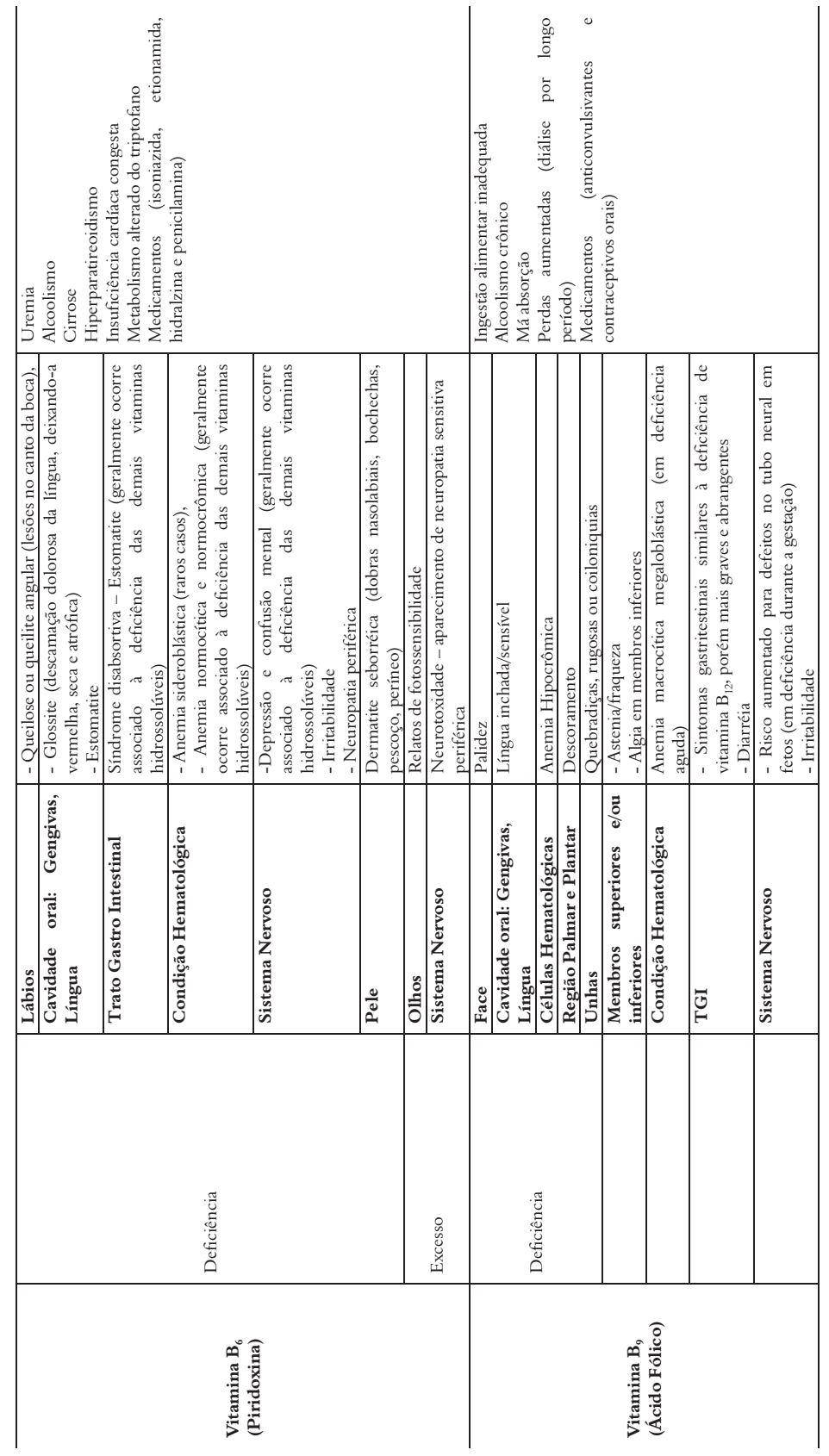

40 Semiologia nutricional 


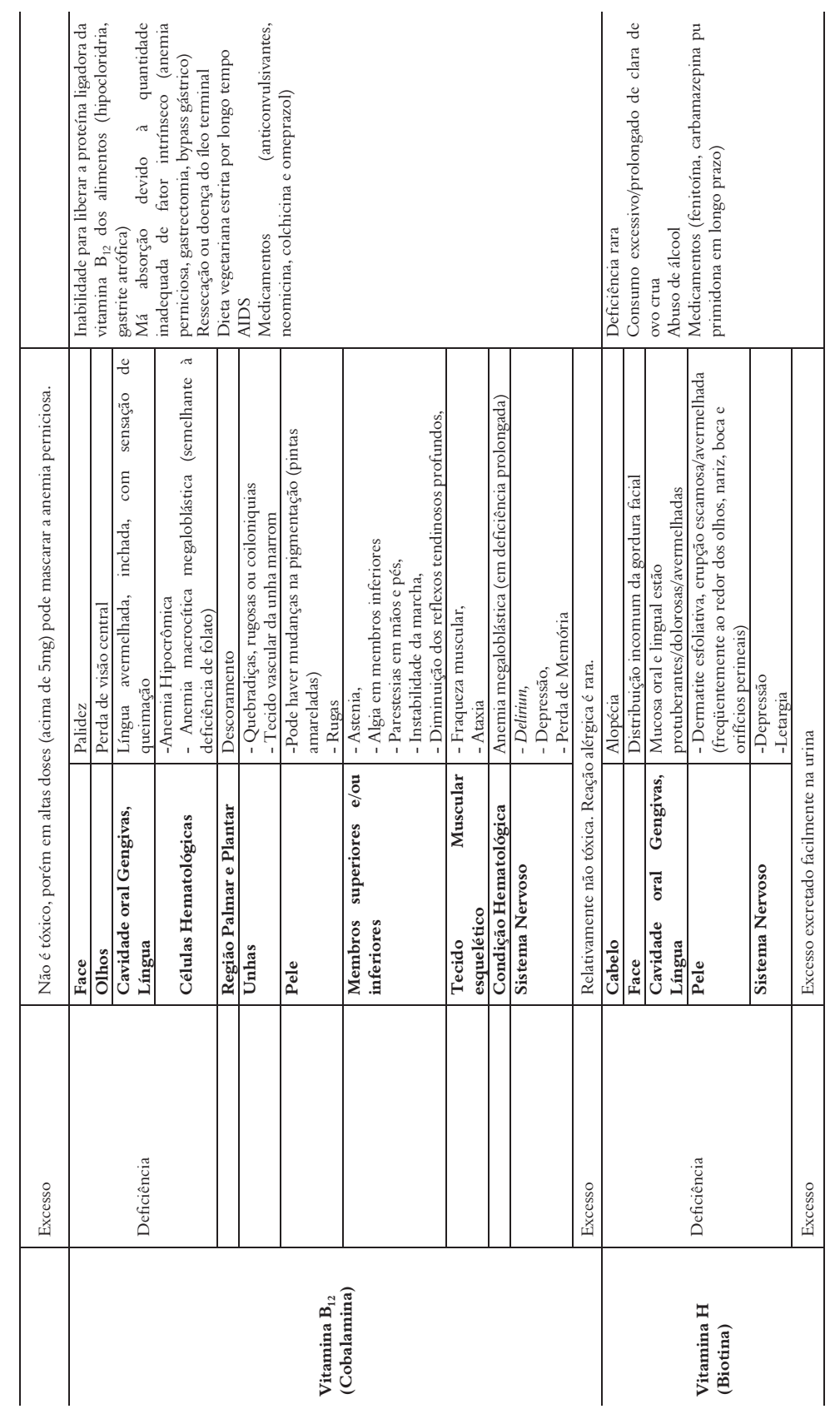




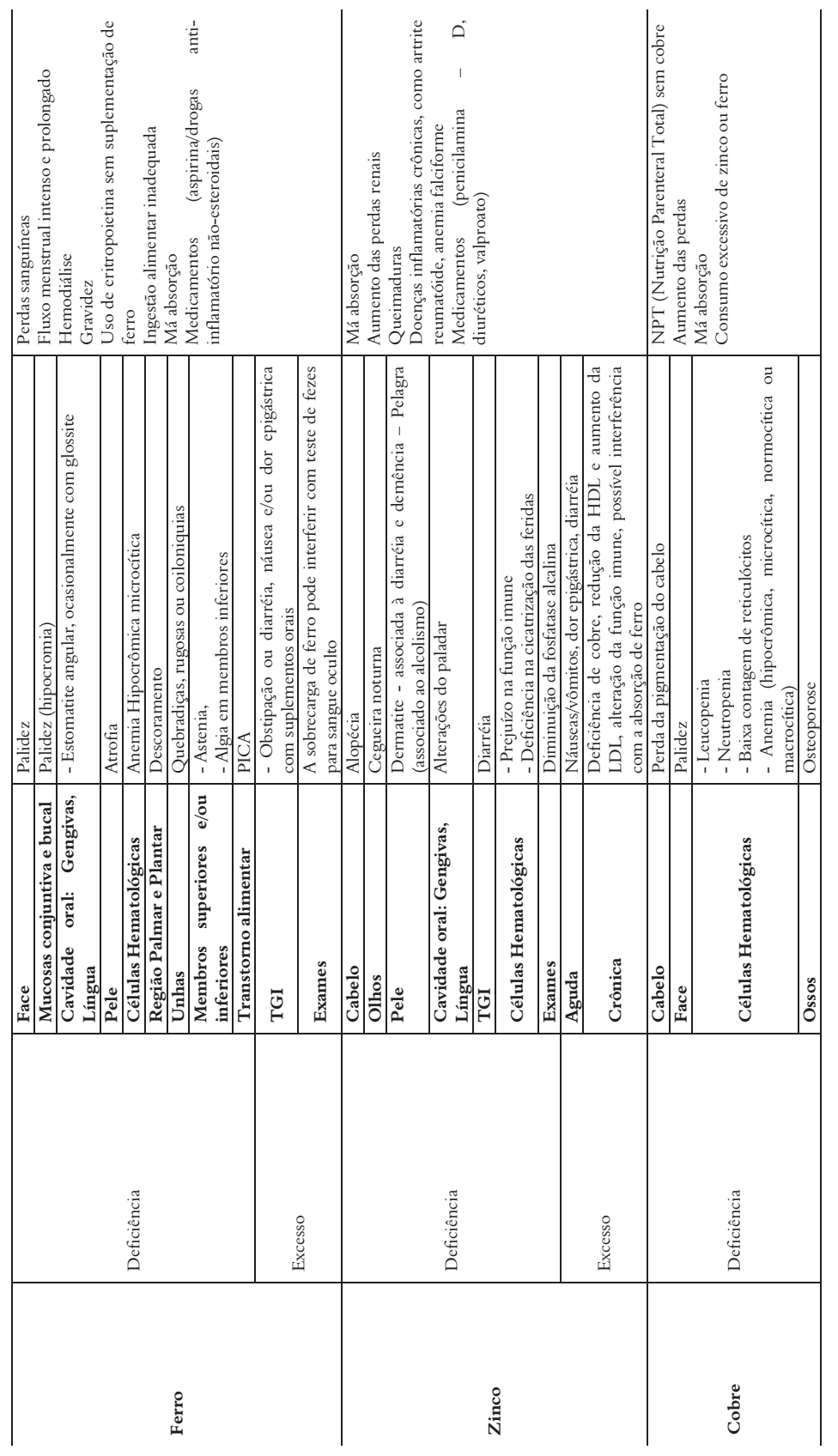

42 Semiologia nutricional 


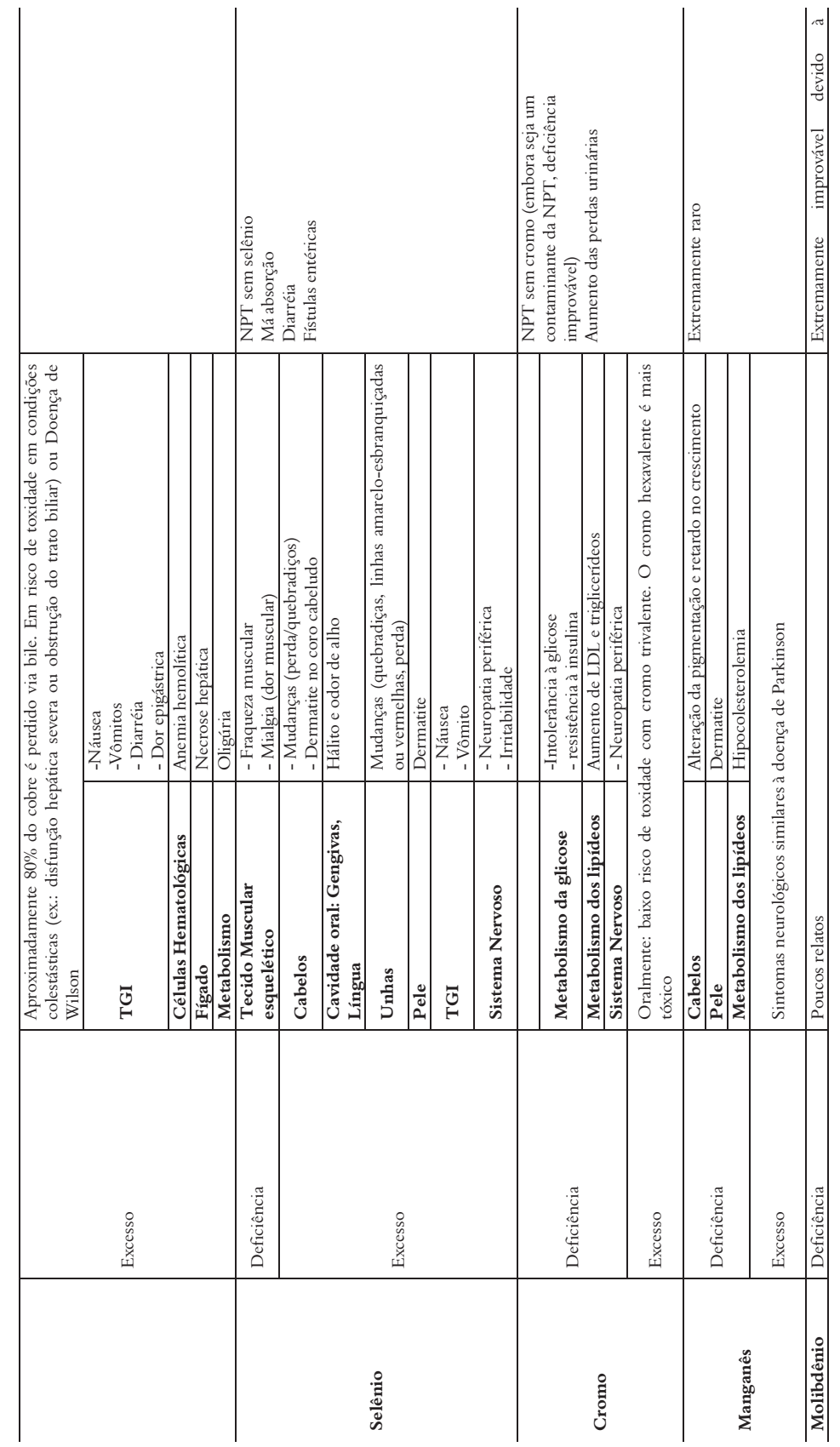




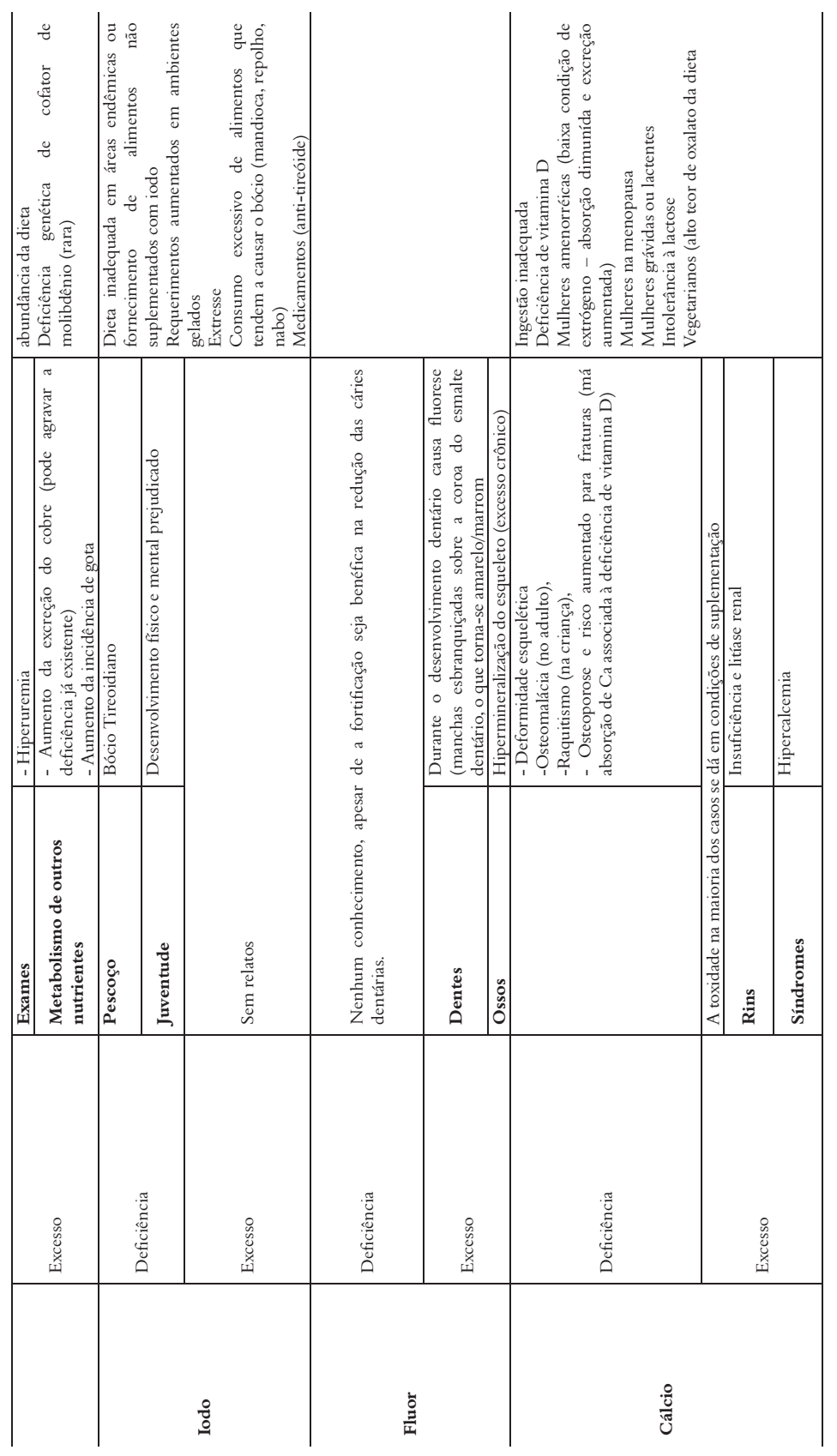

44 Semiologia nutricional 


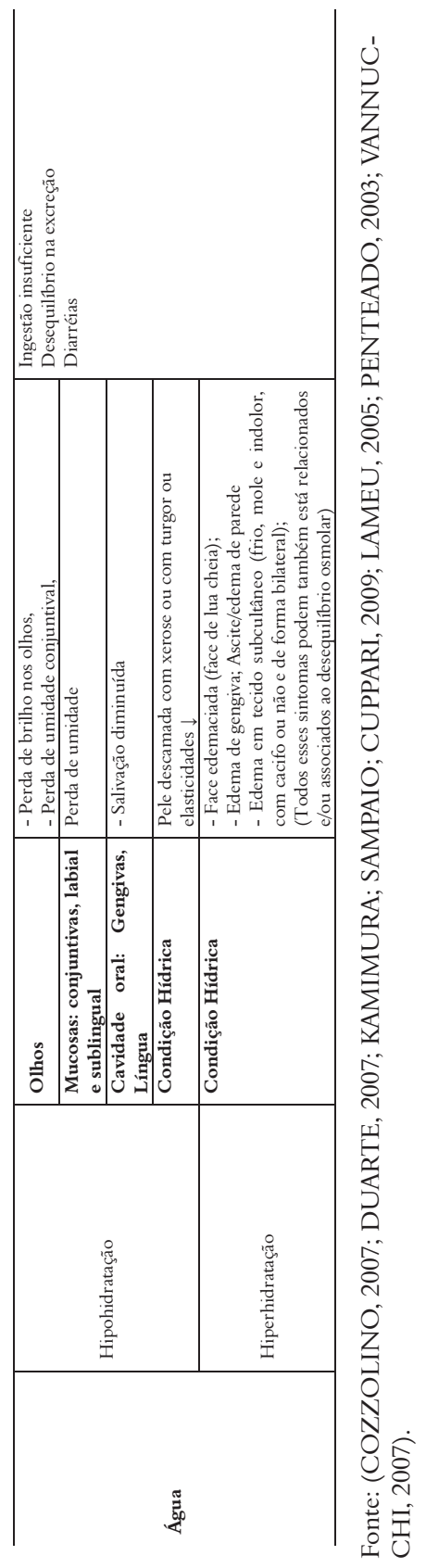

Lílian Sampaio, Maria Silva, Tatiane Oliveira e Venusca Leite 45 


\section{Referências}

BEVILACQUA, Fernando et al. Manual do exame clínico. 11. ed. Rio de Janeiro: Cultura Médica. 1997. 475 p.

COZZOLINO, S. M. F. Deficiências de minerais. Estudos Avançados. São Paulo, v. 60, p. 119-126, 2007.

DUARTE, A. C. Avaliação nutricional: aspectos clínicos e laboratoriais. São Paulo: Atheneu, 2007.

DUARTE, A. C.; CASTELLANI, F. R. Semiologia nutricional. Rio de Janeiro: Axcel Books do Brasil, 2002.

GERUDE M. Terapia Nutricional. São Paulo: Atheneu, 1995.

GIBSON RS. Nutritionnal assessment: a laboratory manual. New York: University Press, 1993. 196 p.

GUIMARÃES R. M.; CUNHA U. G. V. Sinais e sintomas em geriatria. Rio de Janeiro: Ed. Revinter, 1989, 196 p.

KAMIMURA, M. A.; SAMPAIO, L. R.; CUPPARI, L. Avaliação nutricional na prática clínica. In: CUPPARI, L. et al. Nutrição: nas doenças crônicas nãotransmissíveis. Barueri, SP: Manole, 2009.

KATCH, F. J.; MCARDLE W. Nutrição, controle de peso e exercício. 3. ed. Rio de Janeiro: Médica Científica, 1990. 327 p.

LAMEU E. B. Clínica nutricional. Rio de Janeiro: Editora Revinter, 2005.

LÓPEZ, M.; MEDEIROS, JL. Semiologia Médica: as bases do diagnóstico clínico. 4. ed. Rio de Janeiro, RJ: REVINTER, 2001. 1 v.

MAHAN, L. K.; ESCOTT-STUMP, S. (Ed.). Krause alimentos, nutrição e dietoterapia. 10. ed. São Paulo: Rocca, 2002. p. 1157.

MARTINS, C. Avaliação do estado nutricional e diagnóstico. Paraná: Nutroclínica, 2008. $1 \mathrm{v}$.

NEHME, M. N. et al. Contribuição da semiologia para o diagnóstico nutricional de pacientes hospitalizados. Caracas, Archivos Latinoamericanos de Nutrición, Caracas, v. 56, n. 2, p. 153-159, jun. 2006.

OLIVEIRA, D. de.; MARCHINI, J. S. Ciências nutricionais. São Paulo: Sarvier, 1998. p. 19, cap. 2.

ORGANIZAÇÃO MUNDIAL DA SAÚDE (OMS). Ministério da Saúde. Medicion del cambio del estado nutricional. Genebra, 1983. 
ORGANIZAÇÃO PAN - AMERICANA DE SAÚDE (OPAS) /

ORGANIZAÇÃO MUNDIAL DA SAÚDE (OMS). Conocimientos actuales sobre nutrición. Publicación Científica, Washington, n. 565, 731 p. 1997.

PENTEADO, M. V. C. Vitaminas: aspectos nutricionais, bioquímicos, clínicos e analíticos. Barueri, SP: Manole, 2003.

REZENDE, I. F. B. et al. Avaliação muscular subjetiva como parâmetro complementar de diagnóstico nutricional em pacientes no pré-operatório. Revista de Nutrição, Campinas, v. 20, n. 6, p. 613-615, dez. 2007.

SAMPAIO L. R. Avaliação nutricional no envelhecimento. Revista de Nutrição, Campinas, v. 18, n. 4, p. 507-514, out/dez. 2004.

SANTOS, J. B. Ouvir o paciente: a anamnese no diagnóstico clínico. Revista Brasília Médica, São Paulo, v. 36, n. 3, p. 90-95, 1999.

SHILS, M. E. et al. Tratado de nutrição moderna na saúde e na doença. 9. ed. São Paulo: Manole, 2002.

VANNUCCHI, H. Hipovitaminoses: fisiopatologia e tratamento. In: VANNUCCHI, H. et al. Nutrição clínica: nutrição e metabolismo. Rio de Janeiro: Guanabara Koogan, 2007.

WAITZBERG, D. L.; FERRINI, M. T. Avaliação nutricional. In:

WAITZBERG, D. L. Nutrição enteral e parenteral na prática clínica. 2. ed. Rio de Janeiro: Atheneu, 1995. 642 p. 


\title{
Avaliação bioquímica do estado nutricional
}

\author{
Lílian Ramos Sampaio \\ Maria da Conceição Monteiro da Silva \\ Andréia Nishiyamamoto de Oliveira \\ Catarina Lobo Santos de Souza
}

\section{Introdução}

Os indicadores bioquímicos fornecem medidas objetivas das alterações do estado nutricional, tendo como vantagens principais: a confirmação das deficiências nutricionais; a identificação precoce de problemas nutricionais antes que qualquer sinal e/ou sintoma clínico nutricional de deficiência e/ou excesso de nutrientes seja percebido pelo indivíduo ou nutricionista, e o monitoramento do indivíduo em tratamento. No entanto, tais indicadores possuem limitações por sofrerem influência de várias doenças; pela sua baixa especificidade para os problemas nutricionais; pela interação droga/nutriente e pela ingestão recente, entre outras razões. Assim, 
recomenda-se não utilizar, isoladamente, os indicadores bioquímicos para estabelecer o diagnóstico nutricional.

A avaliação bioquímica do estado nutricional é geralmente realizada por meio de indicadores hematológicos, protéicos viscerais; de indicadores protéicos somáticos; do colesterol sérico e do balanço nitrogenado. Além destes, estão disponíveis as proteínas da fase aguda, os testes de avaliação de competência imunológica e a avaliação laboratorial de micronutrientes.

\section{Avaliação do Estado Nutricional Relativo às Proteínas:}

As proteínas são essenciais para as funções reguladoras e estruturais. Um homem adulto de referência (70kg) tem 10 a $13 \mathrm{~kg}$ de proteínas que possuem funções estruturais, reguladoras e mediadoras da resposta imune. Não existe estoque de proteínas dispensáveis no corpo humano. Dessa forma, a perda de proteínas resulta em perda de elementos estruturais essenciais, assim como perda de funções. A maioria da proteína humana está concentrada no músculo esquelético, compreendendo cerca de $30 \%$ a 50\% das proteínas totais, seguida das viscerais (18\%).

\section{Indicadores Hematológicos}

Os parâmetros hematológicos mais utilizados em avaliação nutricional relativos às proteínas são: hematócrito e hemoglobina. A hemoglobina é uma proteína de transformação metabólica muito lenta e sua diminuição ocorre mais tardiamente, na depleção protéica. É um índice sensível, mas pouco específico da 
desnutrição, podendo alterar-se quando há perda sanguínea, estados de diluição sérica e transfusões sanguíneas.

O hematócrito está mais relacionado com as anemias, pois seu valor está reduzido nestas condições. A classificação da desnutrição dar-se-á de acordo com os seguintes valores de hemoglobina e hematócrito:

\begin{tabular}{|llll|}
\hline & Desnutrição leve & $\begin{array}{c}\text { Desnutrição } \\
\text { moderada }\end{array}$ & Desnutrição grave \\
\hline \multicolumn{4}{|c|}{ Hemoglobina $(\mathrm{g} / 100 \mathrm{ml})$} \\
Homens & $>12,0 \mathrm{mg} / \mathrm{dl}$ & $12,0-10 \mathrm{mg} / \mathrm{dl}$ & $<10,0 \mathrm{mg} / \mathrm{dl}$ \\
Mulheres & $>10,0 \mathrm{mg} / \mathrm{dl}$ & $10,0-8 \mathrm{mg} / \mathrm{dl}$ & $<8,0 \mathrm{mg} / \mathrm{dl}$ \\
\hline
\end{tabular}

Quadro 1 - Classificação da desnutrição de acordo com os valores de hemoglobina

Fonte: Adaptado de Sauberlich; Skala; Dowdy (1974).

\begin{tabular}{|llcl|}
\hline & Desnutrição leve & $\begin{array}{l}\text { Desnutrição } \\
\text { moderada }\end{array}$ & Desnutrição grave \\
\hline & \multicolumn{4}{c}{ Hematócrito $(\%)$} \\
Homens & $>36$ & $36-31$ & $<310$ \\
Mulheres & $>31$ & $31-24$ & $<24$ \\
\hline
\end{tabular}

Quadro 2 - Classificação da desnutrição de acordo com os valores de hematócrito

Fonte: Adaptado de Sauberlich; Skala; Dowdy (1974).

\section{Indicadores Protéicos Viscerais (Plasmáticos)}

A restrição alimentar prolongada, bem como situações de injúria, compromete a integridade visceral. Alguns tecidos, como o do fígado, sofrem mais alterações em proporção ao tempo de des- 
nutrição e injúria. A dosagem de proteínas sintetizadas por estes tecidos, em associação com outros parâmetros, são úteis na avaliação do comprometimento visceral e no diagnóstico nutricional.

\section{Proteínas Totais}

O plasma contém muitos tipos de proteínas com diferentes funções. O teste bioquímico denominado proteínas totais é a soma de todas essas proteínas presentes, sendo as principais: a albumina, a transferrina, a pré-albumina e a proteína transportadora de retinol. Geralmente são produzidas no fígado e podem ser utilizadas como marcadores do estado nutricional protéico.

A utilização das proteínas séricas como instrumento de avaliação de desnutrição é um importante e confiável medidor, uma vez que a síntese das proteínas hepáticas depende de aminoácidos disponíveis e o paciente com desnutrição terá essa deficiência em seu organismo. Comparados a outros métodos de avaliação da alteração do estado protéico-calórico, a mensuração das proteínas plasmáticas é rápida, mais precisa e mais barata.

\section{Albumina}

A albumina é a proteína mais abundante circulante do plasma e dos líquidos extracelulares. Possui meia-vida longa (18 a 20 dias) e funções de ligação e transporte de inúmeras substâncias (cálcio, zinco, magnésio, cobre, ácidos graxos de cadeia longa, esteróides, drogas etc.), além de ser responsável pela manutenção da pressão coloidosmótica do plasma, preservando a distribuição de água nos compartimentos corporais.

Tem baixa sensibilidade na avaliação da desnutrição aguda e, por possuir uma meia vida longa, a concentração plasmática de albu- 
mina aumenta lentamente em indivíduos que se recuperam de estresse metabólico e desnutrição energético-protéica, podendo transcorrer vários dias (18 a 20 dias) para ocorrer uma resposta às variações na ingestão dietético-protéica. Prediz, acuradamente, a sobrevivência em $90 \%$ dos casos criticamente doentes.

- $\quad$ Limitações:

\begin{tabular}{|l|l|}
\hline Valores Aumentados & Desidratação \\
\hline Valores Reduzidos & $\begin{array}{l}\text { Situações de estresse metabólico (trauma, sepse, } \\
\text { queimaduras, infecções/inflamaçóes), edema, má } \\
\text { absorção intestinal, doenças hepáticas, síndrome } \\
\text { nefrótica, insuficiência renal crônica, insuficiên- } \\
\text { cia cardíaca congestiva, hiper-hidratação, câncer, } \\
\text { eclampsia, idosos, carência de zinco. }\end{array}$ \\
\hline
\end{tabular}

Quadro 3 - Limitações para o uso da albumina como indicador nutricional

Fonte: Kamimura e colaboradores (2002).

- $\quad$ Valores de referência:

\begin{tabular}{|l|l|}
\hline Normal & $>3,5 \mathrm{~g} / \mathrm{dl}$ \\
\hline Depleção Leve & $3,0 \mathrm{a} 3,5 \mathrm{~g} / \mathrm{dl}$ \\
\hline Depleção Moderada & 2,4 a $2,9 \mathrm{~g} / \mathrm{dl}$ \\
\hline Depleção Grave & $<2,4 \mathrm{~g} / \mathrm{dl}$ \\
\hline
\end{tabular}

Quadro 4 - Valores de referência para Albumina sérica

Fonte: Blackburn e Thornton (1979).

\section{Transferrina}

A transferrina é uma globulina transportadora de ferro que possui meia-vida curta (8 a 10 dias) e tem como função transportar o ferro sérico no plasma. Embora a meia-vida da transferrina seja 
mais curta que a da albumina, aquela ainda não responde de forma rápida nas situações de desnutrição. Devido à baixa especificidade, a proteína se torna somente um pouco mais útil em relação à albumina, como marcador do estado proteico-calórico. Além disso, não é um índice apropriado do estado proteico quando ambas, a anemia por deficiência de ferro e a desnutrição energético-proteica, estão presentes.

- Limitações:

\begin{tabular}{|l|l|}
\hline Valores Aumentados & $\begin{array}{l}\text { Carência de ferro, gravidez, fase precoce das hepa- } \\
\text { tites agudas, sangramento crônico, desidratação. }\end{array}$ \\
\hline Valores Reduzidos & $\begin{array}{l}\text { Situações de estresse metabólico (trauma, sepse, } \\
\text { queimaduras, infecções/inflamações), doenças } \\
\text { hepáticas crônicas, neoplasias, sobrecarga de ferro, } \\
\text { hiperhidratação. }\end{array}$ \\
\hline
\end{tabular}

Quadro 5 - Limitações para o uso da transferrina como marcador nutricional

Fonte: Kamimura e colaboradores (2002).

\begin{tabular}{|l|l|}
\hline Normal & 200 a $400 \mathrm{mg} / \mathrm{dl}$ \\
\hline Depleção Leve & 150 a $200 \mathrm{mg} / \mathrm{dl}$ \\
\hline Depleção Moderada & $100 \mathrm{a} 150 \mathrm{mg} / \mathrm{dl}$ \\
\hline Depleção Grave & $<100 \mathrm{mg} / \mathrm{dl}$ \\
\hline
\end{tabular}

Quadro 6 - Valores de referência para transferrina

Fonte: Lima e colaboradores (2001).

\section{Pré-Albumina (Transtirretina)}

A pré-albumina tem como funções transportar hormônio tireoidiano (tiroxina) e formar um complexo com a proteína ligante de retinol. É uma proteína de rápido turnover, com uma vida média 
curta (2 a 3 dias). Por sua meia-vida curta, a pré-albumina é considerada um melhor indicador das mudanças nutricionais do que a transferrina e a albumina. Os valores se alteram em função da disponibilidade de tiroxina, para a qual funciona como proteína de transporte e na deficiência de zinco, responsável por sua síntese e secreção hepática.

\begin{tabular}{|l|l|}
\hline Valores Aumentados & Desidratação, insuficiência renal \\
\hline Valores Reduzidos & $\begin{array}{l}\text { Situações de estresse metabólico (trauma, } \\
\text { sepse, queimaduras, infecções/inflamações), } \\
\text { doenças hepáticas, hiperhidratação. }\end{array}$ \\
\hline
\end{tabular}

Quadro 7 - Limitações para o uso da pré-albumina como marcador nutricional

Fonte: Kamimura e colaboradores (2002).

\begin{tabular}{|l|l|}
\hline Normal & $>20 \mathrm{mg} / \mathrm{dl}$ \\
\hline Depleção Leve & $10 \mathrm{a} 15 \mathrm{mg} / \mathrm{dl}$ \\
\hline Depleção moderada & $5 \mathrm{a} 10 \mathrm{mg} / \mathrm{dl}$ \\
\hline Depleção Grave & $<5 \mathrm{mg} / \mathrm{dl}$ \\
\hline
\end{tabular}

Quadro 8 - Valores de referência para Pré-albumina

Fonte: Lima e colaboradores (2001).

\section{Proteína Transportadora de Retinol}

Tem a função de transportar a forma alcoólica da vitamina A (retinol) no plasma. Possui uma meia-vida curta (12 horas), sendo, portanto, considerada aquela que tem o índice mais sensível às mudanças nutricionais, em comparação às outras proteínas plasmáticas (pré-albumina, transferrina e albumina). 


\begin{tabular}{|l|l|}
\hline Valores Aumentados & Desidratação, insuficiência renal \\
\hline Valores Reduzidos & $\begin{array}{l}\text { Situações de estresse metabólico (trauma, } \\
\text { sepse, queimaduras, infecções/inflama- } \\
\text { ções), doenças hepáticas, hiperhidratação, } \\
\text { carência de vitamina A e zinco. }\end{array}$ \\
\hline
\end{tabular}

Quadro 9 - Limitações para o uso da proteína transportadora de retinol como marcador nutricional

Fonte: Kamimura e colaboradores (2002).

\begin{tabular}{|l|l|}
\hline Normal & 3 a $5 \mathrm{mEq} / \mathrm{dl}$ \\
\hline Depleção & $<3 \mathrm{mEq} / \mathrm{dl}$ \\
\hline
\end{tabular}

Quadro 10 - Valores de referência para a Proteína Transportadora de Retinol

Fonte: Adaptado de Rosa (2008).

\section{Fibronectina (Alfa-2 Glicoproteína)}

A Fibronectina tem importância nos mecanismos de defesa não imunológicos do organismo, como na adesão das células e cicatrização de feridas. Possui uma vida média de 24 horas. Apresenta níveis reduzidos na desnutrição e durante a administração de dietas de conteúdo calórico muito baixo e/ou carentes de aminoácidos e lipídeos (Waitzberg, 2006). Apesar da resposta rápida, a terapia nutricional, após uma semana de tratamento, apresenta-se reduzida no hipercatabolismo agudo e na coagulação intravascular disseminada, o que limita o seu uso na avaliação nutricional.

\section{Somatomedina C (Insulina-like Growth Factor - IGF-1)}

A Somatomedina $\mathrm{C}$ atua como indicador do estado nutricional proteico, especialmente nas crianças, pois é o mediador da ação 
do hormônio de crescimento. Em crianças gravemente desnutridas, a concentração sérica de IGF-1 se encontra reduzida e, no adulto, está muito bem correlacionada ao balanço nitrogenado.

\begin{tabular}{|l|l|}
\hline Idade & Valores de referência \\
\hline Até 6 anos & $20-200 \mathrm{ng} / \mathrm{ml}$ \\
\hline 6 a 12 anos & $88-450 \mathrm{ng} / \mathrm{ml}$ \\
\hline 13 a 16 anos & $200-900 \mathrm{ng} / \mathrm{ml}$ \\
\hline 17 a 24 anos & $180-780 \mathrm{ng} / \mathrm{ml}$ \\
\hline 25 a 39 anos & $114-400 \mathrm{ng} / \mathrm{ml}$ \\
\hline 40 a 54 anos & $90-360 \mathrm{ng} / \mathrm{ml}$ \\
\hline Acima de 54 anos & $70-290 \mathrm{ng} / \mathrm{ml}$ \\
\hline
\end{tabular}

Quadro 11 - Valores de referência para a Somatomedina C, segundo faixa etária

Fonte: Adaptado de Blackburn e colaboradores (1977).

\section{Proteínas Plasmáticas, Estado Nutricional e Inflamação}

Situações de estresse metabólico (trauma, sepse, cirurgias, queimaduras, inflamação ou infecções) resultam na liberação de citocinas, como interleucina-1, interleucina-6 e fator de necrose tumoral, as quais reorientam a síntese hepática de proteínas plasmáticas e aumentam a degradação de proteínas musculares para satisfazer a demanda elevada de proteína e energia durante a resposta inflamatória.

A síntese hepática das proteínas plasmáticas (albumina, transferrina, pré-albumina e proteína transportadora de retinol) diminui durante a resposta de fase aguda e por este motivo tais proteínas são denominadas proteínas negativas de fase aguda. Em con- 
trapartida, ocorre aumento no fígado da síntese das chamadas proteínas de fase aguda (ou reagentes positivos da fase aguda), sendo a proteína $\mathrm{C}$ reativa uma das mais estudadas. No quadro abaixo, segue as principais proteínas de fase aguda e suas respectivas funções:

\begin{tabular}{|l|l|}
\hline Proteína & Função \\
\hline Fração C3 do complemento & Função imune \\
\hline Proteína C Reativa & $\begin{array}{l}\text { Opsonização/ ativação do sistema } \\
\text { complemento/ fagocitose }\end{array}$ \\
\hline $\begin{array}{l}\alpha-1 \text {-antitripsina } \\
\alpha-2 \text { macroglobulina }\end{array}$ & Atividade antiprotease \\
\hline Fibrinogênio & Coagulação \\
\hline $\begin{array}{l}\text { Ceruloplasmina } \\
\alpha-2 \text { macroglobulina }\end{array}$ & $\begin{array}{l}\text { Neutralização dos radicais livres } \\
\text { de oxigênio }\end{array}$ \\
\hline
\end{tabular}

Quadro 12 - Funções das proteínas

Fonte: Adaptado de Mahan e Escott-Stump (2005).

\section{Proteína C Reativa}

- $\quad$ Valores normais $<0,9 \mathrm{mg} / \mathrm{dl}$.

A proteína C reativa possui meia-vida de algumas horas e é considerada indicadora de fase aguda, em situações de estresse metabólico.

Seus valores estão relacionados com a intensidade da resposta metabólica, ou seja, quanto mais intensa for a agressão, maiores serão os níveis de proteína $\mathrm{C}$ reativa. E os seus valores elevados persistentes são considerados como mau prognóstico, pois indicam que a resposta metabólica está sendo de difícil controle, o que aumenta os riscos de morbimortalidade dos pacientes. Seus 
valores retornam ao normal de forma espontânea com o fim da fase aguda. Assim, a proteína $\mathrm{C}$ reativa é considerada útil para monitorar o progresso das reações de estresse e iniciar uma intervenção nutricional mais agressiva quando este indicador mostrar que as reações inflamatórias estão diminuindo.

\section{Indicadores Somáticos}

A proteína muscular corresponde a $50 \%$ do total das proteínas corporais. Dentre os indicadores somáticos do estado das proteínas, podem ser utilizados o índice de creatinina-altura, o 3- metil- histidina, o balanço nitrogenado e a excreção da ureia.

\section{Índice de Creatinina-Altura (ICA)}

O índice de creatinina-altura é a medida indireta da massa muscular e do nitrogênio corporal. É utilizado para estimar a massa proteica muscular, sendo assim um indicador de catabolismo proteico, apresentando correlação positiva entre ICA, Área Muscular do Braço (AMB) e Massa Corporal Magra. É calculado a partir do volume urinário de 24 horas.

- $\quad$ Considerações sobre a taxa de excreção de creatinina urinária estar relacionada à massa muscular do indivíduo:

a. A creatinina é um metabólito derivado da hidrólise não enzimática irreversível da creatina e da fosfocreatina. Ela é um composto encontrado quase exclusivamente no tecido muscular (98\%) e é sintetizada a partir dos aminoácidos glicina e arginina, no fígado, pâncreas, cérebro, baço, glândula mamária e rim, indo depois para o músculo. A síntese depende das vitaminas B12 e ácido fólico. 
b. Assumindo que o conteúdo de creatina no músculo é constante, quando um indivíduo consome uma dieta livre de creatinina (sem carne), o "pool” muscular é igual ao excretado, possibilitando a avaliação do compartimento proteico somático.

c. Uma vez formada, a creatinina não possui função biológica específica e é excretada por via renal.

- $\quad$ Fórmula para cálculo do ICA:

A excreção de creatinina esperada em 24 horas está relacionada com a altura dos indivíduos. A partir disso, foram construídas tabelas contendo valores esperados.

$\underline{\text { ICA } \%=} \frac{\text { Creatinina na urina em } 24 \text { h } \times 100}{\text { Creatinina ideal em } 24 \mathrm{~h} *}$

Fonte: Oliveira (2005).

$$
\text { *Cr média: } \begin{aligned}
& =18 \mathrm{mg} / \mathrm{Kg} \\
& =23 \mathrm{mg} / \mathrm{Kg}
\end{aligned}
$$

Fonte: Adaptado de Rosa e outros (2008).

\begin{tabular}{|l|l|}
\hline 80 a $90 \%$ & Depleção Leve \\
\hline $60-80 \%$ & Depleção Moderada \\
\hline$<60 \%$ & Depleção Severa \\
\hline
\end{tabular}

Quadro 13 - Interpretação do resultado do Índice Creatitina-Altura Fonte: Kamimura e outros (2002). 


\begin{tabular}{|l|l|}
\hline Sexo & $\begin{array}{l}\text { As mulheres possuem menos massa muscular do que } \\
\text { homens, logo, a excreção de creatinina é menor. }\end{array}$ \\
\hline Idade & $\begin{array}{l}\text { Com o envelhecimento, ocorre perda de massa mus- } \\
\text { cular, então, deste modo, a excreção de creatinina é } \\
\text { menor. } \\
\text { A tabela com valores esperados com base na altura foi } \\
\text { projetada para população de jovens adultos saudáveis, } \\
\text { não se aplicando, assim, para pacientes com idade } \geq \\
\text { 55 anos, enfermos ou com lesões. }\end{array}$ \\
\hline Dieta onívora & $\begin{array}{l}\text { As proteínas da dieta influenciam na excreção de cre- } \\
\text { atinina, principalmente pelo conteúdo de arginina e } \\
\text { glicina (aminoácidos precursores de creatina). Assim, } \\
\text { a creatinina que é formada pela creatina dietética não } \\
\text { pode ser distinguida da produzida por via endógena. } \\
\text { Por este motivo, para o preparo do exame, o consumo } \\
\text { de carne deve ser suspenso de 24 a 48 horas antes da } \\
\text { coleta. }\end{array}$ \\
\hline $\begin{array}{l}\text { Exercício físico e } \\
\text { Situações de } \\
\text { estresse metabó- } \\
\text { lico }\end{array}$ & $\begin{array}{l}\text { Aumento do catabolismo protéico e consequente } \\
\text { elevação na excreção de creatinina. }\end{array}$ \\
\hline Imobilização & Atrofia muscular, diminuindo excreção de creatinina. \\
\hline $\begin{array}{l}\text { Insuficiência } \\
\text { Renal }\end{array}$ & $\begin{array}{l}\text { A excreção urinária de creatinina diminui com a que- } \\
\text { da da função renal, pela redução da taxa de filtração } \\
\text { glomerular. }\end{array}$ \\
\hline $\begin{array}{l}\text { Coleta inadequada } \\
\text { da urina de 24 } \\
\text { horas }\end{array}$ & $\begin{array}{l}\text { A coleta com erro de 15 minutos em 24 horas, aquém } \\
\text { ou além do tempo marcado, é responsável por um } \\
\text { erro de 1\%. Portanto, é recomendado efetuar 3 dias } \\
\text { consecutivos de coleta da urina de 24 horas e fazer a } \\
\text { média da excreção da creatinina urinária. }\end{array}$ \\
\hline Fármacos & $\begin{array}{l}\text { Cefalosporina, levodopa e ácido ascórbico aumentam } \\
\text { a excreção de creatinina. }\end{array}$ \\
\hline ICA deve ser usado com cautela em indivíduos altos, magros ou musculo-
\end{tabular}

Quadro 14 - Limitações para o uso do ICA como marcador nutricional

Fonte: Maicá e Schweigert (2008). 


\section{Excreção de 3-Metil-Histidina}

A excreção de 3-metil-histidina é um indicador de catabolismo protéico.

- $\quad$ Considerações sobre a taxa de excreção urinária de 3 Metil-Histidina estar relacionada à massa muscular do indivíduo e, por conseguinte, a avaliação da proteína somática;

- O3 Metil-Histidina é um aminoácido liberado a partir da actina e miosina do músculo esquelético, sendo excretado de forma inalterada na urina.

\begin{tabular}{|l|}
\hline Difícil dosagem: alto custo \\
\hline Dieta onívora: consumo de carne na dieta \\
\hline Atividade sexual \\
\hline Exercício físico intenso \\
\hline Estados hipercatabólicos, como infecções e traumas. \\
\hline
\end{tabular}

Quadro 15 - Limitações para o uso do 3 Metil-Histidina como marcador nutricional

Fonte: Maicá e Schweigert (2008).

\section{Balanço Nitrogenado (BN)}

O Balanço Nitrogenado (BN) permite avaliar o grau de equilíbrio nitrogenado, verificando a eficácia da terapia nutricional, não sendo considerado, portanto, um indicador do estado nutricional. O BN é extremamente valioso no monitoramento da ingestão de indivíduos que recebem nutrição parenteral total ou alimentação por sonda enteral. O BN deve ser medido, no mínimo, 
semanalmente, naqueles que recebem suporte nutricional de curta duração.

$\mathrm{O}$ cálculo do BN baseia-se no fato de que, aproximadamente, $16 \%$ da massa proteica é nitrogênio e que a perda ocasionada pelo suor, fezes, mais o nitrogênio não proteico é de aproximadamente $4 \mathrm{~g} / \mathrm{dia}$.

$$
\mathrm{BN}=\mathrm{N} \text { ingerido }-\mathrm{N} \text { excretado }
$$

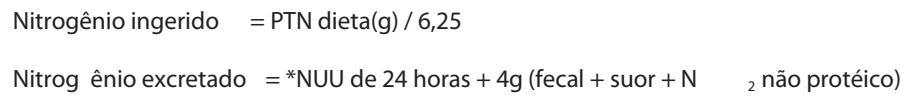

Figura 2 - Fórmula para cálculo do Balanço Nitrogenado Fonte: Oliveira (2007).

\begin{tabular}{|l|l|}
\hline Classificação & Valores BN \\
\hline Normal & 0 ou + \\
\hline Depleção leve & $-5 \mathrm{a}-10$ \\
\hline Depleção Moderada & $-10 \mathrm{a}-15$ \\
\hline Depleção Grave & $>-15$ (ex: sepse) \\
\hline
\end{tabular}

Quadro 16 - Interpretação dos valores do Balanço Nitrogenado Fonte: Bottoni (2002).

\begin{tabular}{|l|l|l|}
\hline BN Negativo & Ingestão $<$ Excreção & Catabolismo \\
\hline BN Positivo & Ingestão $>$ Excreção & Anabolismo \\
\hline BN Equilíbrio & Ingestão $=$ Excreção & ---------- \\
\hline
\end{tabular}

Quadro 17 - Classificação do Balanço Nitrogenado

Fonte: Maicá e Schweigert (2008). 
Dieta

Estado de hidratação; doenças renais; perdas anormais de nitrogênio em decorrência de diarreia, queimaduras extensas, fistulas gastrintestinais etc.

Imprecisão da coleta das amostras, como perda de urina, erros nos tempos de coleta e coleta de fezes incompleta

Dificuldade em estimar a ingestão de proteínas, principalmente daqueles indivíduos que consomem dieta via oral. Estimativa inadequada da ingestão e perdas de nitrogênio.

Quadro 18 - Limitações para o uso do Balanço Nutricional como marcador nutricional

Fonte: Fontoura e outros (2006).

\section{Estado Nutricional e Avaliação da Competência Imunológica}

O estado nutricional está diretamente correlacionado à resposta imunológica do indivíduo. A relação entre nutrição e imunidade é bastante complexa, na qual a carência de nutrientes específicos, como aminoácidos, vitaminas, zinco, ferro, entre outros, é acompanhada por numerosas alterações no sistema imunológico. Indivíduos com desnutrição energético protéica apresentam depressão da imunidade celular e humoral, em função da redução de substratos para a produção de imunoglobulinas e células de defesa orgânica.

Os principais testes imunológicos utilizados são: a linfocitometria e os testes cutâneos, os quais podem sofrer influência de diversos fatores não nutricionais, tais como: infecções, rádio e quimioterapia, doenças auto-imunes, doenças hepáticas e alguns tipos de medicamentos (corticosteróides, imunossupressores). 


\section{Linfocitometria Global ou Contagem Total de Linfócitos Periféricos (CTPL)}

A linfocitometria ou contagem total de linfócitos (CTL) mede as reservas imunológicas momentâneas, indicando as condições do mecanismo de defesa celular do organismo. É uma maneira indireta de avaliar a capacidade do sistema imune humoral e celular. A CTL pode ser calculada a partir do leucograma, utilizando o percentual de linfócitos e a contagem total de leucócitos.

$$
\mathrm{CTL}=\text { \% linfócitos X leucócitos }
$$

100

Figura 3 - Fórmula para o cálculo da Contagem Total de Linfócitos Fonte: Blackburn e Thornton (1979).

\begin{tabular}{|l|l|}
\hline Depleção Leve & 1.200 a $2.000 / \mathrm{mm}^{3}$ \\
\hline Depleção Moderada & 800 a $1.199 / \mathrm{mm}^{3}$ \\
\hline Depleção Grave & $<800 / \mathrm{mm}^{3}$ \\
\hline
\end{tabular}

Quadro 19 - Interpretação dos valores da Contagem Total de Linfócitos

Fonte: Blackburn e Thornton (1979).

\section{Testes de Hipersensibilidade Cutânea Tardia}

Os testes de hipersensibilidade cutânea tardia permitem avaliar a imunidade celular. Eles envolvem a injeção intradérmica de pequenas quantidades de antígenos, bem abaixo da pele, geralmente no antebraço, braço e coxa para determinar a reação do paciente. Os antígenos geralmente utilizados são a candidina, tricofitina, estreptoquinase, varidase e tuberculina. 
A avaliação é feita 24 a 72 horas após a injeção intradérmica. As pessoas saudáveis reagem com induração, indicando que a exposição provavelmente ocorreu e que a imunocompetência está intacta; já os indivíduos desnutridos graves são geralmente anérgicos.

\begin{tabular}{|l|l|}
\hline Classificação & Induração \\
\hline Depleção Moderada & $5-10 \mathrm{~mm}$ \\
\hline Depleção Grave & $<5 \mathrm{~mm}$ \\
\hline
\end{tabular}

Quadro 20 - Interpretação do Teste de Hipersensibildiade Cutânea Tardia

Fonte: Duarte e Castellani (2002).

\section{Estado Nutricional e Lipídeos Corporais}

O perfil lipídico é uma combinação de testes laboratoriais sanguíneos que inclui o colesterol total, as lipoproteínas de alta densidade (HDL), as lipoproteínas de baixa densidade (LDL) e os triglicerídeos. Embora seja usado para estimar o risco de desenvolvimento de doenças cardiovasculares, o perfil lipídico alterado também pode estar associado à desnutrição.

\section{Colesterol Total e Fraçōes}

Os seus níveis plasmáticos são reflexos da ingestão, da absorção da alimentação, da condição de síntese endógena e da capacidade de excreção. Seus valores baixos, incluindo as frações HDL e LDL, podem indicar desnutrição. 
Especialmente em idosos, o colesterol vem sendo usado como método de prognóstico, mostrando relação com o aumento da mortalidade e da permanência hospitalar. Níveis séricos baixos também são observados na insuficiência renal, hepática, na má absorção e no câncer. Apesar de estar relacionada com a desnutrição, a redução do colesterol sérico manifesta-se apenas tardiamente no curso da mesma, o que representa importante limitação do seu uso na avaliação nutricional.

\begin{tabular}{|l|l|l|}
\hline & $\begin{array}{l}\text { Menos de 20 anos } \\
(\mathrm{mg} / \mathrm{dl})\end{array}$ & Acima de 20 anos (mg/dl) \\
\hline Elevado & Acima de 200 & Acima de 240 \\
\hline Limítrofe & 170 a 199 & 200 a 239 \\
\hline Desejável & Inferior a 170 & Inferior a 200 \\
\hline $\begin{array}{l}\text { Baixos } \\
\text { (indicadores de } \\
\text { desnutrição) }\end{array}$ & - & Abaixo de 150 \\
\hline
\end{tabular}

Quadro 21 - Interpretação dos valores de Colesterol Total, segundo faixa etária

Fonte: Kamimura e outros (2002).

\section{Avaliação Laboratorial de Micronutrientes}

Os testes laboratoriais tendem a informar a quantidade e a qualidade de determinados nutrientes e funções que podem estar prejudicados por situações de deficiências ou excesso no organismo. Assim, avaliar o estado nutricional relativo aos micronutrientes (vitaminas e minerais) colaboram com diagnóstico do estado nutricional. 


\section{Valores Adequados e Indicativos de Deficiência de Vitaminas}

\begin{tabular}{|l|l|l|}
\hline & Aceitável & Deficiência \\
\hline $\begin{array}{l}\text { Ácido ascórbico }(\mathrm{mg} / \\
\mathrm{dl})\end{array}$ & $\geq 0,2$ & $<0,1$ \\
\hline $\begin{array}{l}\text { Vitamina A plasmática } \\
(\mu \mathrm{g} / \mathrm{dl})\end{array}$ & $>20$ & $<10$ \\
\hline $\begin{array}{l}\text { Caroteno plasmático } \\
(\mu / \mathrm{dl})\end{array}$ & $\geq 40$ & $<20$ \\
\hline $\begin{array}{l}\text { Vitamina E plasmática } \\
(\mathrm{mg} / \mathrm{dl})\end{array}$ & $\geq 0,6$ & $<0,2$ \\
\hline $\begin{array}{l}\text { Folacina plasmática } \\
(\mathrm{ng} / \mathrm{dl})\end{array}$ & $\geq 6$ & $<2$ \\
\hline Vitamina B12 (mg/dl) & $\geq 100$ & $<100$ \\
\hline
\end{tabular}

Quadro 22 - Valores de referência para vitaminas

Fonte: Adaptado de Nieman (2010).

\section{Valores Séricos Aceitáveis de Elementos-Traço}

\begin{tabular}{|l|l|l|l|l|}
\hline & Ferro $(\mu \mathrm{g} / \mathrm{dl})$ & Zinco $(\mu \mathrm{g} / \mathrm{dl})$ & Cobre $(\mathrm{mg} / \mathrm{dl})$ & $\begin{array}{l}\text { Selênio } \\
(\mathrm{ng} / \mathrm{dl})\end{array}$ \\
\hline 0 a 6 meses & $40-100$ & $70-150$ & $20-70$ & $95-165$ \\
\hline 6 anos & $50-120$ & & $90-190$ & \\
\hline 12 anos & $50-120$ & & $80-160$ & \\
\hline Adulto & $50-170$ & & $70-155$ & \\
\hline
\end{tabular}

Quadro 23 - Valores séricos aceitáveis para Ferro, Zinco, Cobre e Selênio

Fonte: Adaptado de Nieman (2010).

68 Avaliação bioquímica do estado nutricional 


\section{Diagnóstico e Deficiência do Ferro}

O diagnóstico de deficiência de ferro deve ser realizado com base no teor de hemoglobina, ferro sérico e ferritina.

A dosagem de hemoglobina pode definir a condição de anemia e avaliar a sua identidade. Contudo, utilizada isoladamente, é inadequada para o diagnóstico de suspeita da anemia por deficiência de ferro, pois é afetada apenas tardiamente pela doença e não distingue a deficiência de ferro de outras anemias.

Apesar da sua baixa sensibilidade, pode-se caracterizar a anemia como condição na qual a dosagem da hemoglobina sanguínea é menor que o limite de normalidade para idade e sexo.

\begin{tabular}{|l|l|}
\hline Idade & Hemoglobina $\mathbf{( g} / \mathbf{d} \mathbf{l})$ \\
\hline Ate 1 dia & 13,5 a 19,5 \\
\hline 2 a 3 dias & 14,5 a 22,5 \\
\hline 4 a 7 dias & 13,5 a 21,5 \\
\hline 8 a 14 dias & 12,5 a 20,5 \\
\hline 15 a 30 dias & 10 a 18 \\
\hline 31 a 90 dias & 9 a 14 \\
\hline 3 a 6 meses & 9,5 a 13,5 \\
\hline \multicolumn{2}{|l}{} \\
\hline 7 meses a 2 anos & 10,5 a 13,5 \\
\hline 3 a 6 anos & 11,5 a 13,5 \\
\hline 7 a 13 anos & 11,5 a 15,5 \\
\hline \multicolumn{2}{|c|}{ Acima de 13 anos } \\
\hline Sexo feminino & 11 a 18 \\
\hline Sexo masculino & 13 a 20 \\
\hline
\end{tabular}

Quadro 24 - Intervalos de referência para hemoglobina.

Fonte: Adaptado de Andriolo (2005). 
A dosagem de ferro sérico é útil na avaliação das anemias hipocrômicas microcíticas, mas como parâmetro isolado está sujeita a resultados falsos, tanto positivos quanto negativos. Níveis de ferro sérico encontram-se abaixo dos valores de referência em condições de perdas sanguíneas, dieta inadequada, doenças inflamatórias crônicas, neoplasias, desnutrição e síndrome nefrótica. Entre as anemias microcíticas, o ferro sérico deve estar baixo nas carenciais e normal ou elevado nas talassemias e anemias sideroblásticas.

\begin{tabular}{|l|l|l|l|l|}
\hline & 0 a 6 meses & 6 anos & 12 anos & Adulto \\
\hline Ferro $(\mu \mathrm{g} / \mathrm{dl})$ & $40-100$ & $50-120$ & $50-120$ & $50-170$ \\
\hline
\end{tabular}

Quadro 25 - Valores de referências de ferro sérico

Fonte: Adaptado de Rosa (2008).

A ferritina é a principal proteína intracelular responsável pela reserva de ferro no organismo e seu nível circulante tem relação direta com a quantidade de ferro armazenado. Encontra-se diminuída na anemia ferropriva, mas pode estar reduzida mesmo antes de se instalar o quadro anêmico. É considerado o parâmetro mais sensível nas situações de depleção de ferro, pois sua redução plasmática ocorre apenas na presença de deficiência verdadeira de ferro. Entretanto, não é uma proteína específica para o diagnóstico da anemia ferropriva, pois se apresenta elevada nas doenças inflamatórias causadas por aumento da síntese hepática e nas doenças com elevada disponibilidade do ferro, como anemia sideroblástica e hemocromatose. 


\begin{tabular}{|l|l|}
\hline Idade & Ferritina $(\mathbf{n g} / \mathbf{d l})$ \\
\hline Recém-nascidos & $25-200$ \\
\hline 1 mês & $200-600$ \\
\hline 6 meses & $50-200$ \\
\hline Crianças & $7-140$ \\
\hline Adultos (masculino) & $15-200$ \\
\hline Adultos (feminino) & $12-150$ \\
\hline
\end{tabular}

Quadro 26 - Valores de referência de ferritina para diagnóstico de deficiência de ferro

Fonte: Adaptado de Andriolo (2005).

\section{Referências}

ANDRIOLO, A. (Ed). Guia de medicina ambulatorial e hospitalar: medicina ambulatorial. Barueri: Manole, 2005.

AMERICAN SOCIETY OF PARENTERAL AND ENTERAL

NUTRITION (A.S.P.E.N) - Board of directors and the clinical guidelines Task Force. Guidelines for the use of parenteral and enteral nutrition in adult and pediatric patients. Journal of Parenteral and Enteral Nutrition (JPEN) J Parenter Enteral Nutr., Illinois, n. 26 p. 1SA-138SA, 2002. Erratum in: JPEN J Parenter Enteral Nutr. v. 26, n. 2, p. 144, 2002. 1 Suppl.

BLACKBURN, G. L. et al. Nutritional and metabolic assessment of hospitalized patient. Journal of Parenteral and Enteral Nutrition (JPEN), Illinois, v. 1, p. 11-32, 1977.

BLACKBURN, G. L.; THORNTON, P. A. Nutritional assessment of the hospitalized patients. Medical Clinics of North America. Maryland Heights, U.S.A, v. 63, p. 1103-1115, 1979.

BOTTONI, A. Cirurgia e trauma. In: Cuppari, L. (Ed).Guia de Nutrição clínica no adulto. 1. ed. Barueri: Manole, 2002. p. 319-342.

DUARTE, A. C.; CASTELLANI, F. R. Semiologia nutricional. 1. ed. Rio de Janeiro: Axcel Books, 2002. 128 p.

FONTOURA, C. S. M. et al. Avaliação Nutricional de Paciente Critico. Revista Brasileira de Terapia Intensiva, Rua Joaquim Távora, SP, v. 18, n. 3, p. 9 , 2006. 
GIBNEY, M. et al. (Ed.). Nutrição clínica. 1. ed. Rio de Janeiro: Guanabara Koogan, 2007. p. 440. 1 v.

KAMIMURA, M. A. et al. Avaliação nutricional. In: CUPPARI, L. (Ed.). Guia de nutrição: nutrição clínica no adulto. Barueri: Manole, 2002. p. 71-110. cap. 5.

LIMA, A. O. et al. Métodos de laboratório aplicados à clinica. 8. ed. Rio de Janeiro: Guanabara Koogan, 2001.

MAHAN, L. K.; ESCOTT-STUMP, S. Krause: alimentos, nutrição e dietoterapia. São Paulo: Roca, 2005.

MAICÁ, I.; SCHWEIGERT, D. Avaliação nutricional em pacientes graves. Revista Brasileira de Terapia Intensiva, Rua Joaquim Távora, SP, v. 20, n. 3, p. 10, jul./set. 2008.

MARTINS, C. Avaliação do estado nutricional e diagnóstico. Curitiba:

NutroClínica, 2008. p. 297-338. cap.10.

NIEMAN, Carney L. et al. Parenteral and enteral nutrition support: determining the best way to feed. In: CORKINS M. R. (Ed). The A.S.P.E.N. Pediatric Nutrition Support Core Curriculum. American Society of Parenteral and Enteral Nutrition, Fenton Street, p. 460-476, 2010.

OLIVEIRA, F. Avaliação do estado nutricional: avaliação bioquimica In: SILVIA, S. M. C.; MURA, J. D. A. P. (Ed.). Tratado de alimentação, nutrição e dietoterapia. São Paulo: Rocca, 2007. p. 141-145.

ROSA, G. et al. Avaliação nutricional do paciente hospitalizado: uma abordagem teórico-prática. 1. ed. Rio de Janeiro: Editora Guanabara Koogan, 2008.

SAMPAIO, L. R. Avaliação nutricional e envelhecimento. Revista de nutrição, Jd. Ipaussurama, SP, v. 17, n. 4, p. 8, out./dez. 2004.

SAUBERLICH, H. E.; SKALA, J. H.; DOWDY, R. P. Laboratory tests for the assessment of nutritional status. Cleveland, Ohio: CRC Press, 1974. 


\title{
Antropometria
}

\author{
Lílian Ramos Sampaio \\ Maria da Conceição Monteiro da Silva \\ Tatiane Melo de Oliveira \\ Christiane Ishikawa Ramos
}

\section{Introdução}

A palavra antropometria é de origem grega e foi criada através dos termos anthro (corpo) e metria (medida), apresentando-se como a medida das variações das dimensões físicas corporais. Por meio dos indicadores antropométricos, é possível estudar e acompanhar o processo de crescimento e desenvolvimento, de acordo com a faixa etária e /ou sexo, avaliar a massa corporal total, a distribuição de gordura e a composição corporal, permitindo, assim, identificar indivíduos com problemas de saúde/ nutricionais e em risco de doenças. Além disso, a antropometria é importante no monitoramento do estado nutricional, sendo utilizada em pesquisas epidemiológicas e na prática clínica. 
As vantagens de sua aplicação são justificadas pelo uso de equipamentos de baixo custo e portáteis, por suas técnicas não invasivas, pela obtenção rápida dos resultados e fidedignidade do método. Ainda é possível utilizar os indicadores antropométricos para monitorar os efeitos das medidas de intervenção de saúde e nutrição e a influência dos fatores ambientais no estado nutricional, nos âmbitos individual e coletivo.

Mesmo com todas essas vantagens, devemos considerar algumas situações em que os indicadores antropométricos tornam-se limitantes, pois não identificam carências nutricionais específicas, não permitem detectar alterações recentes na composição e distribuição corporal, dependem do estado de hidratação (casos em que há retenção de fluidos como edema, ascite e anasarca, além de organomegalias serem capazes de mascarar o peso e a perda de tecido gorduroso e/ou muscular). Outras questões a serem consideradas envolvem a capacidade limitada dos instrumentos para mensuração e a necessidade de profissionais treinados.

Para realizar a avaliação antropométrica é necessário que as medidas corporais sejam associadas entre si e a parâmetros como sexo e idade, formando índices e indicadores que serão comparados e analisados de acordo com os padrões de referência e pontos de corte recomendados. Um dos problemas encontrados na avaliação nutricional antropométrica é a escassez de padrões de referência, especificamente para a população brasileira, sendo comumente utilizados estudos populacionais americanos e europeus.

Para a avaliação antropométrica, utilizamos as medidas, os índices e indicadores:

- Índices: combinações de uma ou mais medidas associadas ao sexo e/ou idade.

- Indicadores: resultado da avaliação do índice e de medidas através do uso de referências e/ou padrões de normalidade. 
Os indicadores são divididos em grupos que avaliam o crescimento e desenvolvimento, massa corporal total, composição corporal e distribuição da gordura corporal.

\begin{tabular}{|ll|}
\hline O que avaliam & Índices \\
\hline 1. Crescimento e desenvolvimento & $\star$ P/I, A/I, P/A, CB/I, PC/PT \\
2. Massa corporal total & IMC/I, IMC \\
3. Composição corporal & \\
Tecido muscular & $\mathrm{CMB}, \mathrm{AMB}, \mathrm{AMBc}, \mathrm{CP}$ \\
Tecido adiposo & $\mathrm{AGB}, \sum \mathrm{PCT}+\mathrm{PCSE}$, \\
& $\sum$ 4 pregas $(\mathrm{PCT}+\mathrm{PCB}+$ \\
& $\mathrm{PCSE}+\mathrm{PCSI})$ \\
4. Distribuição de gordura corporal & $\mathrm{RCEst}, \mathrm{Ccx} \mathrm{CC}, \mathrm{RCQ}, \mathrm{IC}$, \\
& $\mathrm{DAS}$ \\
& \\
& \\
\hline
\end{tabular}

Quadro 1 - Indicadores antropométricos e suas funções Fonte: Elaborado pelas autoras.

* $\mathrm{P}$ - peso, I - idade, A - altura, CB - circunferência do braço, $\mathrm{PC}$ - perímetro cefáfilo, $\mathrm{PT}$ - perímetro torácico, IMC - índice de massa corporal, CMB - circunferência muscular do braço, $\mathrm{AMB}$ - área muscular do braço, $\mathrm{AMBc}$ - área muscular do braço corrigida, CP - circunferência da panturrilha, AGB - área de gordura do braço, PCT - prega cutânea tricipital, PCSE - prega cutânea subescapular, PCB - prega cutânea bicipital, PCSI - prega cutânea suprailíaca, RCEest - Razão cintura estatura, Ccx - cintura coxa, CC - circunferência da cintura, RCQ - razão cintura quadril, IC - índice de conicidade, DAS - diâmetro abdominal sagital. 
A escolha dos indicadores apropriados para a avaliação do estado nutricional depende, principalmente, dos recursos disponíveis, da faixa etária, das condições de saúde do indivíduo, da validade do indicador e da operacionalização.

A seguir, discutiremos as medidas e índices mais apropriados para a avaliação do estado nutricional. Todas as fórmulas e padrões de referência encontram-se em anexo.

\section{Peso}

O peso é a soma de todos os componentes corpóreos, aferido em balanças ou estimado a partir das equações de Chumlea e Baumgartner (1985). O significado desta medida sofre variação de acordo com o contexto em que é avaliado:

- $\quad$ Peso atual: aferido no momento da avaliação.

- Peso usual ou habitual: é o referido pelo indivíduo e corresponde ao peso que é encontrado normalmente pelo mesmo. Pode coincidir com o peso atual.

- $\quad$ Peso ideal ou desejável: é o considerado adequado de acordo com as características do indivíduo, para que o mesmo mantenha um bom estado de saúde. Para calculá-lo, utilizamos a fórmula do IMC (Índice de Massa Corporal ou Índice de Quetelet $=$ P/altura ${ }^{2}$ ), ajustando o mesmo às particularidades do indivíduo.

- $\quad$ Adequação do peso: reflete a porcentagem de peso acima ou abaixo do ideal.

- $\quad$ Peso ajustado: é obtido a partir da correção do peso ideal para a determinação das necessidades energéticas e de nutrientes do indivíduo, quando a adequação do peso for inferior a $95 \%$ ou superior a $115 \%$. 
- $\quad$ Peso ideal para amputados: peso ideal corrigido ao subtrair a porcentagem de peso relativa ao membro amputado.

- Mudança de peso: utilizada para a avaliação percentual da perda de peso.

Como o peso isolado não discrimina a composição corporal, sua avaliação deve ser realizada com cautela. Mudanças agudas no peso refletem, principalmente, em variações no estado de hidratação do indivíduo. Além disso, no exame físico devem ser observadas alterações como visceromegalias, carcinomas ou presença de edema e/ou ascite, o que superestimam o peso do indivíduo, comprometendo o diagnóstico nutricional. Para o edema e a ascite é possível fazer uma estimativa do peso atribuído a essas condições e descontá-lo, dependendo da gravidade destes problemas (tabela). Esta medida representa um parâmetro importante, visto que perdas ponderais graves, em curto espaço de tempo, estão associadas a altas taxas de morbimortalidade.

Tabela 1 - Excesso de peso atribuído ao edema/ascite de acordo com a intensidade ou gravidade

\begin{tabular}{lll}
\hline Edema & \multicolumn{2}{c}{ Excesso de peso Hídrico } \\
\hline+ & Tornozelo & $1 \mathrm{~kg}$ \\
++ & Joelho & $3 \mathrm{a} 4 \mathrm{~kg}$ \\
+++ & Base da coxa & $5 \mathrm{a} 6 \mathrm{~kg}$ \\
++++ & Anasarca & $1 \mathrm{a} 12 \mathrm{~kg}$ \\
\hline Grau de ascite/ & Líquido ascítico (kg) & Edema periférico (kg) \\
edema & & \\
\hline Leve & 2,2 & 1 \\
Moderado & 6 & 5 \\
Grave & 14 & 10 \\
\hline
\end{tabular}

Fonte: (KAMIMURA.; SAMPAIO; CUPPARI, 2009). 


\section{Estatura}

Para avaliar o estado nutricional, a estatura pode ser utilizada em associação com o peso, ao compor o IMC ou o índice peso/altura (P/A). Pode ser aferida diretamente pelo estadiômetro ou estimada através de fórmulas, da estatura recumbente ou envergadura dos braços, utilizando a fita inelástica ou régua antropométrica. No caso de crianças de até dois anos de idade, utiliza-se o infantômetro ou a régua antropométrica.

\section{Índice de Massa Corporal - IMC}

O IMC é um indicador de avaliação da massa corporal total do indivíduo em relação à altura. É um indicador simples, rápido e fácil de ser aplicado, sendo muito utilizado em pesquisas epidemiológicas e na prática clínica. Tem uma alta correlação com a gordura corporal, ou seja, quanto maior o IMC, maior a probabilidade do indivíduo de ser obeso. Porém, nem todo IMC elevado indica excesso de gordura corporal, visto que este índice não avalia separadamente os compartimentos corporais. O uso do IMC é limitado na avaliação de indivíduos atletas, por exemplo, que podem apresentar excesso de peso, em virtude da massa muscular hipertrofiada.

Além disso, o IMC tem boa correlação com dados de morbimortalidade. Os estudos realizados revelam que valores de IMC abaixo da normalidade predispõem o indivíduo a doenças associadas à desnutrição, como as pulmonares e infecciosas, enquanto que valores elevados relacionam-se com aquelas associadas à obesidade, como as doenças crônicas não transmissíveis (DCNT’s). 
Quanto às limitações, este índice não avalia separadamente os compartimentos corporais ou a distribuição de gordura corporal. Tem correlação com a estatura, apesar de baixa, não sendo aconselhada sua utilização para avaliação de indivíduos muito baixos ou muito altos, bem como para aqueles com desproporcionalidade corporal (troncos grandes, pernas curtas). Dessa forma, para um diagnóstico e conduta nutricional adequados, é necessário que o IMC seja associado a outros indicadores.

\section{Indicadores de Composição Corporal}

Os indicadores de composição corporal são importantes para identificar os riscos à saúde associados à escassez de massa magra ou excesso de gordura corporal; para monitorar as mudanças associadas a certas doenças, crescimento e idade; para formular recomendações dietéticas e para avaliar a eficiência de intervenções nutricionais e da atividade física na alteração da composição corporal.

A antropometria utiliza o modelo bicompartimental para a avaliação da composição corporal, dividindo o corpo em dois seguimentos: massa adiposa e a massa corporal magra (água, proteínas, componentes minerais e lipídeos essenciais).

\section{Gordura Corporal}

As pregas cutâneas correlacionam-se bem com o tecido adiposo subcutâneo e, assim, com a gordura corporal total, de modo que são utilizadas para estimar estas reservas. É um método simples, 
de baixo custo, porém necessita de exaustivo treinamento para o desprendimento correto dos tecidos.

Em avaliação nutricional, podem ser aferidas diversas pregas cutâneas, entretanto, na disciplina, trabalhamos com quatro: tricipital (PCT), bicipital (PCB), subescapular (PCSE) e supra-ilíaca (PCSI). Estes pontos anatômicos foram escolhidos por existirem dados de referência para sua avaliação, por serem de fácil localização, por apresentarem menor quantidade de tecido fibroso - facilitando, assim, o seu desprendimento - e, principalmente, pela elevada correlação com o tecido adiposo corporal total.

Na prática clínica, a PCT é o parâmetro mais usado para avaliação da reserva de gordura corporal. Esta prega pode ser avaliada de forma isolada ou em associação com a circunferência do braço (CB), formando a área gordurosa do braço (AGB). Na literatura sobre o assunto, é possível encontrar outros pontos anatômicos para compor equações de estimação da gordura corporal.

A avaliação pode ser feita com cada prega isoladamente ou de forma associada:

- $\%$ Gordura Corporal Total - \%GCT: $\Sigma$ (PCT, PCB, PCSE, PCSI)

- $\quad \mathrm{S}(\mathrm{PCT}+\mathrm{PCSE})$

- $\quad$ Área Gordurosa do Braço (AGB)

Separadamente, as pregas também podem ser utilizadas como indicadores de acompanhamento, quando avaliadas de forma seriada. No entanto, para estimar a quantidade de gordura corporal, recomenda-se a utilização de equações com mais de uma prega subcutânea.

É importante ressaltar que a composição em tecido adiposo varia com a idade, sexo, estado nutricional e nas diferentes partes do 
corpo, existindo, também, variação de acordo com a compressibilidade e estado de hidratação.

Apesar das técnicas de avaliação da gordura corporal se apresentarem como bom parâmetro para estimativa do tecido adiposo, existem, também, algumas limitações. Em pacientes obesos, a depender do grau de obesidade, não é possível realizar a aferição das pregas cutâneas, em virtude da dificuldade de desprendimento do tecido e por conta da amplitude do plicômetro que não é suficiente, nessas circunstâncias. Em casos de edema local ou generalizado, bem como vísceromegalias, ou a depender do estado de hidratação do paciente, essas técnicas tornam-se inviáveis ou pouco fidedignas. No quesito das diferentes faixas etárias, para crianças menores de 5 anos, tais técnicas podem ser utilizadas no monitoramento em âmbito hospitalar ou em pesquisas. Em idosos, em virtude do remodelamento de tecido adiposo (sendo menor nas extremidades e concentrado na região central), a avaliação da adiposidade corpórea deve ser feita usando-se as pregas associadas a outros indicadores.

\section{Massa Muscular}

A massa muscular pode ser estimada através da circunferência muscular do braço (CMB), área muscular do braço (AMB) e área muscular do braço corrigida $(\mathrm{AMB})$ ). $\mathrm{A}$ CMB considera que todos os tecidos do braço são circulares e concêntricos. A AMB, por sua vez, considera o formato irregular dos tecidos do braço e a $\mathrm{AMBc}$ difere-se das outras por descontar a área óssea, sendo assim a mais precisa.

Outro importante indicador que está sendo bastante estudado é a circunferência da panturrilha $(\mathrm{CP})$, principalmente para ava- 
liação da alteração no tecido muscular em idosos e indivíduos acamados.

A avaliação da massa muscular é importante, principalmente para verificar a depleção de proteínas somáticas, a capacidade de trabalho dos indivíduos (por relacionar-se à força), a progressão de doenças catabólicas e a eficácia da intervenção terapêutica sobre o prognóstico.

\section{Distribuição de Gordura Corporal}

Atualmente a distribuição de gordura corporal é foco de estudos em todo o mundo por relacionar-se, principalmente, com as DCNTs. Pode ser classificada como:

- $\quad$ Andróide, abdominal, superior ou central: quando acumulada na região abdominal, composta pela gordura subcutânea e visceral (associada às DCNTs).

- Intermediária: neste caso, não há concentração de gordura de forma desigual, encontrando-se bem distribuída.

- Ginóide, ginecóide, inferior, periférica ou glúteo-femoral: quando acumulada na região glútea e dos quadris, associada aos riscos de doenças vasculares periféricas.

A concentração de gordura abdominal, independentemente do \% GCT, é um fator de risco para doenças metabólicas e cardiovasculares. Isso porque o adipócito visceral é maior, tem menos receptores de insulina e é mais sensível à estimulação da lipólise pelas catecolaminas, entre outras causas.

Dos indicadores de distribuição de gordura corporal, temos a razão cintura-quadril (RCQ), ou razão abdome glúteo (RAG), a circunferência da cintura (CC), o índice de conicidade (IC), a 
razão cintura-estatura (RCEst) e o diâmetro abdominal sagital. Atualmente, o mais utilizado para predizer o risco associado às DCNTs, relacionado ao acúmulo de gordura na região abdominal, é a CC. Os pontos de corte para este indicador permitem caracterizar os indivíduos como apresentando risco elevado e muito elevado, sendo específicos para cada sexo.

A CC tem a vantagem de ser simples, correlacionar-se fortemente com o IMC, com o RAG e com a gordura intra-abdominal. Um fator limitante do uso da CC é decorrente das diferentes técnicas de aferição, o que requer treinamento do avaliador para fidedignidade da medida. Nos indivíduos muito obesos, o reconhecimento dos pontos anatômicos necessários à realização da medida é dificultado pelo acúmulo de gordura nestas regiões. O uso da CC vem sendo recomendado em detrimento da RCQ, em virtude das limitações deste indicador, pois, no acompanhamento do individuo, não é possível detectar mudanças, uma vez que a medida da cintura varia simultaneamente com a medida do quadril, mantendo a RCQ constante, particularmente na ocorrência da redução de peso, e também pela medida do quadril não considerar variações na estrutura óssea, a exemplo do processo de envelhecimento, no qual há redução no quadril de homens e mulheres. Além disso, para realizar esta medida, é necessário que o indivíduo esteja utilizando roupas de tecido fino para evitar desvios na aferição.

O Índice de Conicidade (IC) é determinado através das medidas de peso, estatura e circunferência da cintura. Proposto no início da década de 90, este índice baseia-se na ideia de que indivíduos que acumulam tecido adiposo na região central tendem a apresentar o corpo na forma de dois cones, dispostos um sobre outro, através da mesma base (duplo cone). Os indivíduos com menor quantidade de tecido adiposo na região abdominal, por- 
tanto, teriam a aparência similar a um cilindro. Assim, o valor do IC de um indivíduo representa - considerando-se o peso e a estatura deste - quantas vezes a CC é superior à que ele teria se não tivesse uma concentração de tecido adiposo abdominal, ou seja, se a forma do corpo fosse semelhante a de um cilindro. $\mathrm{Na}$ última década, alguns estudos têm sugerido o IC como um bom indicador de obesidade para avaliação de risco coronariano.

Outro indicador que vem sendo estudado e que tem apresentado associação com obesidade abdominal e o risco de doenças cardiovasculares é a razão cintura-estatura (RCEst). Segundo Pitanga e Lessa (2006), a circunferência da cintura do indivíduo não deve ser superior à metade de sua estatura. Apesar desta consideração, a utilização deste indicador na prática clínica e ambulatorial ainda é limitada, uma vez que não há pontos de corte específicos para cada grupo etário e sexo. Assim, são necessários mais estudos, a fim de comparar a RCEst com outros indicadores de distribuição de gordura e de morbidade e estabelecer pontos de corte específicos para a população brasileira.

O Diâmetro Abdominal Sagital (DAS) é uma medida de grande relevância. Acredita-se que este prediz melhor o acúmulo de gordura visceral do que os outros indicadores supracitados, sendo recomendado como método alternativo à tomografia computadorizada, que, embora seja o método padrão-ouro, apresenta como desvantagens o alto custo, a emissão de radiação e a necessidade de um profissional especializado para interpretação. Não há um consenso sobre os pontos de corte para o DAS, entretanto os poucos estudos sobre esta medida apontam que diâmetros superiores a $20 \mathrm{~cm}$ significam maior risco para o indivíduo desenvolver doenças metabólicas e cardiovasculares. 


\section{Considerações Finais}

A antropometria é um indicador fundamental e indispensável na avaliação nutricional, com muitas vantagens, de boa operacionalização e acurácia, no entanto apresenta algumas limitações. Por isso, não deve ser utilizada de forma isolada no diagnóstico nutricional. Este requer a contribuição de outros indicadores.

\section{Referências}

BLACKBURN, G. L.; BISTRIAN, B. R.; MAINI, B. S. Nutritional and metabolic assessment of the hospitalized patient. Journal of Parenteral and Enteral Nutrition, Silver Spring, Md., v. 1, n. 1, p. 11-32, jan. 1977.

BLACKBURN, G. L.; THORNTON, P. A. Nutritional assessment of the hospitalized patients. The Medical Clinics of North American, Philadelphia, $\mathrm{n}$. 63, p. 1103-115, set. 1979.

CHUMLEA, W. C. Prediction of body weight for the nonambulatory elderly from anthropometry. Journal of American Dietetic Association, Chicago, US, v. 88, n. 5, p. 564-568, maio 1988.

CHUMLEA, W. C.; BAUMGARTNER, R. N. Status of anthropometry and body composition data in elderly subjects. American Journal of Clinical Nutrition, Baltimore, n. 50, p. 1158-1166, jun. 1989. Supll.

CHUMLEA, W. C.; ROCHE, A. F.; MUKHERFEE, A. Nutritional assessment of the elderly through anthropometry. Columbus, Ohio: Ross Laboratories, 1985.

CHUMLEA W. C.; ROCHE A. F.; STEINBAUGH, M. L. Estimating stature from knee height for persons 60 to 90 years of age. Journal of the American Geriatrics Society. New York, v. 33, n. 2, p. 116-120, fev. 1985.

DUARTE, A C. Avaliação nutricional: aspectos clínicos e laboratoriais. São Paulo: Atheneu, 2007.

DURNIN, J. V.; WOMERSLEY, J. Body fat assessed from total body density and its estimation from skinfold thickness: measurements on 481 men and women aged from 16 to 72 years. The British Journal of Nutrition., Cambridge, Mass., Reino Unido, n. 32, p. 77-97, fev. 1974.

FRISANCHO, A. R. Anthropometric standards for the assessment of growth and nutritional status. Ann Arbor: The University of Michigan Press, 1990. p. 48-53. 
FRISANCHO, A. R. New norms of upper limb fat and muscle areas for assessment of nutritional status. American Journal of Clinical Nutrition, Philadelphia, n. 34, p. 2540- 2545, nov. 1981.

GIBSON, R. S. Nutritionnal assessment: a laboratory manual. New York: University Press, 1993. 196 p.

HEYMSFIELD, S. B. et al. Anthropometric measurement of muscle mass: revised equations for calculating bonefree arm muscle area. American Journal of Clinical Nutrition, Philadelphia, n. 36, p. 680-690, 1982.

HIMES, J. H.; ROCHE, A. F.; WEBB, P. Fat areas as estimates of total body fat. American Journal of Clinical Nutrition, Philadelphia, n. 33, p. 2093-2100, 1980.

KAMIMURA, M. A.; SAMPAIO, L. R.; CUPPARI, L. Avaliação nutricional na prática clínica. In: CUPPARI, L. et al. Nutrição: nas doenças crônicas nãotransmissíveis. Barueri, SP: Manole, 2009.

KUCZMARSKI, M. F. et al. Descriptive anthropometric reference data for older Americans. Jornal of the American Dietetic Association, Philadelphia, v. 100, n. 1, p. 59-66, jan. 2000.

LEE, R. D.; NIEMAN, D. C. Nutritional assessment. Londres: McGraw Hill, 1993.

LIPSCHITZ, D. A. Screening for nutritional status in the elderly. Nutrition in Old Age, v. 21, n. 1, p. 55-67, 1994.

LOHMAN T. G.; ROCHE A. F.; MARTORELL R. Anthropometric standardization reference manual. Champaign: Human Kinetics, 1992. . Anthropometric standardization reference manual. Londres: Abridged edition, 1991.

LOPEZ, F. A.; CAMPOS JUNIOR, D. (Ed.). Tratado de pediatria: sociedade brasileira de pediatria. Barueri, SP: Manole, 2007.

MUST, A.; DALLAL, G. E; DIETZ, W. H. Reference data for obesity: 85th and 95th percentiles of body mass index (wt/ht2) and triceps skinfold thickness. American Journal of Clinical Nutrition, Baltimore, n. 53, p. 834-46, nov. 1991.

ORGANIZAÇÃO MUNDIAL DA SAÚDE. Dieta, nutricion y prevencion de Enfermidades crônicas. Genebra, 1990. (Série de Informes Técnicos, n. 797). . Physical status: the use and interpretation of anthropometry. Geneva, 1994. Report of a who expert committee. (Technical Report Series, n. 854). . Physical status: the use and interpretation of anthropometry. Geneva, 1995. Report of a who expert committee. (Technical Report Series, n. 854). 
ORGANIZACIÓN MUNDIAL DE LA SALUD/ORGANIZACIÓN PANAMERICANA DE LA SALUD. Conocimientos actuales sobre nutrición. 7. ed. Washington, DC: ILSI Press, 1997. (Publicación Científica 565).

OSTERKAMP, L. K. Current perspective on assessment of human body proportions of relevance to amputees. Journal of American Dietic Association, Chicago, n. 95, p. 215-218, 1995.

PITANGA, F. J. G.; LESSA, I. Razão cintura-estatura como discriminador do risco coronariano de adultos. Revista Associação Médica Brasileira, São Paulo, v. 52, n. 3, 2006.

SAMPAIO, L. R. Avaliação nutricional no envelhecimento. Revista de Nutrição, Campinas, SP, v. 17, n. 4, out./dez. 2004.

SHILS, M. E. et al. Tratado de nutrição moderna na saúde e na doença. São Paulo: Manole, 2002.

SILVEIRA, D. H.; ASSUNÇÃO, M. C. F.; BARBOSA E SILVA, M. C. G. Determinação da estatura de pacientes hospitalizados através da altura do joelho. Jornal Brasileiro de Medicina, Rio de Janeiro, v. 67, n. 2, p. 176-180, 1994.

TZAMALOUKAS, A. H. et al. Body mass index in amputees. Journal of parenteral and enteral nutrition, Silver Spring, Md., v. 18, n. 4, p. 355-358, 1994.

WHO, WORLD HEALTH ORGANIZATION. Physical status: The use and interpretation of anthropometry. Geneva, 1995. Report of a who expert committee.

WORLD HELTH ORGANIZATION. Obesity: preventing and managing the global epidemic of obesity. Geneva, jun. 1997. Report of the who consultation of obesity.

VASCONCELOS, F. A. G. Avaliação nutricional de coletividades. 4. ed. rev. e amp. Florianópolis: Ed. UFSC, 2008. 186 p. 


\title{
Técnicas de medidas antropométricas
}

\author{
Lílian Ramos Sampaio \\ Maria da Conceição Monteiro da Silva \\ Tatiane Melo de Oliveira \\ Christiane Ishikawa Ramos
}

\section{Introdução}

Para que as medidas antropométricas sejam realizadas com maior precisão, é necessário que o medidor domine as técnicas de medidas e conheça os instrumentos utilizados. A maioria das medidas é realizada com o indivíduo em posição anatômica, ou seja, em posição ereta, com a face voltada para frente em direção ao Plano Horizontal de Frankfurt (olhar para o horizonte), com os braços estendidos ao longo do corpo e com as palmas das mãos voltadas para frente. A aferição de medidas em membros superiores ou inferiores deve ser realizada de preferência no lado não dominante. 


\section{Peso}

\section{Peso (Em pé)}

Para aferir o peso, utiliza-se uma balança devidamente calibrada, de plataforma ou eletrônica. O ideal é que esta medida seja aferida antes das principais refeições. $\mathrm{O}$ indivíduo deverá estar descalço e utilizar o mínimo de acessórios e roupas possíveis, de preferência leves, para então ser posicionado em pé no centro da balança, com o peso distribuído igualmente em ambos os pés. $\mathrm{O}$ medidor deverá se posicionar em frente à escala e a medida deverá ser aferida e registrada com exatidão. $\mathrm{O}$ instrumento não deve ser posicionado sobre tapete, carpete ou piso irregular.

\section{Peso (Deitado) - Crianças}

O medidor deve seguir as recomendações quanto à calibração, refeições e posicionamento para a leitura, especificadas para a medição em pé. A criança deverá ser posicionada deitada ou sentada na balança pediátrica com o mínimo de roupa possível, de preferência nua. Caso use fraldas, recomenda-se que seja retirada, a fim de não alterar o peso. A balança deve ser posicionada sobre mesa de superfície plana em piso regular.

\section{Estatura}

A estatura pode ser aferida ou estimada a partir da medida da extensão dos braços ou através da fórmula de estimativa de altura, que utiliza a altura do joelho. Normalmente, os instrumentos utilizados são o estadiômetro e o infantômetro. Há também o 
antropômetro fixo à balança, entretanto este apresenta menor acurácia quando comparado ao estadiômetro.

\section{Estatura (Em pé)}

O indivíduo deverá estar descalço ou usando meias finas e roupas leves, de forma a visualizar a posição do corpo, e sem nenhum adereço na cabeça que possibilite alteração da medida. Deverá permanecer em posição anatômica com panturrilha, glúteos, ombros e cabeça tocando a parede ou superfície vertical do dispositivo de medida, sempre que possível. Com a face voltada para frente, no Plano de Frankfurt, o suporte deverá ser posicionado sobre a cabeça, de tal forma que pressione apenas o cabelo. $\mathrm{O}$ medidor deverá estar em frente à escala e a medida ser aferida cuidadosamente no centímetro mais próximo. Caso a parede seja utilizada como suporte de medida, esta deve ser lisa e não possuir rodapés. $\mathrm{O}$ instrumento não deve ser posicionado sobre tapete, carpete ou piso irregular.

\section{Comprimento (Deitado) - Crianças menores de 24 meses}

A criança deverá estar deitada em mesa com superfície plana posicionada em piso regular com a face voltada para cima, no Plano de Frankfurt, e a cabeça encostada na parte fixa do infantômetro. Com os joelhos retos e as pernas encostadas sobre a superfície da mesa, a parte móvel do infantômetro deverá ser deslocada e pressionada sobre a região plantar. É necessário segurar os joelhos, pressionando-os firmemente sobre a mesa de medida, para mantê-la na posição adequada. Registra-se o comprimento no milímetro mais próximo. 


\section{Estatura recumbente}

A estatura recumbente é uma técnica utilizada em casos onde é inviável a movimentação do indivíduo. O mesmo deve permanecer deitado em posição supina e com leito horizontal completo. O lençol da cama é marcado na altura da extremidade da cabeça e da base dos pés (pés flexionados), do lado direito do indivíduo, sendo medida a distância entre as duas marcas com o auxílio de uma fita métrica flexível.

\section{Estimativa da estatura: pode ser realizada utilizando a medida da extensão dos braços e o comprimento das pernas}

\section{Extensão dos braços/ Envergadura dos braços}

Para a realização desta medida, o individuo deve ser posicionado em pé, de costas para a parede; os braços devem ficar estendidos, formando um ângulo de $90^{\circ}$ com o corpo (na altura do ombro), sendo aferida a distância entre os dedos médios do indivíduo com o auxílio de uma fita métrica flexível. Caso não seja possível a extensão dos dois braços, a medida poderá ser aferida medindo a distância entre o dedo médio de um dos braços estendidos e o meio do externo na altura do ombro. Multiplica-se o resultado por dois.

\section{Comprimento da perna (Knee Height)}

O comprimento da perna é utilizado para a estimativa da altura, principalmente em idosos, a partir da fórmula proposta por Chumlea e outros (1985). 
O indivíduo deverá estar sentado o mais próximo possível da extremidade da cadeira, com a perna flexionada, formando um ângulo de $90^{\circ}$ com o joelho e o tornozelo - caso a altura da cadeira não seja compatível com o comprimento da tíbia, utilizar sob os pés um apoio. A parte fixa do instrumento é posicionada na parte inferior dos pés, no meio do calcanhar, e a outra na superfície anterior do joelho, acima dos côndilos do fêmur e próximo à rótula. A régua do calibrador deve ser mantida paralela à tíbia, para tanto, a haste móvel deverá ser posicionada a 2 ou 3 dedos em direção à coxa. Antes da leitura, uma pressão suave nos suportes do calibrador deve ser exercida.

Caso esteja acamado, o indivíduo deverá estar em posição supina, com a perna flexionada, formando um ângulo de $90^{\circ} \mathrm{com}$ o joelho e o tornozelo. A medida deve ser aferida com os mesmos critérios para a posição supracitada.

\section{Circunferências}

Para aferir as circunferências, utiliza-se a fita inelástica. Ao realizar as medidas, deve-se atentar para a posição linear e horizontal da fita, evitando compressão ou folga dos tecidos. A variação máxima aceita entre duas medidas consecutivas é de $1 \mathrm{~cm}$, para as grandes circunferências (como quadril, cintura e coxa), e 0,5 $\mathrm{cm}$, para as pequenas (como braço, tornozelo e pescoço). É importante ressaltar que a aferição da circunferência braquial deve ser realizada no lado não dominante do indivíduo, seguindo os padrões de referência adotados na América do Norte. Sempre que possível, realizar duas medidas e utilizar a média das duas. No caso de utilização dos dados para pesquisas, recomenda-se 
aferição por dois medidores, observando-se sempre a variação máxima entre as medidas.

\section{Perímetro cefálico}

A criança deve estar na posição anatômica ou sentada e o medidor lateralmente à mesma. Com a cabeça da criança posicionada no Plano de Frankfurt, o medidor deverá circundar a fita acima da cavidade supra-orbital e sobre o occipital na circunferência máxima. Deve-se ter cuidado para que a fita esteja no mesmo nível em ambos os pontos supracitados. É preciso pressionar o suficiente para comprimir apenas o cabelo. A leitura deverá ser realizada no milímetro mais próximo.

\section{Perímetro torácico}

A circunferência do tórax é mais utilizada em crianças menores de 5 anos. Para aferir esta medida, a criança deverá estar em posição anatômica ou sentada, com os braços levemente levantados de tal forma que permita a passagem da fita em volta do tórax na altura dos mamilos. Após a fita ser posicionada, a criança deverá manter os braços relaxados ao longo do corpo. A leitura é realizada ao final da expiração, com o medidor em frente ao indivíduo, desviando-se levemente para o lado.

\section{Circunferência do pescoço}

Esta medida é aferida com o indivíduo sentado e ereto, com a face voltada para frente, no Plano de Frankfurt. A fita deve ser posicionada horizontalmente, acima da proeminência laríngea (pomo de Adão). A leitura é realizada lateralmente. 


\section{Circunferência do braço}

O indivíduo deve estar em posição anatômica, de lado para o medidor. Flexiona-se o braço do indivíduo em direção ao tórax, formando um angulo de $90^{\circ}$ com o cotovelo; localiza-se e marca-se o ponto médio entre o processo acromial e a extremidade do olécrano. Após marcar o ponto médio, o indivíduo deverá estender o braço ao longo do corpo com a palma da mão voltada para a coxa. A fita deverá contornar o braço no ponto marcado de forma ajustada, evitando compressão ou folga da pele. A leitura é realizada no milímetro mais próximo.

Caso esteja deitado, o indivíduo deverá estar olhando para cima com a cabeça apoiada no travesseiro. A localização do ponto médio é realizada da mesma forma utilizada para a posição em pé, porém, para a aferição da medida, os braços devem estar estendidos ao lado do corpo, com a palma da mão voltada para cima e os cotovelos apoiados sob alguma superfície, a fim de afastar o braço da cama, possibilitando a realização da medida.

\section{Circunferência da coxa}

$\mathrm{Na}$ aferição desta medida, o indivíduo deverá estar na posição ortostática, com as pernas levemente afastadas. Deve-se localizar o ponto médio entre a linha inguinal e a borda superior da patela. A partir deste ponto meso-femural, circundar a fita horizontalmente, realizando a leitura lateralmente.

\section{Circunferência da cintura}

O indivíduo deverá estar em posição anatômica. Na linha média axial, localiza-se e marca-se o ponto médio entre a crista ilíaca e o rebordo da última costela, no qual circunda a fita. Deve-se 
observar o posicionamento horizontal da fita ao longo da cintura e o ajuste, de forma a evitar folga ou compressão da pele. O medidor deverá posicionar-se lateralmente ao indivíduo e a leitura deverá ser realizada no momento da expiração.

\section{Circunferência do quadril}

O indivíduo deverá estar usando roupas de tecido fino, de preferência ajustada ao corpo, em posição ortostática, e o medidor deverá estar agachado lateralmente ao indivíduo, para que possa visualizar melhor a parte mais saliente do quadril, por onde deverá circundar a fita. A fita deve ser posicionada de forma horizontal e ajustada ao corpo, evitando-se folga ou compressão da pele. Caso o indivíduo não utilize roupas leves, deve-se comprimir um pouco mais a fita, de forma a minimizar as interferências da roupa na medida.

\section{Circunferência da panturrilha}

O indivíduo deverá estar deitado ou sentado na mesma posição utilizada para a altura do joelho. A medida deve ser aferida lateralmente, posicionando a fita na circunferência máxima da panturrilha, e a leitura deve ser realizada no milímetro mais próximo.

\section{Pregas Cutâneas}

Para aferir as pregas cutâneas, utilizamos adipômetros ou plicômetros, com a leitura realizada em milímetros. Recomenda-se aferir a mesma prega três vezes, soltando-a e pinçando-a novamente entre as medidas. 
Instruções gerais

- $\quad$ Identificar e marcar o local a ser pinçado, do lado não dominante do indivíduo;

- $\quad$ Segurar a prega formada pela pele e tecido adiposo com os dedos polegar e indicador a $1 \mathrm{~cm}$ do ponto marcado;

- Manter a prega entre os dedos enquanto a medida é aferida;

- Pinçar a prega com o calibrador exatamente no local marcado a $1 \mathrm{~cm}$ dos dedos;

- $\quad$ Evitar modificar a posição do calibrador. O mesmo deve ser posicionado perpendicularmente em relação à prega;

- $\quad$ Realizar a leitura de 2 a 3 (GIBSON, 1993; LEE; NIEMAN, 1993) ou 4 (LOHMAN, 1988) segundos após o pinçamento, no milímetro mais próximo;

- Caso o indivíduo esteja acamado, recomenda-se o desprendimento da prega a $1 \mathrm{~cm}$ abaixo do ponto de pinçamento, a fim de facilitar a leitura.

\section{Prega Tricipital}

O indivíduo deverá estar em posição ortostática, de costas para o medidor. Marcar-se dois pontos na região onde localiza-se o tríceps braquial: o ponto médio entre o acrômio e o olécrano (ponto marcado para medir a circunferência do braço), em que se posiciona horizontalmente o aparelho, e um ponto a $1 \mathrm{~cm}$ acima deste, onde será formada a prega para desprendimento do tecido adiposo.

Caso o indivíduo esteja deitado, deve ser posicionado de lado, com as costas voltadas para o medidor, o tronco em linha reta, os 
ombros perpendiculares à espinha e à mesa de exame ou cama, as pernas levemente flexionadas e a cabeça apoiada sobre o braço não utilizado para medida. O ponto médio é marcado, seguindo a mesma orientação para circunferência do braço, com o indivíduo deitado, e a prega deverá ser desprendida do tecido muscular a $1 \mathrm{~cm}$ abaixo do ponto médio, no sentido vertical, a fim de facilitar a leitura da medida no aparelho.

\section{Prega bicipital}

O indivíduo deverá estar em posição anatômica, de frente para o medidor. Para realizar esta medida, deve-se transferir o ponto marcado da prega tricipital para a região bicipital e marcar a $1 \mathrm{~cm}$ acima deste. No primeiro ponto, posiciona-se o aparelho horizontalmente e, no último, desprende-se a prega.

\section{Prega subescapular}

O indivíduo deverá estar em posição ortostática, de costas para o medidor. Deve-se solicitar que o mesmo dobre o braço em direção às costas, formando um ângulo de $90^{\circ}$ com o cotovelo. Com o auxílio dos dedos, localizar e marcar um ponto logo abaixo do ângulo inferior da escápula. Marcar outro ponto a $1 \mathrm{~cm}$ acima deste, na diagonal, de forma que a fita mantenha um ângulo de $45^{\circ} \mathrm{com}$ a coluna. Com os braços relaxados, estendidos ao longo do corpo, a prega é desprendida no ponto superior e o aparelho posicionado diagonalmente, em direção à prega, no ponto inferior.

\section{Prega suprailíaca}

O indivíduo deverá estar em posição ortostática, visualizado pelo medidor lateralmente. A prega deverá ser formada com o polegar 
posicionado na linha média axial, imediatamente acima da crista ilíaca e com o dedo indicador diagonalmente seguindo a linha da pelve. $\mathrm{O}$ aparelho deve ser posicionado a, aproximadamente, $1 \mathrm{~cm}$ abaixo do desprendimento da prega.

\section{Diâmetro abdominal sagital}

É aferido com o indivíduo deitado em posição supina, com a face voltada para cima. No lado onde será aferida a medida, a mão é posicionada sobre o peito e o cotovelo alinhado ao corpo, sendo que o outro braço deve estar estendido ao longo do tronco. Deve-se localizar a crista ilíaca, traçar um ponto e transferi-lo com auxílio de uma fita inelástica para o centro do abdome (pode ou não coincidir com a cicatriz umbilical). A haste fixa do calibrador abdominal é posicionada sob as costas do paciente, e a móvel em cima do ponto transferido, mantendo o aparelho na posição vertical. É importante ressaltar que, mesmo em pacientes que apresentem algum desvio postural (cifose, lordose), a haste fixa do calibrador deverá ser posicionada sob as costas. A medida deve ser aferida no milímetro mais próximo, no momento da expiração.

\section{Considerações finais}

Considerando a importância das medidas na construção dos indicadores antropométricos, sendo de grande relevância na definição do diagnostico nutricional, estas devem ser realizadas seguindo, com bastante rigor, as técnicas de medidas, de forma a obter a maior precisão possível. Cuidados também não devem ser dispensados à qualidade dos instrumentos de medida que devem ser periodicamente aferidos por empresas e técnicos especializados. 
No quadro abaixo encontram-se sistematizados os erros mais comuns observados na aferição das medidas antropométricas.

\begin{tabular}{|c|c|c|}
\hline MEDIDAS & ERROS & SOLUÇÕES \\
\hline \multirow[t]{4}{*}{ TODAS } & Instrumento inadequado & $\begin{array}{l}\text { Adequação dos métodos aos } \\
\text { recursos }\end{array}$ \\
\hline & Leitura & $\begin{array}{l}\text { Treinamento exaustivo e } \\
\text { supervisão constante }\end{array}$ \\
\hline & Registro & $\begin{array}{l}\text { Registrar imediatamente os } \\
\text { resultados e ter os resultados } \\
\text { checados por outra pessoa }\end{array}$ \\
\hline & Inquietude da criança & $\begin{array}{l}\text { Solicitar ajuda dos pais e } \\
\text { utilizar procedimentos cultu- } \\
\text { ralmente apropriados }\end{array}$ \\
\hline \multirow[t]{4}{*}{ COMPRIMENTO } & Uso de sapatos & Remoção dos sapatos \\
\hline & Método incorreto para a idade & Apenas para crianças $<2$ anos \\
\hline & Posição do corpo e cabeça & Ajuda dos pais \\
\hline & $\begin{array}{l}\text { Posição do suporte na cabeça ou } \\
\text { nos pés (criança deitada) }\end{array}$ & $\begin{array}{l}\text { Ter um assistente, além de } \\
\text { um dos pais }\end{array}$ \\
\hline \multirow[t]{3}{*}{ ALTURA } & Método incorreto para a idade & $\begin{array}{l}\text { Apenas para crianças }>\text { ou }= \\
\text { a } 2 \text { anos }\end{array}$ \\
\hline & $\begin{array}{l}\text { Posição do corpo, joelhos dobra- } \\
\text { dos, pernas afastadas e pés não } \\
\text { posicionados firmemente sobre } \\
\text { o solo. Cabeça fora do plano }\end{array}$ & $\begin{array}{l}\text { Ter um assistente e estar aten- } \\
\text { to para corrigir a posição do } \\
\text { corpo. Ter bastante calma no } \\
\text { caso de crianças agitadas ou } \\
\text { que não querem colaborar }\end{array}$ \\
\hline & Posição do suporte na cabeça & $\begin{array}{l}\text { Suporte deve comprimir o } \\
\text { cabelo }\end{array}$ \\
\hline \multirow[t]{3}{*}{ PESO } & $\begin{array}{l}\text { Privacidade para retirada do } \\
\text { vestuário }\end{array}$ & $\begin{array}{l}\text { Local apropriado ou padro- } \\
\text { nizar vestimenta e subtrair } \\
\text { do peso }\end{array}$ \\
\hline & Balança não calibrada & $\begin{array}{l}\text { Usar se possível microele- } \\
\text { trônica ou calibrar a balança } \\
\text { antes de cada pesada }\end{array}$ \\
\hline & Inquietude do indivíduo & $\begin{array}{l}\text { Esperar até o indivíduo se } \\
\text { acalmar }\end{array}$ \\
\hline \multirow[t]{2}{*}{$\mathrm{CB}$} & $\begin{array}{l}\text { Posição do indivíduo/pressão } \\
\text { exercida pela fita }\end{array}$ & Treinamento, supervisão \\
\hline & $\begin{array}{l}\text { Marcação correta do ponto } \\
\text { médio }\end{array}$ & $\begin{array}{l}\text { Constante levar em conside- } \\
\text { ração questões culturais }\end{array}$ \\
\hline
\end{tabular}




\begin{tabular}{|c|c|c|}
\hline & Posição da fita /tipo de fita & $\begin{array}{l}\text { Usar sempre o mesmo braço/ } \\
\text { fita adequada }\end{array}$ \\
\hline MEDIDAS & ERROS & SOLUÇÕES \\
\hline \multirow[t]{2}{*}{$\begin{array}{l}\text { CIRC. DA } \\
\text { CABEÇA }\end{array}$} & $\begin{array}{l}\text { Marcadores da protuberância } \\
\text { occipital pobremente definidos }\end{array}$ & $\begin{array}{l}\text { Fita corretamente posicionada } \\
\text { exercitar bastante a técnica }\end{array}$ \\
\hline & $\begin{array}{l}\text { Tensão exercida na fita na hora } \\
\text { da leitura }\end{array}$ & $\begin{array}{l}\text { Remover qualquer enfeite } \\
\text { que altere o resultado }\end{array}$ \\
\hline \multirow[t]{4}{*}{ PCT } & Momento da leitura & Padronizar tempo \\
\hline & Posição do braço & Relaxamento do braço \\
\hline & $\begin{array}{l}\text { Posição do examinador em } \\
\text { relação ao instrumento }\end{array}$ & Treinamento sistemático \\
\hline & $\begin{array}{l}\text { Posição calibrador/profundidade } \\
\text { do pinçamento }\end{array}$ & Treinamento \\
\hline
\end{tabular}

Quadro 1 - Erros mais comuns observados na realização das medidas antropométricas

Fonte: Gibson (1990).

\section{Referências}

CHUMLEA, W. C.; ROCHE A. F.; MUKHERJEE A. Nutritional assessment of the elderly through anthropometry. Columbus, Ohio: Ross Laboratories, 1985.

GIBSON, R. S. Anthropometric assessment of growth. In: Gibson R. S. Principles ofnutritional assessment. New York: Oxford University Press, 1990. p. 163-186.

. Nutritionnal assessment: a Laboratory Manual. New York: University Press, 1993. 196 p.

LEE, R. D.; NIEMAN, D. C. Nutritional assessment. Londres: McGraw Hill, 1993.

LOHMAN, T. G.; ROCHE, A. F.; MARTORELL, R. Anthropometric standardization reference manual. Champaign: Human Kinetics, 1992.

ORGANIZAÇÃO MUNDIAL DA SAÚDE. Physical status: the use and interpretation of anthropometry. Genebra, 1995. Report of a WHO Expert Committee. (Technical Report Series, n. 854). 


\title{
Inquérito alimentar
}

\author{
Lílian Ramos Sampaio \\ Maria da Conceição Monteiro da Silva \\ Anna Karla Carneiro Roriz \\ Venusca Rocha Leite
}

\section{Introdução}

A importância dos métodos de inquérito alimentar está associada ao binômio dieta-saúde que, por sua vez, vem sendo cada vez mais estudado pela ciência. Na Avaliação Nutricional, conhecer o consumo dietético é indispensável também para estudar a relação entre alimentação e doença, investigando a participação dos nutrientes na manutenção da saúde e, consequentemente, na prevenção de morbidades; para identificar indivíduos ou grupos em risco nutricional (vigilância alimentar); para avaliar a ingestão alimentar de forma qualitativa e/ou quantitativa; para direcionar a prescrição dietética, avaliando a eficiência da intervenção; para monitorar tendências 
de ingestão; para promover a educação alimentar e para planejar e avaliar políticas públicas de alimentação e nutrição.

Dessa forma, ao escolher o método, deve-se entender a finalidade da investigação, conhecer o público alvo, os recursos disponíveis e o tipo de estudo a ser desenvolvido. Sua validade e reprodutibilidade dependem muito da habilidade do avaliador e da cooperação do entrevistado. É de extrema importância ressaltar que não há, entre todos os métodos, aquele que denominaríamos como perfeito, entretanto podemos definir o método mais adequado para cada situação.

Existem algumas definições básicas necessárias para entender e escolher o melhor método a ser aplicado. De acordo com a temporalidade, os métodos de inquérito alimentar podem ser classificados em:

1. Prospectivos: registram informações recentes e estão associados à dieta atual, ou seja, com a média do consumo alimentar em um curto período de tempo corrente. Os métodos utilizados dentro desta categoria são o recordatório 24 horas, o registro alimentar diário, a pesagem direta e o orçamento familiar;

2. Retrospectivos: colhem a informação do passado imediato ou em longo prazo e estão associados com a dieta habitual, ou seja, com um consumo padrão que o indivíduo mantém rotineiramente em um período de tempo prolongado. Para esta investigação, utilizam-se a frequência alimentar, a história dietética e os recordatórios periódicos de 24 horas. 


\section{Recordatório de 24 horas}

O recordatório de 24 horas consiste em definir e quantificar todos os alimentos (descrevendo também os horários e tipos de preparações) e bebidas consumidos nas últimas 24 horas, anteriores à entrevista - mais comumente, no dia anterior. Este deve ser um dia típico, a fim de tornar o relato do entrevistado mais próximo e real da sua dieta atual. As quantidades de alimentos e bebidas consumidos, geralmente, são estimadas em medidas caseiras e cabe ao aplicador estabelecer um elo de comunicação compreensível com o entrevistado, no propósito de colher as informações da maneira mais detalhada possível, sem induzir (Quadro 1).

\begin{tabular}{|ll|}
\hline Vantagens & Limitações \\
\hline Baixo custo, fácil e rápida apli- & Depende da memória do entrevistado \\
cação & Requer treinamento do investigador \\
Quando realizado em série, for- & para evitar indução \\
nece estimativa da ingestão usual & A ingestão prévia nas últimas 24 horas \\
do indivíduo & pode ter sido atípica \\
$\begin{array}{l}\text { Pode ser aplicado em diferentes } \\
\text { faixas etárias e em analfabetos }\end{array}$ & $\begin{array}{l}\text { Não reflete diferenças entre a ingestão } \\
\text { de dias da semana e fim de semana. }\end{array}$ \\
$\begin{array}{l}\text { Pode ser utilizado para estimar a } \\
\text { ingestão energética e de macro- } \\
\text { nutrientes. }\end{array}$ & $\begin{array}{l}\text { Dificuldade em estimar o tamanho } \\
\text { das porções }\end{array}$ \\
Não altera a dieta usual & $\begin{array}{l}\text { Bebidas e lanches tendem a ser omi- } \\
\text { tidos }\end{array}$ \\
Descreve hábitos culturais & \\
\hline
\end{tabular}

Quadro 1 - Vantagens e limitações do recordatório de 24 horas

Fonte: Kamimura e colaboradores (2005). 


\section{Registro Alimentar}

Neste método, o indivíduo registra detalhadamente todos os alimentos e bebidas consumidos em um determinado espaço de tempo, descrevendo tipo de preparações, ingredientes, marca do alimento, porção em medidas caseiras e horário das refeições. Preconiza-se o registro de 3 a 7 dias para que seja possível avaliar a ingestão habitual, sem induzir modificações no hábito alimentar (Quadro 2). A aplicação deve ser realizada em dias alternados, incluindo, se possível, um dia do fim de semana. Essa metodologia proporciona uma melhor estimativa da ingestão alimentar habitual do indivíduo.

Uma variação deste método é o registro alimentar por peso dos alimentos, em que o indivíduo deve fazer uso de balança, tornando a avaliação de consumo mais precisa e exata quanto às porções ingeridas. Neste método, todos os alimentos, bebidas e sobras devem ser pesados com seus respectivos pesos registrados. Suas limitações incluem o custo elevado pela aquisição da balança, bem como sua calibração, além de uma possível tendência em modificar os hábitos alimentares simples. Apesar de ser mais preciso que o registro alimentar estimado, a aplicação desta variação requer investimento, treinamento e colaboração do cliente, o que torna mais rara sua utilização na prática. 


\begin{tabular}{|ll|}
\hline Vantagens & Limitações \\
\hline Não depende da memória & Pode interferir no padrão alimentar \\
$\begin{array}{l}\text { Proporciona maior acurácia e preci- } \\
\text { são quantitativa dos alimentos }\end{array}$ & Requer tempo \\
$\begin{array}{l}\text { Identifica tipos de alimentos, } \\
\text { preparações e intervalos entre as }\end{array}$ & escrever o indivíduo saiba ler e \\
refeições & $\begin{array}{l}\text { Dificuldade para estimar as quanti- } \\
\text { dades ingeridas }\end{array}$ \\
\hline
\end{tabular}

Quadro 2 - Vantagens e limitações do registro alimentar por estimativa Fonte: Kamimura e colaboradores (2005).

\section{História Alimentar ou História Dietética}

Consiste em uma ampla entrevista que objetiva descrever a ingestão dos alimentos do ponto de vista qualitativo e quantitativo, coletando informações referentes aos hábitos alimentares atuais e passados, tratamento dietético anterior; modificações nas condições de vida e na ingestão alimentar, além de preferências, intolerâncias e aversões alimentares. Além destes aspectos, são também contemplados fatores relacionados ao estilo de vida e ao uso de medicamentos e/ou suplementos. A entrevista pode incluir o recordatório de 24 horas, o registro alimentar (se possível) e/ou o questionário de frequência alimentar. É muito utilizada em atendimentos de primeira consulta (Quadro 3). 


\begin{tabular}{|c|c|}
\hline Vantagens & Limitações \\
\hline \multirow{2}{*}{$\begin{array}{l}\text { Leva em consideração as variações } \\
\text { sazonais }\end{array}$} & Alto custo \\
\hline & Requer um nutricionista altamente \\
\hline \multirow{2}{*}{$\begin{array}{l}\text { Fornece uma completa e detalhada } \\
\text { descrição quantitativa e qualitativa } \\
\text { na ingestão alimentar }\end{array}$} & treinado \\
\hline & $\begin{array}{l}\text { Depende da memória do entrevis- } \\
\text { tado }\end{array}$ \\
\hline Elimina variações do dia-a-dia & Tempo de administração longo \\
\hline $\begin{array}{l}\text { Fornece uma boa descrição da in- } \\
\text { gestão usual }\end{array}$ & $\begin{array}{l}\text { Dificuldade de padronização a } \\
\text { informação na abordagem coletiva }\end{array}$ \\
\hline \multicolumn{2}{|l|}{ Informa o hábito alimentar } \\
\hline $\begin{array}{l}\text { Importante para estudo da relação } \\
\text { entre o alimento e doença/proble- } \\
\text { mas nutricionais na clínica }\end{array}$ & \\
\hline
\end{tabular}

Quadro 3 - Vantagens e limitações da história alimentar

Fonte: Kamimura e colaboradores (2005).

\section{Questionário de Frequência Alimentar}

Este método estima a ingestão habitual de alimentos ou nutrientes específicos, com base em uma lista contendo diferentes alimentos e suas respectivas frequências de consumo por dia, semana, mês ou ano. Assim, o padrão alimentar pode ser avaliado qualitativamente e semi-quantitativamente, uma vez que, neste último, há a padronização prévia do tamanho da porção de cada alimento/preparação, de acordo com o hábito do grupo ou população que está sendo investigado (Quadro 4). Através da elaboração prévia de um questionário direcionado (lista de alimentos e/ou preparações), é possível avaliar o consumo e as necessidades alimentares específicas de diferentes populações. 


\begin{tabular}{|c|c|}
\hline Vantagens & Limitações \\
\hline $\begin{array}{l}\text { Baixo custo, simples administra- } \\
\text { ção, não requerendo tanta especia- } \\
\text { lização do entrevistador }\end{array}$ & $\begin{array}{l}\text { Impossibilidade em saber as cir- } \\
\text { cunstâncias em que o alimento foi } \\
\text { consumido }\end{array}$ \\
\hline Não altera o padrão de consumo & Quantificação pouco exata \\
\hline Estima a ingestão habitual & Pode haver subestimação por não \\
\hline $\begin{array}{l}\text { Pode descrever padrões de inges- } \\
\text { tão alimentar }\end{array}$ & $\begin{array}{l}\text { contemplar todos os alimentos con- } \\
\text { sumidos pelo indivíduo }\end{array}$ \\
\hline $\begin{array}{l}\text { Utilidade nas pesquisas epidemio- } \\
\text { lógicas }\end{array}$ & $\begin{array}{l}\text { Dificuldade da análise sem uso de } \\
\text { computadores e programas especiais }\end{array}$ \\
\hline $\begin{array}{l}\text { Pode ser utilizado para associar } \\
\text { nutrientes específicos às patologias } \\
\text { e necessidades fisiológicas. }\end{array}$ & $\begin{array}{l}\text { Necessidade em elaborar questioná- } \\
\text { rios direcionados. Listas pequenas } \\
\text { ( }<50 \text { itens) podem subestimar a } \\
\text { ingestão e as grandes ( }>150 \text { itens) }\end{array}$ \\
\hline Pode ser autoaplicável & podem gerar fadiga. \\
\hline Gera resultados padronizados & $\begin{array}{l}\text { Depende da memória do entrevista- } \\
\text { do e, caso seja auto-aplicado, depen- } \\
\text { derá do grau de escolaridade. }\end{array}$ \\
\hline
\end{tabular}

Quadro 4 - Vantagens e limitações da frequência alimentar Fonte: Kamimura e colaboradores (2005).

\section{Fontes de Erro na Avaliação do Consumo Alimentar}

As etapas de avaliação do consumo alimentar envolvem a coleta de dados sobre a dieta, a transformação das medidas caseiras em gramas, o cálculo do teor dos nutrientes nos alimentos e a análise da ingestão.

As fontes de erro mais frequentes neste processo de avaliação estão relacionadas ao entrevistador, ao entrevistado e ao instrumento de coleta, e interferem na precisão da avaliação do consumo dietético, o que compromete a qualidade do resultado. 
Entre as fontes mais comuns, destacam-se aquelas referentes à confiabilidade da informação (dependente da cooperação do entrevistado), falta de habilidade do entrevistador (perguntas facilitadas que terminam por induzir o entrevistado), erros inerentes à própria técnica ou da tabela de composição dos alimentos e padrões de referência. Outros como o processamento e a cocção dos alimentos podem favorecer a perda de micronutrientes, interferindo na sua biodisponibilidade, ocasionando um viés no resultado da avaliação.

Para minimizar esses erros e melhorar a acurácia das estimativas do consumo alimentar, é necessário avaliar qual método se aplica a uma determinada situação, visto que não há um método ideal ou que seja padrão-ouro, pois todos apresentam alguma(s) fonte(s) de erro(s). Sendo assim, deve-se investir no aperfeiçoamento dos métodos já existentes, através da elaboração de questionários padronizados e de lista de alimentos, bem como na utilização de técnicas estatísticas sofisticadas de análise.

O preenchimento do instrumento de coleta deve ser realizado cuidadosamente, atentando para o tamanho das porções e para o uso de utensílios. Além disso, torna-se indispensável o treinamento de entrevistadores para garantir habilidade em coletar os dados com mais precisão.

\section{Considerações Finais}

Em que pese as tentativas de aperfeiçoamento dos métodos de coleta de consumo alimentar, no sentido da obtenção de dados com melhor precisão e acurácia, os métodos citados acima (recordatório de 24 horas e frequência alimentar) são os mais utilizados na prática clinica e epidemiológica, pelas vantagens já referidas. 
Os cuidados com treinamento, padronização e validação são importantes para a qualidade das informações necessárias à determinação do padrão alimentar de indivíduos e grupos populacionais, assim como da explicação do diagnóstico nutricional e identificação de grupos de risco. Salienta-se, também, a importância do conhecimento do perfil alimentar na tomada de decisão para definição de políticas públicas. No Brasil, vários estudos têm sido realizados para conhecer o padrão alimentar do povo brasileiro. Na década de 70, mais precisamente de 1974 a 1975, foi realizada a primeira pesquisa nacional sobre consumo familiar pelo IBGE e o Instituto Nacional de Alimentação e Nutrição (INAN), intitulado Estudo Nacional de Despesas familiares (ENDEF). Neste estudo, foi utilizado o método de peso e medidas ou pesada direta durante 7 dias, considerado, na época, pela FAO, como o método de maior confiabilidade e exatidão. A partir de então, pelo alto custo e complexidade logística do método de pesada direta em estudos populacionais, tem-se estudado a mudança no perfil alimentar da população brasileira por meio do método do orçamento familiar.

Deste modo, a pesquisa de orçamento familiar (POF's), realizada pela primeira vez em 1961/1962, nas regiões Sul, Sudeste e Nordeste, pela Fundação Getulio Vargas (FGV), é retomada em 1987/1988, sendo realizada desta vez pelo IBGE nas áreas metropolitanas de Porto Alegre, Curitiba, São Paulo, Rio de Janeiro, Belo Horizonte, Salvador, Recife, Fortaleza, Belém, Goiânia e Brasília, acontecendo, assim, em 1996/1997 (IBGE). Já em 2002/2003, a POF também foi realizada pelo IBGE, nas áreas rurais e urbanas de todo o território nacional. 


\section{Referências}

FISBERG, R. M. et al. Inquéritos alimentares: métodos e bases científicos. São Paulo: Manole, 2005.

HOLANDA, L. B.; BARROS FILHO, A. A. Métodos aplicados em inquéritos alimentares. Revista Paulista de Pediatria, São Paulo, v. 24, n. 1, mar. 2006.

KAMIMURA, M. A. et al. Avaliação nutricional. In: CUPPARI, L.; SCHOR, N. Guias de Medicina ambulatorial e hospitalar: nutrição clínica no adulto 2. ed. Barueri: Manole, 2005. p. 89-127.

MAHAN, L K.; ESCOTT- STUMP, S. Krause: alimentos, nutrição e dietoterapia. 11. ed. São Paulo: Roca, 2005. 


\title{
Bioimpedância elétrica
}

\author{
Lílian Ramos Sampaio \\ Michaela Eickemberg \\ Pricilla de Almeida Moreira \\ Carolina Cunha de Oliveira
}

\section{Introdução}

A estimativa da composição corporal constitui uma importante etapa na identificação de possíveis distúrbios nutricionais e nas intervenções dietética e dietoterápica. Encontram-se disponíveis na literatura diferentes métodos para a determinação da composição corporal, desenvolvidos e validados em várias populações e com inúmeras finalidades.

Objeto de crescente número de estudos, a Bioeletrictal Impedance Analysis - Bioimpedância Elétrica (BIA) tem sido indicada como um método preciso e confiável para determinar a composição corporal, sobretudo pela boa reprodutibilidade e possibilidade de se trabalhar com equipamento portátil, de fácil manuseio. 
A BIA tem sido validada para estimar a composição corporal e o estado nutricional em indivíduos saudáveis e em diversas situações clínicas, como desnutrição, traumas, câncer pré e pós-operatório, doenças hepáticas e insuficiência renal em crianças, idosos e atletas.

\section{Princípios da BIA}

A análise da BIA baseia-se na medida da resistência (R) total do corpo à passagem de uma corrente elétrica de pequena intensidade (imperceptível ao corpo humano), de baixa amplitude $(0,8$ $\mathrm{mA})$ e alta frequência $(50 \mathrm{KHz})$. A BIA fundamenta-se no princípio de que os tecidos corporais oferecem diferentes oposições à passagem da corrente elétrica, que flui através do corpo pela movimentação dos íons.

Os tecidos magros são altamente condutores de corrente elétrica devido à grande quantidade de água e eletrólitos, ou seja, apresentam baixa resistência à passagem da corrente elétrica. Por outro lado, a gordura, o osso, a pele e os pulmões constituem um meio de baixa condutividade, apresentando, portanto, elevada resistência. Assim, quanto maior a quantidade de água contida em um órgão, mais facilmente a corrente irá passar e menor será a impedância (resistência).

A oposição ao fluxo total da corrente, também chamada impedância $(Z)$, medida através do analisador de BIA, gera dois componentes: a resistência $(\mathrm{R})$ e a reactância $(\mathrm{Xc})$. O vetor $\mathrm{R}$ é a medida de oposição ao fluxo da corrente elétrica através dos espaços intra e extracelulares do corpo, estando esta diretamente associada ao nível de hidratação destes meios. O vetor Xc reflete a oposição ao fluxo de corrente causada pela capacitância produzida 
pela membrana celular. Após identificar os níveis de R e Xc, do organismo à corrente elétrica, o analisador avalia a quantidade de água corporal total e, assumindo que o corpo mantém uma hidratação constante, prediz a quantidade de massa livre de gordura para, em seguida, calcular a gordura corporal.

A Xc, ou resistência capacitiva, é a oposição ao fluxo da corrente causado pela capacitância (propriedade de armazenar energia), assemelhando-se a um capacitor que é formado por duas ou mais membranas condutoras separadas por um material isolante ou não condutivo, capaz de armazenar energia elétrica. Do mesmo modo, a membrana celular do ser humano é constituída por duas camadas de material protéico (bom condutor) e uma camada de lipídio (isolante), podendo tanto armazenar energia por um período pequeno de tempo, "atrasando" a corrente, quanto atuar como resistor - isso dependerá da frequência da corrente elétrica a ser aplicada. Este "atraso" no fluxo da corrente elétrica, causado pela capacitância, gera uma queda na tensão da corrente ou uma mudança de fase, que é definida como ângulo de fase (AF), ou ainda como arco tangente da relação Xc e R.

A relação geométrica entre $Z, R, X c$ e AF depende da frequência da corrente elétrica administrada e é ilustrada na Figura 1. Em frequências menores $\left(f_{1}\right)(\sim 1 \mathrm{kHz})$, a impedância das células e de suas membranas é muito alta para que a corrente consiga penetrar no conteúdo celular; logo, nenhuma corrente elétrica passa pelas membranas celulares e estas funcionam como resistores com apenas o fluido extracelular sendo possível de ser medido. O componente capacitivo do sistema é um circuito aberto, sendo a $\mathrm{Xc}$ igual a zero e a $\mathrm{Z}$ puramente resistiva $\left(\mathrm{R}_{\mathrm{o}}\right)$.

Conforme a frequência aumenta, a Xc avança na proporção da R, constituindo o AF, e, neste ponto máximo, o semicírculo atinge a frequência característica (fc) específica para o sistema. A fc é o 
valor máximo do semicírculo imaginário da bioimpedância e, ao alcançá-la, a Xc começa a diminuir na proporção da R, enquanto ocorre aumento na frequência da corrente elétrica.

Em frequências maiores (fh) $(50$ e $100 \mathrm{kHz})$, a corrente elétrica passa através das membranas celulares, permitindo as medidas de impedância dentro e fora das células, o que determina o balanço hídrico intra e extracelular e causa redução na Xc, aumento na $\mathrm{R}$ e diminuição do AF. Em altas frequências, o componente capacitivo do sistema é um curto circuito, sendo a $\mathrm{Z}$ nova e puramente resistiva $\left(\mathrm{R}_{\mathrm{i}}\right)$.

Desta forma é possível determinar a relação entre $\mathrm{Z}$ e os compartimentos corporais, em que a magnitude da $Z$ é igual ao vetor função de $\mathrm{R}$ e $\mathrm{Xc}$, ou seja, $\mathrm{Z}=\mathrm{R}^{2}+\mathrm{Xc}^{2}$, que é dependente da frequência.

Assim, através dos valores obtidos para estas variáveis (Z, R e Xc), em diferentes frequências, o analisador calcula a quantidade de água corporal total e sua distribuição intra e extracelular. Ao assumir uma hidratação constante, é determinada, primeiramente, a massa corporal magra e, em seguida, a composição corporal.

O gráfico de Cole (figura 1) permite visualizar estas descrições e fundamenta-se na aproximação dos valores obtidos por uma curva e no prolongamento desta até o eixo $\mathrm{R}$, formando um semicírculo. Este prolongamento permite extrapolar valores de Z obtidos para cada frequência (entre $5 \mathrm{KHz}$ e $1000 \mathrm{KHz}$ ), relacionando Z, R, Xc, AF e frequência. É importante salientar que esta é uma abordagem teórica, uma vez que frequências muito baixas ou muito altas não devem ser introduzidas ao corpo devido à ocorrência de múltiplas dispersões, ou ainda pelo possível estímulo elétrico de alguns tecidos condutores, como o tecido cardíaco. 


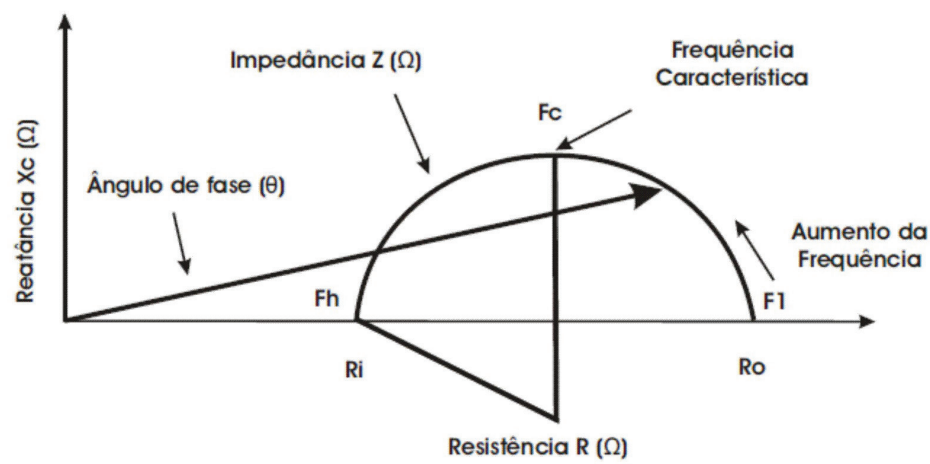

Figura 1 - Demonstração da derivação gráfica do ângulo de fase, sua relação com a resistência, reactância, impedância e frequência da corrente aplicada através do Gráfico de Cole

Fonte: Adaptado de Cole (1940).

\section{Método da BIA}

Existe uma variedade de aparelhos de BIA disponíveis no mercado que avaliam a composição corporal de diferentes formas: por região, quando a corrente atravessa apenas a porção superior ou inferior do corpo (BIA mão-mão ou pé-pé); total, quando a corrente atravessa todo o corpo (BIA mão-pé), e segmentar, onde os segmentos corporais ou membros separadamente podem ser avaliados. Quanto ao tipo de frequência, atualmente é possível encontrar aparelhos de frequência única (50 KHz) e multifrequenciais (de 5 a $1000 \mathrm{KHz}$ ).

A transmissão da corrente elétrica pelo corpo se dá, geralmente, por quatro sensores metálicos (modelo tetrapolar) que, em contato com as mãos e/ou pés, registram a impedância dos segmentos 
corporais entre membros superiores e tronco, ou somente entre membros inferiores, ou ainda entre membros superiores e inferiores. Todavia, o aparelho que avalia os segmentos superiores e inferiores é o modelo mais utilizado da BIA, pois consiste na utilização de quatro eletrodos fixados à mão, próximo à articulação metacarpo-falangea da superfície dorsal; ao pulso, entre as proeminências distais do rádio e da ulna; ao pé, no arco transverso da superfície superior e ao tornozelo, entre os maoléolos medial e lateral (Figura 2).

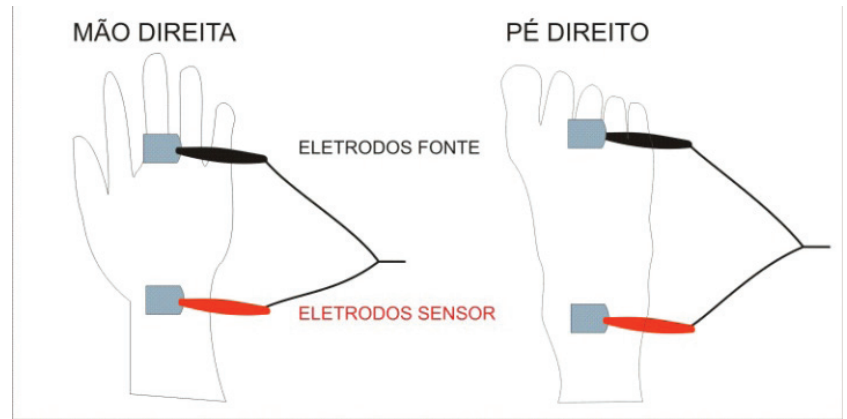

Figura 2 - Demonstração do local de colocação dos eletrodos Fonte: Adaptado de Britto e Mesquita (2008).

Em seguida, uma corrente de excitação é aplicada aos eletrodos-fonte (distais) na mão e no pé, e a queda de tensão, provocada pela impedância, é detectada pelos eletrodos-sensor (proximal), localizados no pulso e no tornozelo.

Nos aparelhos de BIA, modelo mão-mão ou pé-pé, a transmissão da corrente elétrica se dá por sensores metálicos que, em contato com as mãos ou pés, registram a impedância dos segmentos corporais entre membros superiores e tronco, ou somente entre membros inferiores (Figura 3).

O modelo de BIA tradicional (mão-pé) parece apresentar melhor acurácia do que os aparelhos que possuem apenas um segmento 
corporal, como o BIA mão-mão ou pé-pé, sendo este último geralmente realizado através de plataforma de balanças. Nestes, os eletrodos estão em contato apenas com as regiões plantares, passando a corrente elétrica apenas pelas pernas e região pélvica. Isto possivelmente resulta em uma avaliação deficitária da composição corporal, devido ao fato desta técnica desconsiderar o tronco e os membros superiores, podendo superestimar a proporção de água se o indivíduo apresentar edema, por exemplo, ao nível dos membros inferiores, ou simplesmente se a bexiga estiver cheia. Entretanto, até o momento, as informações não são conclusivas.
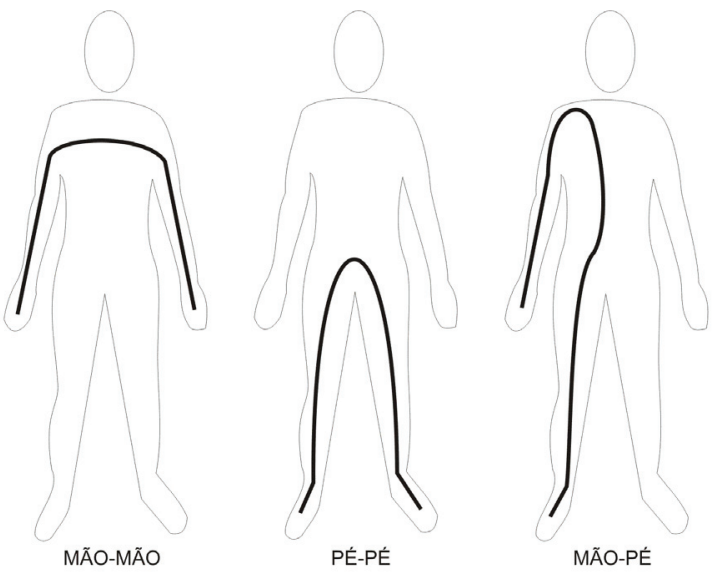

Figura 3 - Demonstração da BIA mão-mão (à esquerda), pé-pé (ao centro) e mão-pé (à direita)

Fonte: Jambassi Filho e colaboradores (2010).

Mais recentemente, a BIA segmentar foi desenvolvida. Ela aborda aspectos da análise da composição corporal que podem eliminar certas inconsistências existentes na avaliação da massa corporal total, analisando o corpo por segmento; ou seja: esta técnica determina, isoladamente, a massa dos membros e do tronco (Figura 4). 
Estudiosos afirmam que as alterações na massa magra do tronco, separadamente, provavelmente não são descritas de forma confiável através das medidas de impedância do corpo inteiro, e ainda que mudanças na impedância do corpo inteiro podem estar relacionadas às alterações tanto na massa magra dos membros, como do tronco, e que, por isso, é dada a importância da avaliação isolada.

A BIA segmentar tem sido utilizada para determinar deslocamentos e distribuição de fluidos em algumas doenças, como ascite e insuficiência renal, e em cirurgia. Esta técnica pode também ser útil em fornecer informações sobre o acúmulo de líquidos na região pulmonar ou abdominal. Entretanto, ressalta-se que ainda não existem estudos conclusivos sobre a aplicação do modelo segmentar da BIA.

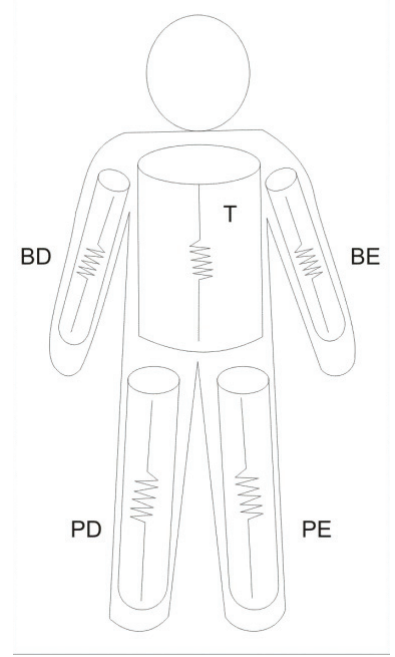

Figura 4 - Demonstração da BIA segmentar (BD - braço direito; BE braço esquerdo, T- tronco; RD- perna direita; PE - perna esquerda Fonte: KYLE e colaboradores (2004). 


\section{Equações de Predição}

Encontram-se disponíveis, na literatura, diversas equações de predição que, a partir dos valores de R e Xc, obtidos pela BIA e combinados com informações de peso corporal, altura, idade, sexo e atividade física, estimam a composição corporal e, assim, quantificam a massa de gordura, massa magra e água corporal total.

Estudos de desenvolvimento e validação de equações de BIA vêm sendo amplamente realizados, entretanto, as equações de predição variam conforme o aparelho e apresentam validade apenas para a população de origem, o que constitui um fator limitante para sua utilização em outros grupos populacionais. Neste sentido, deve-se analisar cuidadosamente a escolha de uma equação de BIA que seja específica para determinado grupo de indivíduos.

\section{Aplicação da BIA}

A BIA é um método de avaliação nutricional que estima os componentes corporais e a distribuição dos fluidos nos espaços intra e extracelulares. É um método que permite detectar precocemente a retenção de fluidos corporais, podendo auxiliar na terapêutica medicamentosa, inibindo a deterioração funcional e a piora da qualidade de vida.

O emprego da BIA na avaliação da composição corporal tem se tornado comum em diversas situações clínicas, mas existem algumas controvérsias sobre seu uso, principalmente em condições em que há uma alteração do estado de hidratação do indivíduo, a exemplo dos casos de hiperhidratação, que podem superestimar o valor da massa magra corporal. 
Abaixo segue uma tabela reunindo pesquisas que utilizaram a BIA como método de avaliação da composição corporal, em comparação com outros métodos tradicionalmente utilizados.

Tabela 1 - Estudos de comparação da BIA com outros métodos de avaliação da composição corporal

\begin{tabular}{|c|c|c|}
\hline Autores & Amostra & Resultados encontrados \\
\hline FRANZ & $\begin{array}{l}125 \text { pacientes de } 44 \text { a } 80 \\
\text { anos de idade. }\end{array}$ & $\begin{array}{l}\text { Correlação positiva para valores } \\
\text { de BIA, IMC e PCT. }\end{array}$ \\
\hline HEITMANN & $\begin{array}{l}139 \text { dinamarqueses } \\
\text { com idade entre } 35 \mathrm{e} \\
65 \text { anos. }\end{array}$ & $\begin{array}{l}\text { Estimativas confiáveis do IMC, } \\
\Sigma \text { quatro pregas cutâneas e BIA } \\
\text { para gordura corporal total. }\end{array}$ \\
\hline $\begin{array}{l}\text { FERNANDEZ e } \\
\text { outros }\end{array}$ & $\begin{array}{l}811 \text { jovens de } 11 \text { a } 17 \\
\text { anos de idade. }\end{array}$ & $\begin{array}{l}\text { BIA apresentou bom desempe- } \\
\text { nho na identificação do excesso } \\
\text { de gordura visceral e sobrepe- } \\
\text { so/obesidade, em comparação } \\
\text { com PCT e CC. }\end{array}$ \\
\hline $\begin{array}{l}\text { BARRETO-SILVA e } \\
\text { outros }\end{array}$ & $\begin{array}{l}105 \text { pacientes com } \\
\text { doença renal crônica } \\
\text { estágios III e IV. }\end{array}$ & $\begin{array}{l}\text { Para não obesos, o IMC, as } \\
\text { dobras cutâneas e a BIA podem } \\
\text { ser aplicados com boa equi- } \\
\text { valência para estimar gordura } \\
\text { corporal. }\end{array}$ \\
\hline $\begin{array}{l}\text { RODRÍGUEZ e } \\
\text { outros }\end{array}$ & $\begin{array}{l}230 \text { pré-escolares ar- } \\
\text { gentinas saudáveis de } 4 \\
\text { a } 6 \text { anos. }\end{array}$ & $\begin{array}{l}\text { Alta correlação entre IMC, } \\
\text { CC, BIA e DEXA para estimar } \\
\text { composição corporal. }\end{array}$ \\
\hline $\begin{array}{l}\text { LIMA; RECH; } \\
\text { PETROSKI }\end{array}$ & $\begin{array}{l}60 \text { homens idosos, de } \\
60 \text { a } 81 \text { anos de idade. }\end{array}$ & $\begin{array}{l}\text { Forte correlação entre BIA, } \\
\text { DEXA e IMC }(\mathrm{r}=0,90) \text { para } \\
\text { estimar a massa muscular } \\
\text { esquelética. }\end{array}$ \\
\hline $\begin{array}{l}\text { COCETTI; } \\
\text { CASTILHO; } \\
\text { BARROS FILHO }\end{array}$ & $\begin{array}{l}1286 \text { escolares de } 7 \text { a } \\
9 \text { anos. }\end{array}$ & $\begin{array}{l}\text { Alta e significante correlação } \\
\text { entre dobras cutâneas e BIA } \\
\text { para o percentual de gordura } \\
\text { corporal, para massa gorda e } \\
\text { massa magra, mostrando boa } \\
\text { concordância. }\end{array}$ \\
\hline
\end{tabular}

^BIA- bioimpedância elétrica; IMC- índice de massa corporal; PCT- prega cutânea triciptal; $\Sigma$ - somatório; ${ }^{\star} \mathrm{CC}$ - circunferência da cintura; DEXA- absorção do raio X de dupla energia.

Fonte: Elaborado pelas autoras. 


\section{Procedimentos para Realização da BIA}

Como os resultados obtidos através da BIA podem ser afetados por diversas condições, o controle prévio de alguns fatores deve ser realizado para a confiabilidade do método na prática clínica, sendo estes apresentados no quadro a seguir:

\begin{tabular}{|l|}
\hline Fatores a serem controlados para aplicação da bia \\
\hline Calibração regular do aparelho. \\
\hline Mantimento dos eletrodos em sacos fechados, protegidos do calor. \\
\hline $\begin{array}{l}\text { No momento da avaliação, o avaliado deve estar na posição supina, em } \\
\text { uma superfície não condutora, com braços separados do tronco em um } \\
\text { ângulo de } 30^{\circ} \text { e pernas a } 45^{\circ} \text {. }\end{array}$ \\
\hline O avaliado deve estar em jejum de 4 horas. \\
\hline $\begin{array}{l}\text { A ingestão alcoólica e a prática de atividade física ou sauna não devem } \\
\text { ocorrer por, no mínimo, } 8 \text { horas antes do exame. }\end{array}$ \\
\hline A bexiga deve ser esvaziada antes da realização do exame. \\
\hline A temperatura do ambiente deve estar em torno de $22^{\circ}$ C. \\
\hline $\begin{array}{l}\text { Antes de colocar os eletrodos, a pele deve ser limpa com álcool e não deve } \\
\text { conter lesões. }\end{array}$ \\
\hline A distância entre os eletrodos deve ser, no mínimo, de 5 cm. \\
\hline Observar a fase do ciclo menstrual por conta da possível retenção hídrica. \\
\hline $\begin{array}{l}\text { Utilizar material isolante entre as pernas de indivíduos obesos (ex. toa- } \\
\text { lhas). }\end{array}$ \\
\hline A técnica é contra-indicada para pacientes que utilizam marca-passo. \\
\hline
\end{tabular}

Quadro 1 - Recomendações para aplicações práticas da BIA

Fonte: Kyle e colaboradores (2004). 


\section{BIA e o Ângulo de Fase}

O Ângulo de Fase (AF) é um parâmetro derivado da relação entre as medidas de $\mathrm{R}$ e Xc, obtidas a partir da BIA, sendo calculado pela equação: Xc/R x 180\% $\pi$. Este ângulo é formado quando parte da corrente elétrica é armazenada pelas membranas celulares (capacitância dos tecidos), criando uma mudança de fase, medida geometricamente como transformação angular da capacitância .

Cada vez mais utilizado na prática clínica, a medida do ângulo de fase, por ser uma ferramenta de diagnóstico nutricional que se relaciona com o equilíbrio celular, tem sido utilizado como medida de gravidade de doença, como instrumento de avaliação funcional e como indicador geral de saúde. Estudos recentes têm validado este ângulo como indicador prognóstico em pacientes críticos.

O ângulo de fase está associado também com a qualidade, tamanho e integridade celulares, portanto, indica alterações na composição corporal, na função da membrana celular ou no estado de saúde. Em um indivíduo saudável, o AF pode apresentar valores de, aproximadamente, 4 a 15 graus. Valores de AF menores podem ser associados à existência ou agravamento de doença, morte celular ou a alguma alteração na permeabilidade seletiva da membrana. Valores mais altos podem associar-se à maior quantidade de membranas celulares intactas, ou seja, maior massa celular corpórea e adequado estado de saúde.

Assim, modificações na massa celular corporal ou defeitos funcionais das membranas celulares podem resultar em mudanças no $\mathrm{AF}$, sendo esperado que ocorram mudanças em seus valores de acordo com o sexo e idade, pois, com o envelhecimento, a capacitância dos tecidos associada à variabilidade do tamanho das 
células, à permeabilidade da membrana celular e à composição intracelular tornam-se diferentes, assim como a distribuição dos fluidos corporais entre os tecidos.

Pesquisas realizadas para investigar o papel do AF como indicador prognóstico em pacientes hospitalizados, portadores de doenças graves, como alguns tipos de câncer, AIDS, insuficiência renal crônica, doença pulmonar obstrutiva crônica, cirrose hepática ou bacteremia, e em pacientes criticamente doentes, evidenciaram associação positiva com o tempo de sobrevida destes pacientes. Os autores sugerem que o AF poderia ser uma importante ferramenta para avaliar sinais clínicos e monitorar a progressão da doença, sendo até mesmo superior a outros indicadores, séricos ou antropométricos.

O AF também tem sido utilizado como um indicador do estado nutricional. Cogita-se que, clinicamente, ele seja um marcador de nutrição relevante que possa caracterizar o acréscimo de massa extracelular corporal e o decréscimo de massa celular corporal, provavelmente porque a nutrição está interligada às alterações na integridade da membrana celular e no equilíbrio dos fluidos corporais.

O AF é um parâmetro que independe de equações de regressão e pode ser realizado mesmo em situações nas quais a aplicação da BIA não é recomendada para estimar a composição corporal, eliminando uma enorme fonte de erro casual. Este parâmetro pode, inclusive, ser utilizado mesmo em pacientes nos quais o peso e a altura não possam ser mensurados.

Contudo, sua escassa utilização na prática clínica deve-se ao fato da inexistência de valores de referência para a população. Estes valores são necessários para avaliar os desvios individuais em 
relação à média populacional e para analisar a influência do AF em resultados de estudos epidemiológicos.

A seguir, na tabela 2, estão descritos alguns trabalhos que analisaram a utilização do AF como indicador prognóstico e de estado nutricional de indivíduos em diferentes condições clínicas.

Tabela 2 - Estudos que avaliaram o ângulo de fase como indicador prognóstico e de estado nutricional

\begin{tabular}{|c|c|c|}
\hline Autores & Amostra & Resultados encontrados \\
\hline GUPTA e outros & $\begin{array}{l}73 \text { pacientes com CA } \\
\text { colorretal estágios III e IV. }\end{array}$ & $\begin{array}{l}\text { Pacientes bem nutridos apre- } \\
\text { sentaram média de AF signi- } \\
\text { ficativamente maior quando } \\
\text { comparados aos desnutridos. Os } \\
\text { autores sugerem que o AF é um } \\
\text { potencial indicador nutricional } \\
\text { nesta população. }\end{array}$ \\
\hline $\begin{array}{l}\text { BARBOSA-SILVA } \\
\text { e outros }\end{array}$ & $\begin{array}{l}1967 \text { americanos saudá- } \\
\text { veis, de } 18 \text { a } 94 \text { anos de } \\
\text { idade. }\end{array}$ & $\begin{array}{l}\text { Os autores mostram que o } \\
\text { AF muda conforme o gênero, } \\
\text { idade, IMC e \%GC. O AF } \\
\text { demonstrou correlação positiva } \\
\text { com o IMC. }\end{array}$ \\
\hline $\begin{array}{l}\text { MAGGIORI e } \\
\text { outros }\end{array}$ & $\begin{array}{l}131 \text { pacientes em hemo- } \\
\text { diálise. }\end{array}$ & $\begin{array}{l}\text { AF apresentou correlação sig- } \\
\text { nificativa com todos os índices } \\
\text { nutricionais, exceto IMC. } \\
\text { Houve uma associação significa- } \\
\text { tiva para AF e albumina sérica, } \\
\text { índice de catabolismo proteico, } \\
\text { ASG, massa celular corporal } \\
\text { total e idade. }\end{array}$ \\
\hline $\begin{array}{l}\text { NAGANO e } \\
\text { outros }\end{array}$ & $\begin{array}{l}81 \text { crianças hospitaliza- } \\
\text { das, de } 1 \text { mês a } 6 \text { anos de } \\
\text { idade. }\end{array}$ & $\begin{array}{l}\text { O AF foi correlacionado ao peso } \\
\text { corporal e à CMB nos pacientes } \\
\text { bem nutridos, sendo menos nos } \\
\text { desnutridos. }\end{array}$ \\
\hline
\end{tabular}




\begin{tabular}{|c|c|c|}
\hline Autores & Amostra & Resultados encontrados \\
\hline $\begin{array}{l}\text { BARBOSA-SILVA } \\
\text { e outros }\end{array}$ & $\begin{array}{l}279 \text { pacientes de cirurgia } \\
\text { gastrointestinal eletiva, de } \\
18 \text { a } 80 \text { anos de idade. }\end{array}$ & $\begin{array}{l}\text { Concordância moderada entre a } \\
\text { ASG e AF. Os pacientes desnu- } \\
\text { tridos graves, de acordo com a } \\
\text { ASG, tiveram menores valores } \\
\text { de AF. }\end{array}$ \\
\hline GUPTA e outros & $\begin{array}{l}52 \text { pacientes com CA } \\
\text { colorretal estágio IV. }\end{array}$ & $\begin{array}{l}\text { O AF é um indicador de prog- } \\
\text { nóstico em pacientes com CA } \\
\text { colorretal avançado. }\end{array}$ \\
\hline $\begin{array}{l}\text { SCHWENK e } \\
\text { outros }\end{array}$ & $\begin{array}{l}598 \text { pacientes } \mathrm{HIV}^{+} \mathrm{em} \\
\text { tratamento antirretroviral } \\
\text { altamente ativo (HAART) }\end{array}$ & $\begin{array}{l}\text { Baixo AF é um marcador } \\
\text { prognóstico adverso indepen- } \\
\text { dente da evolução clínica e } \\
\text { sobrevivência dos pacientes em } \\
\text { HAART. }\end{array}$ \\
\hline GUPTA e outros & $\begin{array}{l}259 \text { pacientes com CA de } \\
\text { mama. }\end{array}$ & $\begin{array}{l}\text { O AF é um indicador prognós- } \\
\text { tico independente em pacientes } \\
\text { com CA de mama. }\end{array}$ \\
\hline $\begin{array}{l}\text { SELBERG e } \\
\text { outros }\end{array}$ & $\begin{array}{l}\text { Pacientes com cirrose } \\
\text { hospitalizados e pacientes } \\
\text { com controles saudáveis. }\end{array}$ & $\begin{array}{l}\text { AF baixos associaram-se com } \\
\text { reduzido tempo de sobrevivên- } \\
\text { cia nos pacientes com cirrose, } \\
\text { sendo os maiores valores de } \\
\text { AF observados nos controles } \\
\text { saudáveis. }\end{array}$ \\
\hline
\end{tabular}

^CA- câncer; AF- ângulo de fase; BIA- bioimpedância elétrica; ASG- avaliação subjetiva global; IMC- índice de massa corporal; \%GC- percentual de gordura corporal; HIVvírus da imunodeficiência humana; HAART- tratamento anti-retroviral altamente ativo; R- resistência; Xc- reactância; CMB- competência motora baixa.

Fonte: Elaborado pelas autoras. 


\section{Vantagens e Limitações da BIA}

No quadro a seguir estão descritas, resumidamente, as principais vantagens e limitações da BIA.

\begin{tabular}{|l|l|}
\hline Vantagens & Limitações \\
\hline Confortável e não-invasiva. & $\begin{array}{l}\text { Nem sempre os equipamentos dispõem } \\
\text { das equações adequadas para avaliar } \\
\text { determinados grupos de indivíduos, a } \\
\text { exemplo de jovens e idosos. }\end{array}$ \\
\hline $\begin{array}{l}\text { Equipamento portátil, de fácil } \\
\text { manuseio e custo relativamente } \\
\text { baixo. }\end{array}$ & $\begin{array}{l}\text { Apresenta custo mais elevado do que as } \\
\text { técnicas antropométricas, comumente } \\
\text { utilizadas. }\end{array}$ \\
\hline $\begin{array}{l}\text { Fornece resultados rapida- } \\
\text { mente. }\end{array}$ & $\begin{array}{l}\text { Influenciada pelo estado de hidratação } \\
\text { dos indivíduos avaliados, que pode } \\
\text { inviabilizar sua utilização. }\end{array}$ \\
\hline $\begin{array}{l}\text { Alta correlação com os méto- } \\
\text { dos antropométricos e técnicas } \\
\text { consideradas padrão-ouro para } \\
\text { avaliar a composição corporal. }\end{array}$ & $\begin{array}{l}\text { A confiabilidade depende do seguimen- } \\
\text { to do protocolo. }\end{array}$ \\
\hline $\begin{array}{l}\text { Não requer a presença de téc- } \\
\text { nicos altamente especializados } \\
\text { para a sua utilização. }\end{array}$ & $\begin{array}{l}\text { Depende de grande colaboração do } \\
\text { avaliado. }\end{array}$ \\
\hline
\end{tabular}

Quadro 2 - Vantagens e limitações da utilização da Bioimpedância Fonte: (HEYWARD; STOLARCZYK, 2000; COSTA, 2000). 


\section{Referências}

ACOSTA, E. J.; GÓMES-TELLO, V.; RUIZ S. S. Nutritional assessment of the severely ill patient. Nutrición Hospitalaria, Madrid, v. 20, n. 2, p. 5-8, 2005.

AZEVEDO, Z. M. A. et al. Associação entre ângulo de fase, PRISM I e gravidade da sepse. Revista brasileira de terapia intensiva. São Paulo, v. 19, n. 3 , p. 297-303, jul./set. 2007.

BARBOSA-SILVA, M. C., et al. Bioelectrical impedance analysis: population reference values for phase angle by age and sex. American Journal of Clinical Nutrition, Bethesda, MD, v. 82, n. 1, p. 49-52, jul. 2005.

. Can bioelectrical impedance analisys identify malnutrition in

preoperative nutrition assessment? Nutrition, Bethesda, MD, v. 19, n. 5, p. 422-426, maio, 2003.

BARRETO-SILVA, M. I. et al. Agreement between anthropometry and bioelectrical impedance for measuring body fat in nonobese and obese nondialyzed chronic kidney disease patients. Journal of renal nutrition, Philadelphia, v. 18, n. 4, p. 355-362, jul, 2008.

BAUMGARTNER, R. N. et al. Bioelectric impedance phase angle and body composition. American Journal of Clinical Nutrition, Houston, TX, v. 48, n. 1, p. 16-23, jul. 1998.

BRITTO, E. P.; MESQUITA, E. T. Bioimpedância elétrica aplicada à insuficiência cardíaca. Revista da SOCERJ, Rio de Janeiro, v. 21, n. 3, p. 178183, maio/jun. 2008.

COCETTI M.; CASTILHO S. D.; BARROS FILHO A. A. Dobras cutâneas e bioimpedância elétrica perna-perna na avaliação da composição corporal de crianças. Revista nutrição, Campinas, v. 22, n. 4, p. 527-536, jul./ago. 2009.

COLE, K. S. Permeability and Impermeability off cell membranes for íons. Cold Spring Harbor Symposia on Quantitative Biology, New York, v. 8, n. 1, p. 110-22, 1940.

COSTA, R. F. A Impedância Bioelétrica e Suas Aplicações Para a Educação Física e Áreas Afins. Revista de Educação Física da Cidade de São Paulo, São Paulo, v. 1, n. 1, p. 43-50, 2000.

DEMINICI, R.; ROSA, F. T. Pregas cutâneas vs impedância bioelétrica na avaliação da composição corporal de atletas: uma revisão crítica. Revista brasileira cineantropometria e desempenho humano, Santa Catarina, v. 11, n. 3, p. 334-340, 2009.

DEURENBERG, P. Assessment of body composition by bioelectrical impedance in a population aged $>60$ years. American Journal of Clinical Nutrition, Bethesda, MD, v. 51, n. 1, p. 3-6, 1990. 
DITTMAR, M. Comparison of bipolar and tetrapolar impedance techniques for assessing fat mass. American Journal of Human Biology, New York, v. 16, n. 1, p. 593-597, 2004.

FERNANDEZ, R. A. et al. Utilização da impedância bioelétrica na indicação do excesso de gordura visceral e subcutânea. Jornal de pediatria, Porto Alegre, v. 83, n. 6, p. 529-534, 2007.

FRANZ, L. B. B. Bioimpedância elétrica como método de avaliação da composição corporal de indivíduos adultos e idosos. São Paulo: Centro Universitário São Camilo, 1998. p. 87.

GUPTA, D. et al. Bioelectrical impedance phase angle as a prognostic indicator in breast cancer. BMC Cancer, London, v. 8, p. 249, ago. 2008a.

. Bioelectrical impedance phase angle in clinical practice: implications for prognosis in stage IIIB and IV non-small cell lung cancer. BMC Cancer, London, v. 9, p. 37, jan, 2009.

The relationship between bioelectrical impedance phase angle and subjective global assessment in advanced colorectal cancer. Nutrition journal, Bethesda, MD, v. 7, p. 19. jun, 2008b.

HEITMANN, B. L. Avaliação de gordura corporal estimado do índice de massa corporal, dobras cutâneas e impedância. Um estudo comparativo. European journal of clinical nutrition, London, v. 44, n. 11, p. 831-837, 1990. HEYWARD, V. H.; STOLARCZYK, L. M. Avaliação da composição corporal aplicada. São Paulo: Manole, 2000.

JAMBASSI FILHO, J. C. et al. Estimativa da composição corporal e análise de concordância entre analisadores de impedância bioelétrica bipolar e tetrapolar. Revista Brasileira de Medicina do Esporte, São Paulo, v. 16, n. 1, p. 1317, jan./fev. 2010.

KAMIMURA, M. A. et al. Métodos de avaliação da composição corporal em pacientes submetidos à hemodiálise. Revista de nutrição São Paulo, v. 17, n. 1, p. 97-105, jan./ mar. 2004.

KYLE, U. G. et al. Bioelectrical impedance analysis - part I: review of principles and methods. Clinical nutrition, ESPEN Guidelines, Philadelphia, v. 23, n. 5, 1226-1246, 2004.

LIMA, L. R. A.; RECH, C. R.; PETROSKI, E. L. Utilização da impedância bioelétrica para estimativa da massa muscular esquelética em homens idosos. Archivos latino-americanos de nutricion - ALAN, Caracas, v. 58, n. 4, p. 386-391, dez. 2008.

LINTSI, M.; KAARMA, H.; KULL, I. Comparison of hand-to-hand bioimpedance and anthropometry equations versus dual-energy X-ray absorptiometry for the assessment of body fat percentage in 17-18-year-old 
conscripts. Clinical Physiology and Functional Imaging., Oxford, v. 24, n. 2, p. 85-90, mar. 2004.

LUKASKI, H. Biological indexes considered in the derivation of the bioelectrical impedance analysis. American Journal of Clinical Nutrition, Bethesda, MD, v. 64, n. 3, p. 307-404, set. 1996.

MAGGIORE, Q. et al. Nutritional and prognostic correlates of boielectrical impedance indexes in hemodialysis patients. Kidney International, Cranford, NJ, v. 50, n. 6, p. 2103-2108, dez. 1996.

MATTAR, R. Avaliação da composição corporal por bioimpedância: uma nova perspectiva. Journal of biomolecular medical, New England, v. 4, n. 1, p. 27-29, 1998.

Mc ARDLE, W. C.; KATCH, F. I.; KATCH, V. L. Fisiologia do exercício: energia, nutrição e desempenho humano. Tradução de Giuseppe Taranto. 3. ed. Rio de Janeiro: Guanabara Koogan, 1992.

NAGANO, M.; SUITA, S.; YAMANOUCHI, T. The validity of bioelectrical impedance phase angle for nutrition assessment in children. Journal of pediatric survery, Northern Ireland, v. 35, n. 7, p. 1035-1039, jul. 2000.

NOLAN, M. F. Conductive differences in electrodes used with transcutaneous electrical nerve stimulation devices. Physical theraphy, North Fairfax Street Alexandria, v. 71, n. 10, p. 746-751, out. 1991.

NYBOER, J. Electrical impedance plethysmography. A physical and physiologic approach to peripheral vascular study. Circulation, Dallas, v. 2, p. 811-821, dez. 1950.

OTT. M. et al. Bioelectrical impedance analysis as a predictor of survival in patients with human immunodeficiency virus infection. J Acquir Immune Defic Syndr Hum Retrovirol, v. 9, n. 1, p. 20-25, maio 1995.

PIRLICH, M. et al. Bioelectrical impedance analysis is a useful bedside technique to assess malnutrition in cirrhotic patients with and without ascites. Hepatology, Geneva, Switzerland, v. 32, p. 1208-1215, dez. 2000.

REZENDE, F. Revisão crítica dos métodos disponíveis para avaliar a composição corporal em grandes estudos populacionais e clínicos. Archivos latino-americanos de nutricion - ALAN, Caracas, v. 57, n. 4, dez. 2007.

RODRIGUES, M. N.; et al. Estimativa da gordura corporal através de equipamentos de bioimpedância, dobras cutâneas e pesagem hidrostática. Revista Brasileira de Medicina e Esporte. Rio de Janeiro, v. 7, n. 4, p. 125-130, jul./ago. 2001.

RODRÍGUEZ, P. N. Composición corporal en niños preescolares: comparación entre métodos antropométricos simples, bioimpedancia y 
absorciometría de doble haz de rayos X. Archivos Argentinos de Pediatria, v. 106, n. 2, p. 102-109, mar./abr. 2008.

ROMAN, M.C.; TORRES, S. P.; BELLIDO, M. C. Bases físicas del análisis de La impedância bioelétrica. Vox Paediatr., v. 7, n. 2, p. 139-143, 1999.

SANT'ANNA, M. S. et al. Body fat assessment by bioelectrical impedance and its correlation with different anatomical sites used in the measurement of waist circumference in children. Journal of Pediatrics, Porto Alegre, v. 85, n. 1, p. 61-66, jan./fev. 2009.

SCHEUNEMANN L.; WAZLAWIK, E.; TRINDADE, E. B. S. M.

Aplicação do ângulo de fase na prática clínica nutricional. Revista Brasileira de Nutrição Clínica, Porto Alegre, v. 23, n. 4, p. 292-297, 2008.

SCHWENK, A. Phase angle from bioelectrical impedance analysis remains an independent predictive marker in HIV-infected patients in the era of highly active antiretroviral treatment. The American Journal of Clinical Nutrition, Bethesda, MD, n. 72, p. 496-501, ago. 2000.

SELBERG, O.; SELBERG, D. Norms and correlates of bioimpedance phase angle in healthy human subjects, hospitalized patients, and patients with liver cirrhosis. European Journal of Applied Physiology, New York, NY, n. 86, p. 509516, abr. 2002.

SLINDE, F.; ROSSANDER-HULTHEN, L. Bioelectrical impedance: effect of three identical meals on diurnal impedance variation and calculation of body composition. The American Journal of Clinical Nutrition, v. 74, n. 474-478, out. 2001.

THOMASSET, A. Bioeletrical properties of tissue impedance measurements. Journal of medicine Lyon, Lyon, n. 207, p. 107-118, jul. 1962. 


\section{Anexos}

Anexo A - Fórmulas utilizadas na avaliação nutricional antropométrica

\section{Estimativas de estatura e peso}

Estimativa da estatura (adulto) - (Silveira et. a.I., 1994)

Masculino: Alt. $=72.803+1.830 \mathrm{KH}$

Feminino: Alt. $=51.875+2.184 \mathrm{KH}$

Estimativa da altura (idoso) - Americanos - (Chumlea et al; 1985)

Masculino $=(2.02 \times \mathrm{KH}(\mathrm{cm})-(0.04 \times$ idade $($ anos $))+64.19$

Feminino $=(1.83 \times \mathrm{KH}(\mathrm{cm})-(0.24 \times$ idade $($ anos $))+84.88$

Estimativa do peso adultos/idosos (Chumlea et al; 1988)

Masculino $=(0.98 \times \mathrm{CP})+(1.16 \times \mathrm{KH})+(1.73 \times \mathrm{CB})+$ $0.37 \times$ PCSE) -81.69

Feminino $=(1.27 \times \mathrm{CP})+(0.87 \times \mathrm{KH})+(0.98 \times \mathrm{CB})+$ (0.4 x PCSE) -62.35 
Pacientes amputados:

- Correção do peso pós-amputação

Peso corrigido $=\underline{\text { PAAMP }(100-\% \text { AMP })}$

100

PAAMP $=$ peso antes da amputação

AMP $=$ amputação

- Correção da altura pós-amputação

Alt corrigida $=\frac{(\text { AAMP }) 2 \times(100-\% \text { AMP })}{100}$

AAMP $=$ altura antes da amputação

OBS: a altura só deverá ser corrigida quando houver comprometimento da mesma

- IMC pós- amputação (IMCPAMP) (Tzamaloukas et. al. 1994)

IMCPAMP $=\frac{\text { Peso corrigido }(\text { PPAMP })}{\text { Altura corrigida }(\text { APAMP) }}$

- Peso esperado antes da amputação (PEAAMP)

PEAAMP $=(\text { AAMP })^{2} \times$ IMC esperado

- Peso esperado pós-amputação (PEPAMP)

PEPAMP $=\underline{\text { PEAAMP X }(100-\% A M P)}$

100 


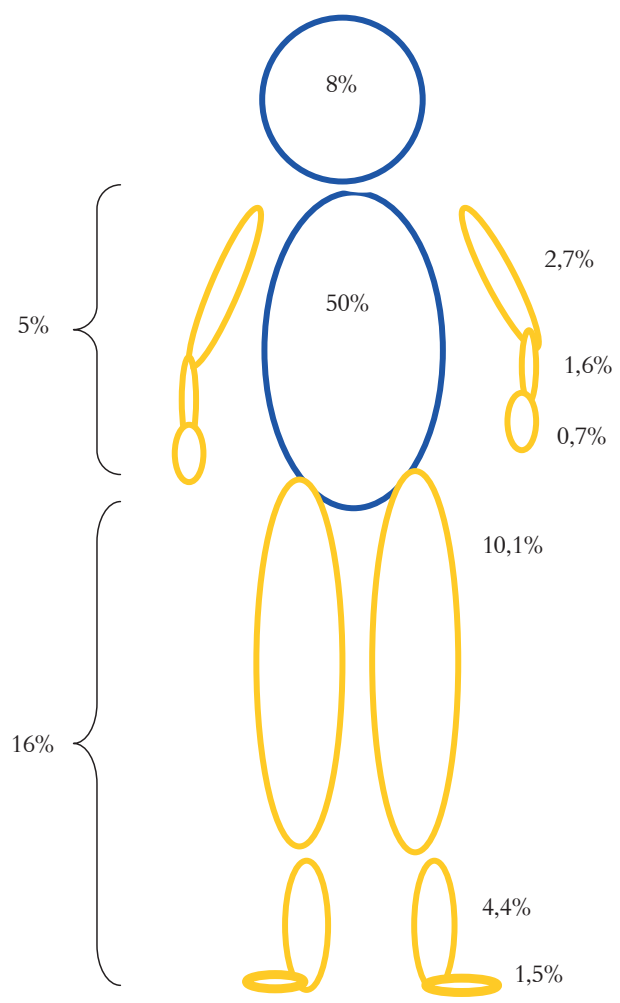

Figura 1 - Paciente amputado: avaliação nutricional Fonte: Modelo proposto por Osterkemp (1995).

Avaliação da mudança de peso

$$
\% \text { Perda de peso }=\frac{P U-P A}{P U} \times 100
$$

Índice de massa corporal (IMC)

$$
\operatorname{IMC}\left(\mathrm{Kg} / \mathrm{m}^{2}\right)=\frac{\operatorname{PESO}(\mathrm{kg})}{(\text { ALTURA m })^{2}}
$$


- Cálculo do peso ideal através do IMC médio

Peso ideal $=(\text { altura })^{2} \times$ IMC médio

IMC médio para homens $=22,5 \mathrm{~kg} / \mathrm{m}^{2}$

IMC médio para mulheres $=21,5 \mathrm{~kg} / \mathrm{m}^{2}$

IMC médio para ambos os sexos $=22,0 \mathrm{~kg} / \mathrm{m}^{2}$

\section{Composição corporal}

- Circunferência Muscular do Braço (CMB)

$\mathrm{CMB}=\mathrm{CB}-\mathrm{p} \times \mathrm{PCT}(\mathrm{cm})$

- Área Muscular do Braço (AMB) (Frisancho, 1990)

$$
\mathrm{AMB}=\frac{[\mathrm{CB}(\mathrm{cm})-\pi \times \mathrm{PCT} / 10(\mathrm{~cm})]^{2}}{4 \pi}
$$

- Área Muscular do Braço corrigida (AMBC) (HEYMSFIELD et., al., 1982):

$$
\text { Homem } \rightarrow \text { AMBc }=\frac{[\mathrm{CB}(\mathrm{cm})-\pi \times \mathrm{PCT} / 10(\mathrm{~cm})]^{2}-10}{4 \pi}
$$

$$
\text { Mulher } \rightarrow \text { AMBc }=\frac{[\mathrm{CB}(\mathrm{cm})-\pi \times \mathrm{PCT} / 10(\mathrm{~cm})]^{2}-6,5}{4 \pi}
$$

- Área de Gordura do Braço (AGB) (HIMES, ET AL. 1980)

$$
\operatorname{AGB}\left(\mathrm{cm}^{2}\right)=\frac{\mathrm{CB}(\mathrm{cm}) \times \operatorname{PCT}(\mathrm{cm})}{2}-\frac{[\pi \times \text { PCT }(\mathrm{cm})]^{2}}{4}
$$




\section{Distribuição corporal}

- Índice de Conicidade

$$
\text { Indice } \mathrm{C}=\frac{\text { Circunferência-Cintura }(\mathrm{m})}{0.109 \sqrt{\frac{\text { Peso Corporal }(\mathrm{kg})}{\text { Estatura }(\mathrm{m})}}}
$$

- Razão Cintura Quadril (RCQ)

$$
\mathrm{RCQ}=\frac{\mathrm{CC}}{\mathrm{CQ}}
$$

- Razão Cintura Estatura (RCEst)

$$
\text { RCEst }=\underset{\text { Estatura }}{\text { CC }}
$$

Anexo B - Quadros e gráficos de referência

\begin{tabular}{|l|l|l|}
\hline \multicolumn{2}{|l|}{ Classificação do peso ao nascer } & Peso ao nascer \\
\hline MBPN & Muito baixo & $<1,5$ \\
\hline BPN & Baixo & $<2,5$ \\
\hline PIN & Peso insuficiente & 2,5 a 3,0 \\
\hline PAN & Peso adequado & 3,0 a 4,0 \\
\hline EPN & Excesso & $>4,0$ \\
\hline
\end{tabular}

Quadro 1 - Classificação do peso ao nascer

Fonte: Organização Mundial da Saúde, (1995). 


\begin{tabular}{|l|l|}
\hline Idade & Ganho de peso \\
\hline $1^{\circ}$ mês & $25 \mathrm{a} 35 \mathrm{~g} /$ dia \\
\hline $2^{\circ} 3^{\circ}$ mês & $20 \mathrm{a} 30 \mathrm{~g} /$ dia \\
\hline $2^{\circ}$ trimestre & $20 \mathrm{~g} /$ dia \\
\hline $3^{\circ}$ trimestre & $15 \mathrm{~g} / \mathrm{dia}$ \\
\hline $4^{\circ}$ trimestre & $10 \mathrm{~g} / \mathrm{dia}$ \\
\hline 2 a 6 anos & $2 \mathrm{Kg} / \mathrm{ano}$ \\
\hline 6 a 9 anos & 3 a $3,5 \mathrm{Kg} / \mathrm{ano}$ \\
\hline
\end{tabular}

Quadro 2 - Acompanhamento do ganho de peso das crianças

Fonte: Lopez e Campos Junior (2007).

\begin{tabular}{|l|l|l|}
\hline Percentil & Desvio padrão & Classificação \\
\hline$<0,1$ & $<-3$ & Desnutrição grave \\
\hline$\geq 0,1 \mathrm{a}<3$ & $\geq-3 \mathrm{e}<-2$ & Desnutrição moderada \\
\hline$\geq 3 \mathrm{a}<10$ & $\geq-2 \mathrm{e}<-1$ & $\begin{array}{l}\text { Desnutrição leve/ risco de } \\
\text { desnutrição }\end{array}$ \\
\hline$\geq 10 \mathrm{a}<90$ & $\geq-1 \mathrm{e}<+1$ & Eutrofia \\
\hline$\geq 90 \mathrm{a}<97$ & $\geq 1 \mathrm{e}<2$ & Risco de obesidade \\
\hline$\geq 97$ & $\geq 2 \mathrm{e}<3$ & Obesidade \\
\hline & $\geq 3$ & Obesidade grave \\
\hline
\end{tabular}

Quadro 3 - Pontos de corte para A/I, P/A, P/I, em percentil e Desvio padrão

Fonte: Organização Mundial da Saúde (1995).

OBS: Para A/I, acima de P10 e -1 DP: crescimento linear adequado. 


\begin{tabular}{|l|l|l|}
\hline Classificação & OMS, 1995 & MUST et al. 1991 \\
\hline Magreza & $<$ P5 & $<$ P5 \\
\hline Risco de Magreza & --- & P5 a P15 \\
\hline Eutrofia & P5 a P85 & P15 a P85 \\
\hline Risco de sobrepeso & $\geq$ P85 & $\geq$ P85 \\
\hline Obesidade & $\begin{array}{l}\geq \text { P85 + PCT ou } \\
\text { PCSE > P90 }\end{array}$ & \\
\hline
\end{tabular}

Quadro 4 - Pontos de corte IMC/I para escolares e adolescentes Fonte: (ORGANIZAÇÃO MUNDIAL DA SAÚDE, 1995; MUST et al., 1991).

\begin{tabular}{|l|l|}
\hline IMC $\left.\mathbf{( K g} / \mathbf{m}^{2}\right)$ & Classificação \\
\hline$<16$ & Magreza grau III \\
\hline $16-16,9$ & Magreza grau II \\
\hline $17-18,4$ & Magreza grau I \\
\hline $18,5-24,9$ & Eutrofia \\
\hline $25-29,9$ & Sobrepeso \\
\hline $30-34,9$ & Obesidade grau I \\
\hline $35-39,9$ & Obesidade grau II \\
\hline$>40$ & Obesidade grau III \\
\hline
\end{tabular}

Quadro 5 - Classificação do estado nutricional segundo o IMC Fonte: Organização Mundial da Saúde (1997).

\begin{tabular}{|l|l|}
\hline Adequação do peso & Estado Nutricional \\
\hline$\leq 70$ & Desnutrição Grave \\
\hline $70,1-80$ & Desnutrição Moderada \\
\hline $80,1-90$ & Desnutrição Leve \\
\hline $90,1-110$ & Eutrofia \\
\hline $110,1-120$ & Sobrepeso \\
\hline$>120$ & Obesidade \\
\hline
\end{tabular}

Quadro 6 - Classificação do estado nutricional de acordo com a adequação do peso

Fonte: Blackburn e Thornton (1979). 


\begin{tabular}{|l|l|l|}
\hline Percentil & Tec. Adiposo & Tecido muscular \\
\hline$\leq 5$ & Déficit & Depleção \\
\hline $5-15$ & Risco de déficit & Risco de déficit \\
\hline $15-85$ & Média & Média \\
\hline $85-90$ & Acima da média & Boa nutrição \\
\hline$\geq 90$ & Excesso de gordura & Boa nutrição \\
\hline
\end{tabular}

Quadro 7 - Interpretação da CB/ AMB/ AMBc/ AGB/ PCT + PCSE (crianças, adolescentes e adultos)

Fonte: Adaptado de Lee e Nieman (1993 apud FRISANCHO, 1990).

\begin{tabular}{|l|l|l|}
\hline Classificação & Homens & Mulheres \\
\hline Risco & $\leq 5$ & $\leq 8$ \\
\hline Abaixo da média & $6-14$ & $9-22$ \\
\hline Média & 15 & 23 \\
\hline ACIMA DA MÉDIA & $16-24$ & $24-31$ \\
\hline Risco & $\geq 25$ & $\geq 32$ \\
\hline
\end{tabular}

Quadro 8 - Padrões percentuais de gordura corporal para homens e mulheres (risco de doenças)

Fonte: Lohman (1991).

à Obesidade $\geq 25 \%$ do peso corporal em gordura no caso dos homens e $\geq 32 \%$ no caso das mulheres.

\begin{tabular}{|l|l|l|}
\hline \multirow{2}{*}{ Sexo } & \multicolumn{2}{|l|}{ Risco para complicações metabólicas } \\
\cline { 2 - 3 } & Elevado $\mathbf{( c m})$ & Muito elevado $(\mathbf{c m})$ \\
\hline Homens & 94 & $>102$ \\
\hline Mulheres & 80 & $>88$ \\
\hline
\end{tabular}

Quadro 9 - Interpretação para Circunferência da cintura para adultos Fonte: Organização Mundial da Saúde (1997). 


\begin{tabular}{|l|l|l|}
\hline Tempo & $\begin{array}{l}\text { Perda significativa de } \\
\text { peso \% }\end{array}$ & $\begin{array}{l}\text { Perda severa de } \\
\text { peso (\%) }\end{array}$ \\
\hline 1 semana & $1-2$ & $>2$ \\
\hline 1 mês & 5 & $>5$ \\
\hline 3 meses & 7.5 & $>7.5$ \\
\hline 6 meses & 10 & $>10$ \\
\hline
\end{tabular}

Quadro 10 - Significado do percentual de mudança de peso Fonte: Blackburn (1977).

\begin{tabular}{|l|l|}
\hline IMC $\left.\mathbf{( K g} / \mathbf{m}^{2}\right)$ & Classificação \\
\hline$<22$ & Baixo peso \\
\hline $22-27$ & Eutrofia \\
\hline$>27$ & Excesso de peso \\
\hline
\end{tabular}

Quadro 11 - Classificação do estado nutricional segundo o IMC Fonte: Lipzshitz (1994). 


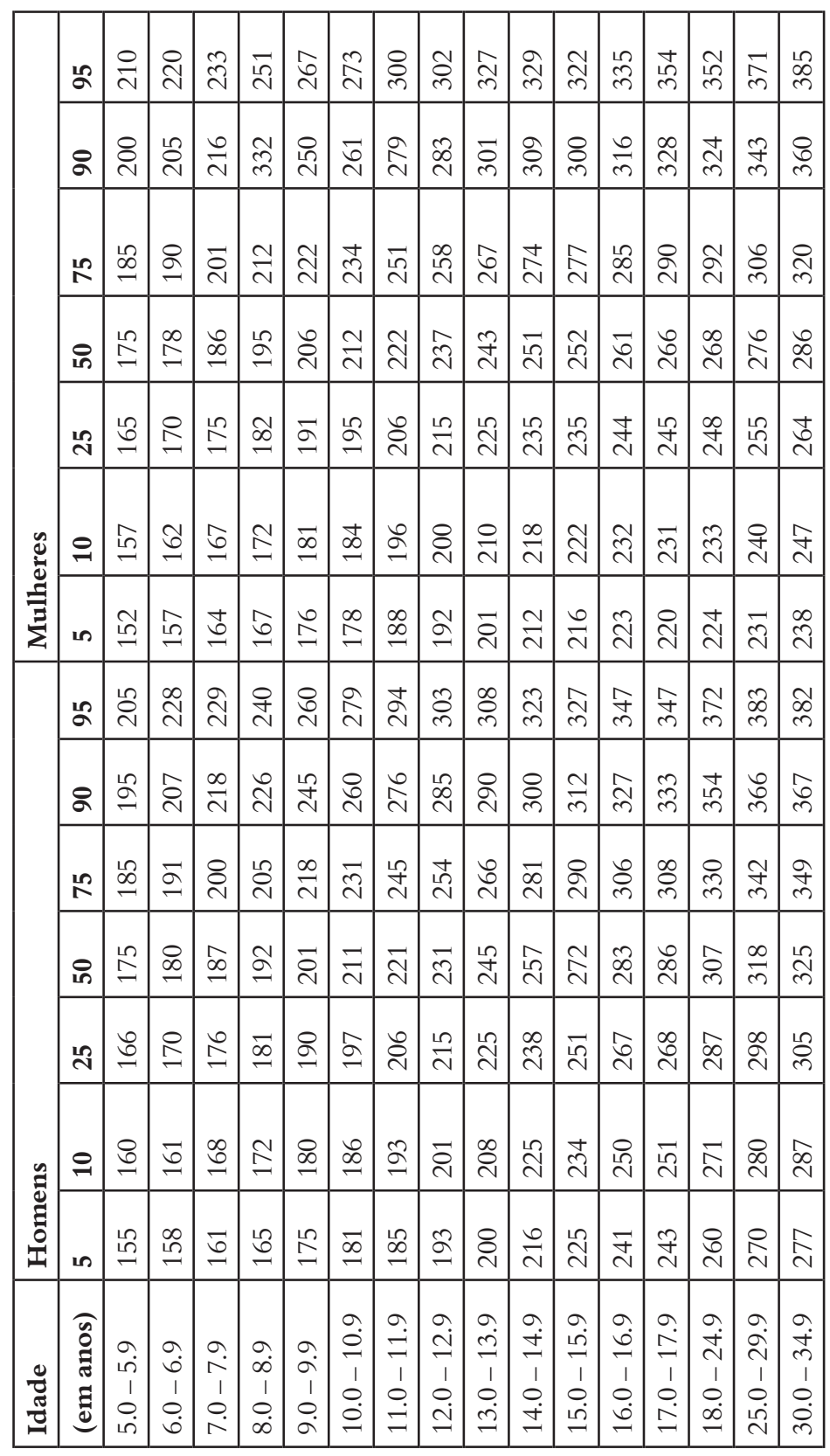




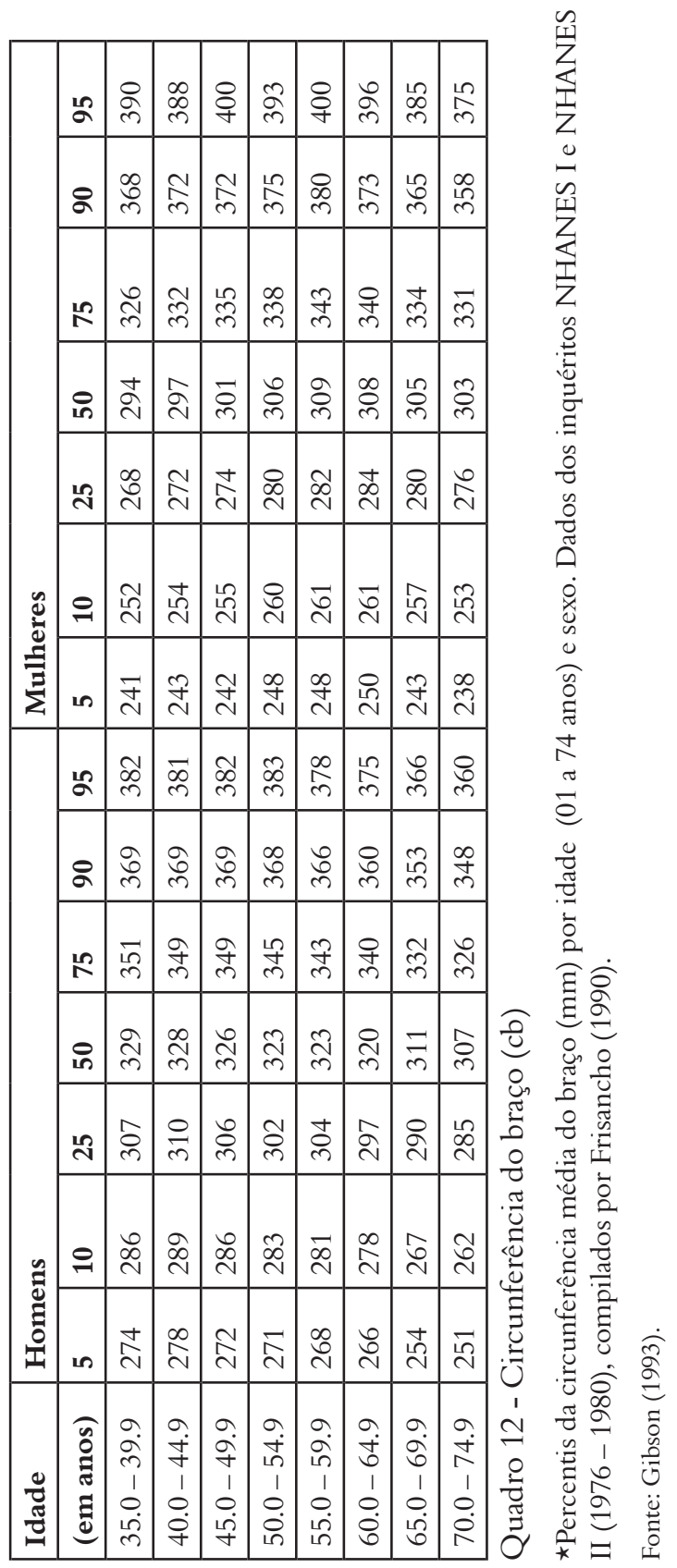




\begin{tabular}{|c|c|c|c|c|c|c|c|c|c|c|c|c|c|c|c|c|c|}
\hline \multirow{7}{*}{$\frac{\tilde{J}}{2}$} & ํㅡ & ֶֶ & $\stackrel{?}{\beth}$ & $\begin{array}{l}\infty \\
\infty \\
\infty\end{array}$ & $\stackrel{\infty}{\stackrel{\infty}{\rightleftharpoons}}$ & $\stackrel{\overparen{N}}{\overparen{N}}$ & $\underset{\sim}{\stackrel{\sim}{\sim}}$ & $\stackrel{?}{\sim}$ & $\begin{array}{l}0 \\
\infty \\
\stackrel{\infty}{N}\end{array}$ & $\underset{m}{\ddot{m}}$ & $\vec{\oplus}$ & $\stackrel{\sim}{\sim}$ & $\stackrel{n}{\mathfrak{q}}$ & $\stackrel{\dot{\vartheta}}{\dot{q}}$ & 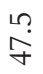 & $\begin{array}{l}q \\
\dot{\varphi}\end{array}$ & $\begin{array}{l}\dddot{m} \\
\stackrel{\infty}{+}\end{array}$ \\
\hline & ฉ & $\stackrel{n}{\sim}$ & $\underset{\bullet}{*}$ & $\stackrel{+}{\beth}$ & $\begin{array}{l}0 \\
\infty \\
=\end{array}$ & $\begin{array}{l}0 \\
\stackrel{\sim}{\sim}\end{array}$ & 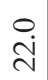 & $\stackrel{\vartheta}{\hat{\imath}}$ & 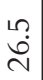 & 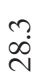 & $\frac{0}{\dot{m}}$ & ثि. & $\stackrel{\infty}{\infty}$ & $\begin{array}{l}\dot{0} \\
\stackrel{\sim}{ }\end{array}$ & $\stackrel{\overbrace{}}{\mathcal{H}}$ & $\stackrel{\curvearrowright}{\stackrel{f}{子}}$ & $\stackrel{\sim}{\Im}$ \\
\hline & n & $\begin{array}{l}\infty \\
\stackrel{\oplus}{\sigma}\end{array}$ & $\stackrel{\searrow}{ \pm}$ & $\begin{array}{l}\infty \\
\stackrel{0}{0}\end{array}$ & $\underset{-}{0}$ & $\stackrel{?}{\infty}$ & $\stackrel{n}{2}$ & $\frac{N}{N}$ & 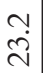 & $\stackrel{+}{\stackrel{\sim}{N}}$ & $\underset{\text { N }}{0}$ & $\hat{\overbrace{}}$ & $\stackrel{\sim}{m}$ & $\stackrel{n}{n}$ & 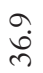 & $\stackrel{m}{n}$ & $\begin{array}{l}0 \\
\stackrel{0}{\infty} \\
\stackrel{m}{0}\end{array}$ \\
\hline & 으 & $\stackrel{\overbrace{}}{\sim}$ & $\stackrel{\sim}{\dddot{\nu}}$ & $\stackrel{?}{ \pm}$ & $\stackrel{n}{n}$ & $\stackrel{+}{\bullet}$ & $\stackrel{+}{\stackrel{+}{\sigma}}$ & $\begin{array}{l}a \\
\infty\end{array}$ & 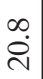 & $\frac{\sigma}{\sim}$ & $\begin{array}{l}\infty \\
\ddot{\sim}\end{array}$ & $\begin{array}{l}\forall \\
\stackrel{\sim}{v}\end{array}$ & $\stackrel{\circ}{\stackrel{\Omega}{े}}$ & $\begin{array}{l}\infty \\
\dot{0} \\
m\end{array}$ & $\begin{array}{l}\infty \\
\stackrel{\sim}{~}\end{array}$ & $\underset{\sim}{\stackrel{0}{~}}$ & $\begin{array}{l}\stackrel{\ominus}{m} \\
\stackrel{m}{m}\end{array}$ \\
\hline & $\stackrel{2}{\sim}$ & $\stackrel{\infty}{\circ}$ & $\stackrel{\infty}{\rightleftarrows}$ & $\begin{array}{l}\stackrel{0}{ } \\
\stackrel{\sim}{\sim}\end{array}$ & $\begin{array}{l}\ddot{0} \\
\ddot{2}\end{array}$ & $\begin{array}{l}\infty \\
\dot{\sim} \\
\end{array}$ & $\begin{array}{l}\ddot{1} \\
\dot{n}\end{array}$ & $\stackrel{n}{0}$ & $\underset{\infty}{\infty}$ & $\stackrel{\infty}{\sigma}$ & $\stackrel{\tilde{\Omega}}{\tilde{\Omega}}$ & ָे & $\begin{array}{l}\stackrel{n}{n} \\
\stackrel{n}{N}\end{array}$ & $\frac{\vec{N}}{\widehat{N}}$ & $\stackrel{\circ}{\mathrm{\vartheta}}$ & $\stackrel{\curvearrowright}{\curvearrowright}$ & ஜ̊. \\
\hline & 으 & $\hat{a}$ & $\stackrel{\varrho}{\circ}$ & $\stackrel{+}{\rightleftarrows}$ & $\underset{\sim}{\sim}$ & $\stackrel{\sim}{2}$ & $\stackrel{\sqsupset}{ \pm}$ & 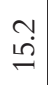 & $\begin{array}{l}0 \\
\stackrel{6}{0}\end{array}$ & $\stackrel{9}{\simeq}$ & $\begin{array}{l}n \\
\infty\end{array}$ & $\frac{0}{\vec{N}}$ & $\frac{\infty}{i}$ & 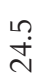 & ָे & $\begin{array}{l}\infty \\
\stackrel{\leftrightarrow}{N}\end{array}$ & $\begin{array}{l}\infty \\
\stackrel{\omega}{0} \\
\sim\end{array}$ \\
\hline & in & $\stackrel{\vartheta}{\infty}$ & $\ddot{\varrho}$ & $\stackrel{\infty}{\stackrel{0}{0}}$ & $\stackrel{N}{\beth}$ & $\stackrel{+}{\underset{\sim}{\sim}}$ & $\stackrel{n}{2}$ & $\stackrel{+}{ \pm}$ & 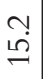 & $\begin{array}{l}0 \\
\end{array}$ & $\begin{array}{l}0 \\
\end{array}$ & $\stackrel{\text { Ln }}{2}$ & $\stackrel{+}{\stackrel{\sim}{d}}$ & $\begin{array}{l}\infty \\
\stackrel{N}{N}\end{array}$ & $\underset{\stackrel{+}{d}}{\stackrel{\circ}{.}}$ & $\stackrel{+}{\stackrel{+}{d}}$ & $\stackrel{\sim}{\sim}$ \\
\hline \multirow{7}{*}{ 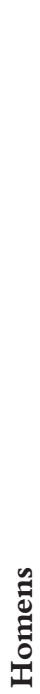 } & น2 & $\underset{\nearrow}{N}$ & $\begin{array}{l}+ \\
\infty\end{array}$ & $\stackrel{n}{2}$ & $\stackrel{\tilde{\Omega}}{\tilde{\Omega}}$ & $\stackrel{\sim}{\curvearrowright}$ & $\stackrel{\sim}{\sim}$ & $\begin{array}{l}0 \\
\dot{\infty} \\
\stackrel{N}{0}\end{array}$ & $\begin{array}{l}0 \\
\stackrel{2}{\Omega}\end{array}$ & $\stackrel{a}{\sim}$ & $\frac{r}{n}$ & $\stackrel{?}{q}$ & $\stackrel{q}{\dot{y}}$ & $\begin{array}{l}\text { กิ } \\
\text { กิ }\end{array}$ & 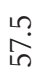 & $\begin{array}{l}0 \\
3\end{array}$ & $\vec{\sim}$ \\
\hline & 요 & ?ֶ? & $\underline{\theta}$ & $\stackrel{m}{\infty}$ & $\stackrel{\infty}{\stackrel{\infty}{\nu}}$ & $\stackrel{ }{\vec{N}}$ & $\begin{array}{l}\infty \\
\ddot{v}\end{array}$ & 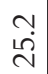 & $\begin{array}{l}\stackrel{0}{0} \\
\stackrel{0}{v}\end{array}$ & $\stackrel{+}{\dot{m}}$ & $\begin{array}{l}\text { ते } \\
\text { ले }\end{array}$ & $\vec{b}$ & $\dot{q}$ & $\stackrel{\leftrightarrow}{+\infty}$ & $\begin{array}{l}0 \\
\dot{\Delta}\end{array}$ & 命 & $\frac{a}{6}$ \\
\hline & in & $\begin{array}{l}\stackrel{0}{ \pm} \\
\stackrel{+}{*}\end{array}$ & $\begin{array}{l}0 \\
\stackrel{0}{ }\end{array}$ & $\stackrel{+}{\bullet}$ & $\stackrel{9}{\sim}$ & $\stackrel{n}{2}$ & $\frac{?}{\sim}$ & 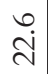 & $\begin{array}{l}\stackrel{0}{\sim} \\
\stackrel{\sim}{N}\end{array}$ & $\vec{\sim}$ & $\stackrel{\circ}{\stackrel{\sim}{\sim}}$ & $\frac{0}{m}$ & $\begin{array}{l}a \\
\dot{n}\end{array}$ & $\stackrel{\Re}{\underset{\gamma}{\gamma}}$ & $\underset{+}{\stackrel{+}{+}}$ & $\vec{n}$ & $\begin{array}{l}\infty \\
\text { in }\end{array}$ \\
\hline & 으 & $\stackrel{0}{\stackrel{0}{\sigma}}$ & $\stackrel{\vartheta}{\vartheta}$ & $\begin{array}{l}0 \\
\text { ம) }\end{array}$ & $\stackrel{\sim}{0}$ & $\begin{array}{l}0 \\
\end{array}$ & $\stackrel{\curvearrowright}{\infty}$ & $\begin{array}{l}\stackrel{0}{0} \\
\stackrel{\sim}{\sim}\end{array}$ & $\begin{array}{l}\dot{\sim} \\
\stackrel{\sim}{N}\end{array}$ & $\begin{array}{l}\tilde{N} \\
\tilde{n}\end{array}$ & $\stackrel{\sqrt{n}}{\sim}$ & $\stackrel{\widehat{N}}{\widehat{N}}$ & $\stackrel{+}{\circ}$ & ñ. & & ?ִ & $\frac{\sigma}{10}$ \\
\hline & $\stackrel{\sim}{\mathrm{N}}$ & $\stackrel{0}{\stackrel{0}{二}}$ & $\stackrel{+}{\sim}$ & $\stackrel{n}{\sim}$ & $\stackrel{n}{ \pm}$ & ڤ̊ & $\stackrel{\infty}{\underline{\varphi}}$ & $\begin{array}{l}n \\
\infty \\
0\end{array}$ & $\stackrel{n}{2}$ & $\stackrel{\curvearrowright}{\sim}$ & $\underset{\sim}{\stackrel{\sim}{0}}$ & $\begin{array}{l}\infty \\
\stackrel{+}{d}\end{array}$ & $\hat{\sigma}$ & $\stackrel{+}{\stackrel{\oplus}{\oplus}}$ & Ґֶ. & $\stackrel{?}{q}$ & $\begin{array}{l}\hat{\sigma} \\
\stackrel{\sigma}{q}\end{array}$ \\
\hline & 으 & $\stackrel{+}{\ominus}$ & $\stackrel{\varrho}{\varrho}$ & $\begin{array}{c}\stackrel{ }{\sim} \\
\stackrel{-}{1}\end{array}$ & $\stackrel{\Im}{\sim}$ & 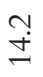 & $\stackrel{?}{n}$ & $\stackrel{v}{0}$ & $\begin{array}{l}\infty \\
\stackrel{-}{-}\end{array}$ & $\stackrel{?}{\sim}$ & 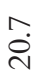 & $\begin{array}{l}\stackrel{0}{\mathrm{~N}} \\
\mathrm{~N}\end{array}$ & $\stackrel{\stackrel{J}{d}}{\square}$ & $\stackrel{\sim}{\vec{v}}$ & $\frac{m}{n}$ & ले & $\stackrel{\rho}{g}$ \\
\hline & in & $\hat{a}$ & $\ddot{\varrho}$ & $\underset{f}{\mathcal{E}}$ & $\begin{array}{c}\text { ㅁ } \\
\sim\end{array}$ & $\stackrel{\overbrace{}}{\dddot{\sigma}}$ & $\begin{array}{l} \pm \\
\pm\end{array}$ & 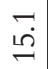 & $\stackrel{?}{?}$ & $\underset{\infty}{\infty}$ & $\begin{array}{l}0 \\
\stackrel{\theta}{ }\end{array}$ & $\frac{0}{i}$ & $\begin{array}{l}0 \\
\stackrel{N}{N}\end{array}$ & 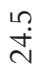 & $\begin{array}{l}\stackrel{?}{N} \\
\infty\end{array}$ & $\frac{\sigma}{\pi}$ & $\stackrel{\circ}{\circ}$ \\
\hline 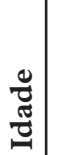 & 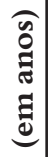 & 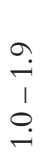 & $\begin{array}{c}a \\
\text { N } \\
1 \\
0 \\
\text { i }\end{array}$ & $\begin{array}{l}a \\
\dot{1} \\
0 \\
\dot{0}\end{array}$ & $\begin{array}{l}9 \\
\dot{+} \\
1 \\
0 \\
\dot{+}\end{array}$ & $\begin{array}{c}a \\
10 \\
1 \\
0 \\
\dot{10}\end{array}$ & $\begin{array}{l}a \\
0 \\
1 \\
0 \\
0\end{array}$ & $\begin{array}{c}a \\
\\
1 \\
0 \\
\end{array}$ & $\begin{array}{c}a \\
\infty \\
1 \\
0 \\
\infty\end{array}$ & $\begin{array}{l}a \\
a \\
1 \\
0 \\
a\end{array}$ & $\begin{array}{l}\varrho \\
0 \\
1 \\
0 \\
0 \\
0\end{array}$ & $\begin{array}{l}9 \\
= \\
1 \\
0 \\
=\end{array}$ & 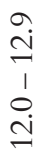 & $\begin{array}{c}\stackrel{a}{7} \\
1 \\
0 \\
\ddot{\theta}\end{array}$ & $\begin{array}{l}9 \\
\pm \\
\dot{ \pm} \\
0 \\
\dot{ \pm}\end{array}$ & $\begin{array}{l}0 \\
\stackrel{0}{0} \\
1 \\
0 \\
10\end{array}$ & $\begin{array}{l}\sigma \\
\overrightarrow{0} \\
1 \\
0 \\
0 \\
0\end{array}$ \\
\hline
\end{tabular}




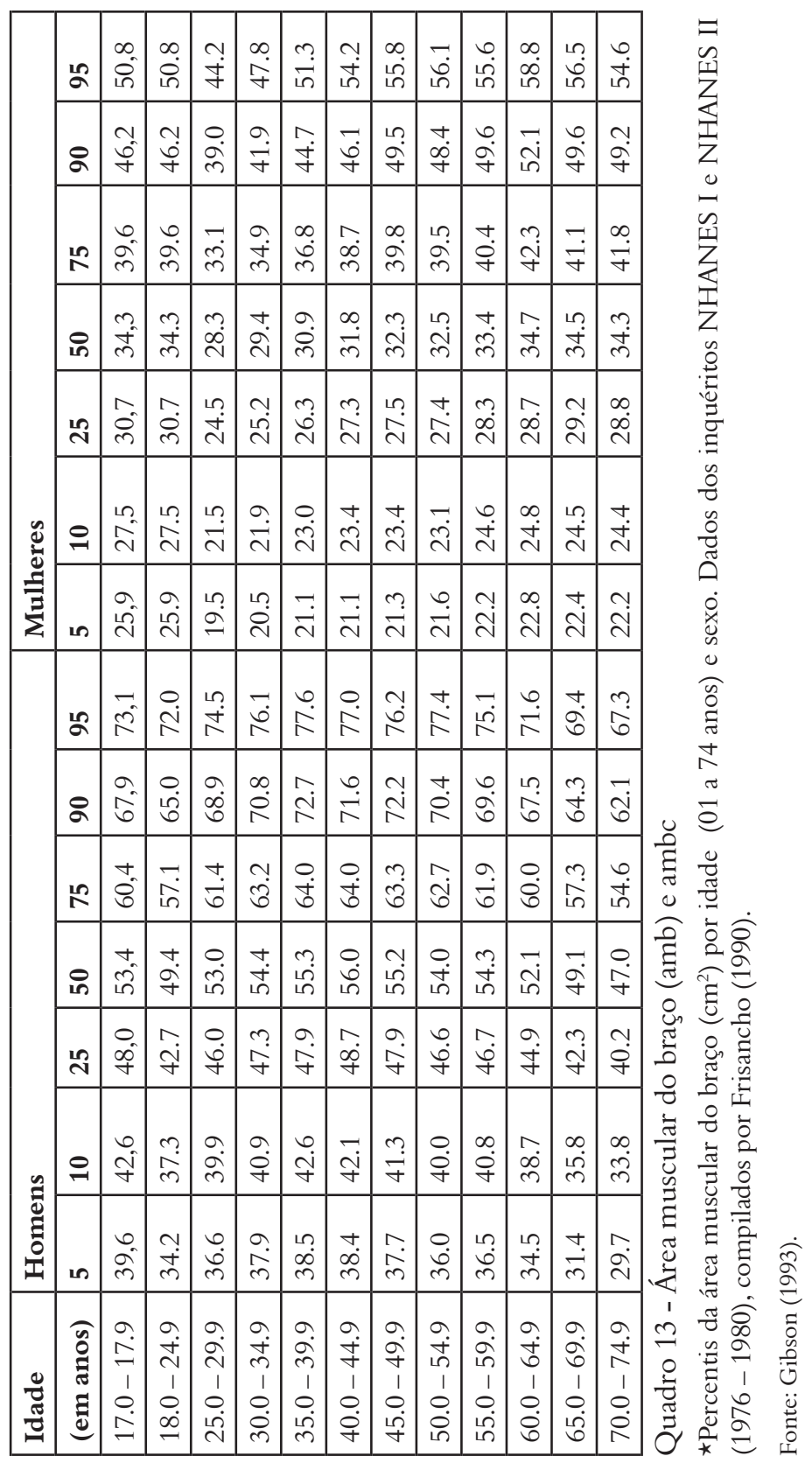




\begin{tabular}{|c|c|c|c|c|c|c|c|c|c|c|c|c|c|c|c|c|}
\hline \multirow{7}{*}{ 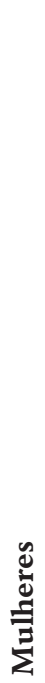 } & ณ2 & $\stackrel{0}{0}$ & $\stackrel{0}{0}$ & $\stackrel{0}{0}$ & $\begin{array}{l}\stackrel{n}{0} \\
\stackrel{n}{\longrightarrow}\end{array}$ & $\begin{array}{l}0 \\
\end{array}$ & $\begin{array}{l}0 \\
\end{array}$ & $\stackrel{\circ}{\stackrel{0}{\sigma}}$ & 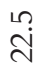 & $\begin{array}{l}0 \\
\stackrel{\leftrightarrow}{\sim}\end{array}$ & 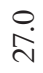 & $\stackrel{\circ}{\stackrel{े}{े}}$ & $\stackrel{n}{\widehat{N}}$ & $\stackrel{\circ}{\stackrel{\leftrightarrow}{0}}$ & $\begin{array}{l}\text { o } \\
\text { ते }\end{array}$ & तn \\
\hline & ฉด & $\begin{array}{l}0 \\
\dot{ \pm}\end{array}$ & 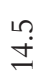 & $\begin{array}{l}0 \\
\dot{ \pm}\end{array}$ & $\begin{array}{l}0 \\
\stackrel{ \pm}{ \pm}\end{array}$ & $\begin{array}{l}0 \\
\stackrel{0}{\longrightarrow}\end{array}$ & $\begin{array}{l}0 \\
\stackrel{10}{0}\end{array}$ & $\stackrel{0}{0}$ & 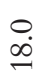 & $\stackrel{0}{\stackrel{\sim}{\sim}}$ & $\stackrel{10}{\mathrm{~N}}$ & $\begin{array}{l}\stackrel{0}{+} \\
\stackrel{d}{ }\end{array}$ & $\begin{array}{l}\stackrel{0}{+} \\
\stackrel{d}{~}\end{array}$ & $\begin{array}{l}\stackrel{\circ}{\sim} \\
\stackrel{\leftrightarrow}{v}\end{array}$ & 吕 & $\begin{array}{l}0 \\
\text { ஸे } \\
\text { N }\end{array}$ \\
\hline & In & $\stackrel{\circ}{\stackrel{\circ}{\sim}}$ & $\stackrel{\circ}{\stackrel{\circ}{\sigma}}$ & 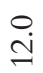 & $\underset{\sim}{\stackrel{O}{\sim}}$ & $\underset{\sim}{\stackrel{O}{\sim}}$ & 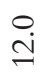 & $\stackrel{1}{\sim}$ & $\stackrel{\text { Ln }}{ \pm}$ & $\underset{0}{0}$ & $\stackrel{1}{1}$ & $\underset{\infty}{\infty}$ & $\stackrel{10}{\infty}$ & $\stackrel{\circ}{\stackrel{N}{0}}$ & $\stackrel{0}{\stackrel{0}{N}}$ & $\stackrel{n}{\stackrel{2}{N}}$ \\
\hline & 으 & $\stackrel{0}{\circ}$ & $\stackrel{\circ}{\circ}$ & $\stackrel{\circ}{\circ}$ & $\stackrel{\circ}{\circ}$ & $\stackrel{\circ}{\ominus}$ & $\stackrel{\circ}{\stackrel{0}{0}}$ & $\stackrel{1}{?}$ & $\stackrel{0}{=}$ & $\stackrel{\circ}{\stackrel{\circ}{-}}$ & $\stackrel{1}{\stackrel{1}{\sim}}$ & $\stackrel{0}{\stackrel{0}{\sim}}$ & $\begin{array}{l}0 \\
\pm \\
\pm\end{array}$ & $\begin{array}{l}0 \\
\stackrel{0}{0}\end{array}$ & $\stackrel{0}{0}$ & $\stackrel{n}{0}$ \\
\hline & $\stackrel{10}{N}$ & $\stackrel{0}{\infty}$ & 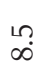 & 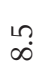 & $\stackrel{0}{\infty}$ & $\underset{\infty}{\infty}$ & $\underset{\infty}{\infty}$ & $\underset{\infty}{\infty}$ & $\stackrel{1}{\infty}$ & $\stackrel{\circ}{a}$ & $\stackrel{\circ}{\sigma}$ & $\stackrel{0}{\circ}$ & $\begin{array}{l}0 \\
\rightleftharpoons\end{array}$ & $\stackrel{0}{\stackrel{0}{\beth}}$ & $\stackrel{\text { in }}{=}$ & $\stackrel{\circ}{\stackrel{ }{-1}}$ \\
\hline & 으 & $\stackrel{\circ}{r}$ & $\stackrel{\circ}{\circ}$ & $\underset{\sim}{0}$ & $\stackrel{0}{0}$ & $\underset{N}{0}$ & 1? & $\stackrel{0}{N}$ & $\stackrel{0}{0}$ & $\stackrel{0}{r}$ & $\underset{\infty}{0}$ & $\underset{\infty}{0}$ & $\underset{\infty}{\infty}$ & $\underset{\infty}{\infty}$ & $\stackrel{\circ}{a}$ & $\stackrel{1 ?}{a}$ \\
\hline & in & $\stackrel{0}{0}$ & ๑̊ & $\underset{0}{0}$ & @़ & L? & $\stackrel{0}{0}$ & $\underset{0}{0}$ & $\underset{0}{0}$ & $\stackrel{n}{6}$ & $\underset{r}{\circ}$ & $\stackrel{\circ}{1}$ & $\stackrel{\circ}{N}$ & $\stackrel{\circ}{\circ}$ & $\underset{\infty}{\infty}$ & $\stackrel{\circ}{\infty}$ \\
\hline \multirow{7}{*}{ 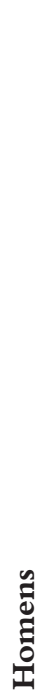 } & ำ & $\begin{array}{l}\text { Ln } \\
\text { 10 }\end{array}$ & $\begin{array}{l}0 \\
\text { ம் }\end{array}$ & $\begin{array}{l}0 \\
\text { ம் }\end{array}$ & $\begin{array}{l}0 \\
\dot{I}\end{array}$ & $\stackrel{1}{ \pm}$ & $\stackrel{0}{6}$ & $\underset{0}{0}$ & $\stackrel{\circ}{2}$ & $\stackrel{\circ}{\stackrel{0}{\sim}}$ & $\begin{array}{l}\stackrel{+}{d} \\
\stackrel{d}{*}\end{array}$ & $\stackrel{0}{\stackrel{N}{N}}$ & in & $\begin{array}{l}0 \\
\stackrel{\operatorname{din}}{0}\end{array}$ & in & तn \\
\hline & ฉి & $\begin{array}{l}\stackrel{0}{ \pm} \\
\underset{+}{+}\end{array}$ & $\begin{array}{l}\stackrel{0}{ \pm} \\
\stackrel{+}{\prime}\end{array}$ & $\stackrel{n}{\sim}$ & 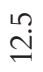 & $\begin{array}{l}\stackrel{0}{\sim} \\
\stackrel{\sim}{r}\end{array}$ & $\stackrel{0}{\stackrel{0}{\sim}}$ & $\begin{array}{l}\stackrel{0}{ \pm} \\
\stackrel{ \pm}{\prime}\end{array}$ & $\underset{\theta}{0}$ & $\stackrel{0}{\circ}$ & 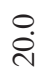 & $\begin{array}{c}0 \\
\ddot{v}\end{array}$ & in & in & $\stackrel{\circ}{\infty}$ & $\begin{array}{l}0 \\
\infty\end{array}$ \\
\hline & $\stackrel{n}{N}$ & $\stackrel{\circ}{\stackrel{\circ}{\sim}}$ & $\stackrel{\circ}{\stackrel{\circ}{\sim}}$ & $\stackrel{\text { 우 }}{=}$ & 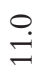 & $\stackrel{\circ}{\circ}$ & $\stackrel{\circ}{\circ}$ & $\stackrel{1}{\stackrel{n}{0}}$ & $\stackrel{0}{=}$ & $\stackrel{\text { Ln }}{\sim}$ & $\begin{array}{l}\stackrel{0}{ \pm} \\
\pm\end{array}$ & $\underset{0}{0}$ & $\stackrel{10}{ \pm}$ & $\stackrel{0}{\stackrel{0}{\sim}}$ & $\stackrel{\text { In }}{\sim}$ & $\stackrel{0}{=}$ \\
\hline & 오 & $\stackrel{0}{\stackrel{0}{0}}$ & $\stackrel{\circ}{\circ}$ & !? & $\stackrel{\circ}{a}$ & $\underset{\infty}{\infty}$ & $\underset{\infty}{\infty}$ & $\underset{\infty}{\infty}$ & $\stackrel{?}{\infty}$ & $\stackrel{\circ}{\circ}$ & $\stackrel{\circ}{\circ}$ & $\stackrel{0}{\circ}$ & $\stackrel{10}{0}$ & $\stackrel{\circ}{a}$ & $\stackrel{1}{\infty}$ & $\stackrel{19}{\sim}$ \\
\hline & $\stackrel{10}{\sim}$ & $\underset{\infty}{\infty}$ & $\underset{\infty}{\infty}$ & $\underset{\infty}{\infty}$ & ᄂ? & $\underset{1}{0}$ & in & $\underset{0}{0}$ & $\stackrel{0}{\circ}$ & in & in & $\stackrel{n}{n}$ & In & $\stackrel{0}{N}$ & $\stackrel{0}{0}$ & $\stackrel{0}{0}$ \\
\hline & 윽 & $\stackrel{\circ}{\sim}$ & ?? & $\underset{\sim}{0}$ & ?? & $\underset{\sigma}{0}$ & 1? & $\begin{array}{l}0 \\
10\end{array}$ & in & in & $\stackrel{0}{0}$ & $\stackrel{0}{0}$ & $\underset{0}{0}$ & $\begin{array}{l}0 \\
\text { ம. }\end{array}$ & $\begin{array}{l}0 \\
\text { 10 }\end{array}$ & 오. \\
\hline & in & ๒? & $\underset{0}{0}$ & $\underset{\theta}{0}$ & $\begin{array}{l}n \\
\text { ம? }\end{array}$ & $\begin{array}{l}0 \\
\text { ம) }\end{array}$ & $\begin{array}{l}0 \\
10\end{array}$ & $\stackrel{n}{+}$ & $\begin{array}{l}0 \\
\text { ம }\end{array}$ & $\underset{1}{0}$ & $\begin{array}{l}0 \\
\text { in }\end{array}$ & $\underset{10}{0}$ & $\stackrel{n}{+}$ & $\stackrel{?}{+}$ & $\underset{\forall}{\stackrel{0}{*}}$ & 오. \\
\hline $\begin{array}{l}\frac{0}{\tilde{T}} \\
\frac{\tilde{J}}{\sigma} \\
\end{array}$ & 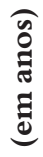 & $\begin{array}{l}9 \\
1 \\
0 \\
0\end{array}$ & $\begin{array}{l}a \\
\text { in } \\
1 \\
0 \\
\text { i }\end{array}$ & $\begin{array}{c}9 \\
\dot{1} \\
0 \\
\dot{0}\end{array}$ & $\begin{array}{l}a \\
\dot{+} \\
1 \\
0 \\
\dot{+}\end{array}$ & $\begin{array}{c}9 \\
1 \\
1 \\
0 \\
\text { in }\end{array}$ & $\begin{array}{l}a \\
0 \\
1 \\
0 \\
0\end{array}$ & $\begin{array}{l}0 \\
1 \\
0 \\
0\end{array}$ & $\begin{array}{c}a \\
\infty \\
1 \\
0 \\
\infty\end{array}$ & $\begin{array}{l}\hat{a} \\
1 \\
0 \\
a\end{array}$ & $\begin{array}{l}0 \\
0 \\
1 \\
0 \\
0 \\
0\end{array}$ & $\begin{array}{l}9 \\
= \\
1 \\
0 \\
=\end{array}$ & 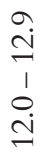 & $\begin{array}{c}\stackrel{a}{2} \\
\stackrel{1}{1} \\
0 \\
\stackrel{0}{\sigma}\end{array}$ & $\begin{array}{l}9 \\
\pm \\
1 \\
0 \\
\pm \\
\pm\end{array}$ & $\begin{array}{l}a \\
\stackrel{1}{n} \\
1 \\
0 \\
\stackrel{1}{n}\end{array}$ \\
\hline
\end{tabular}




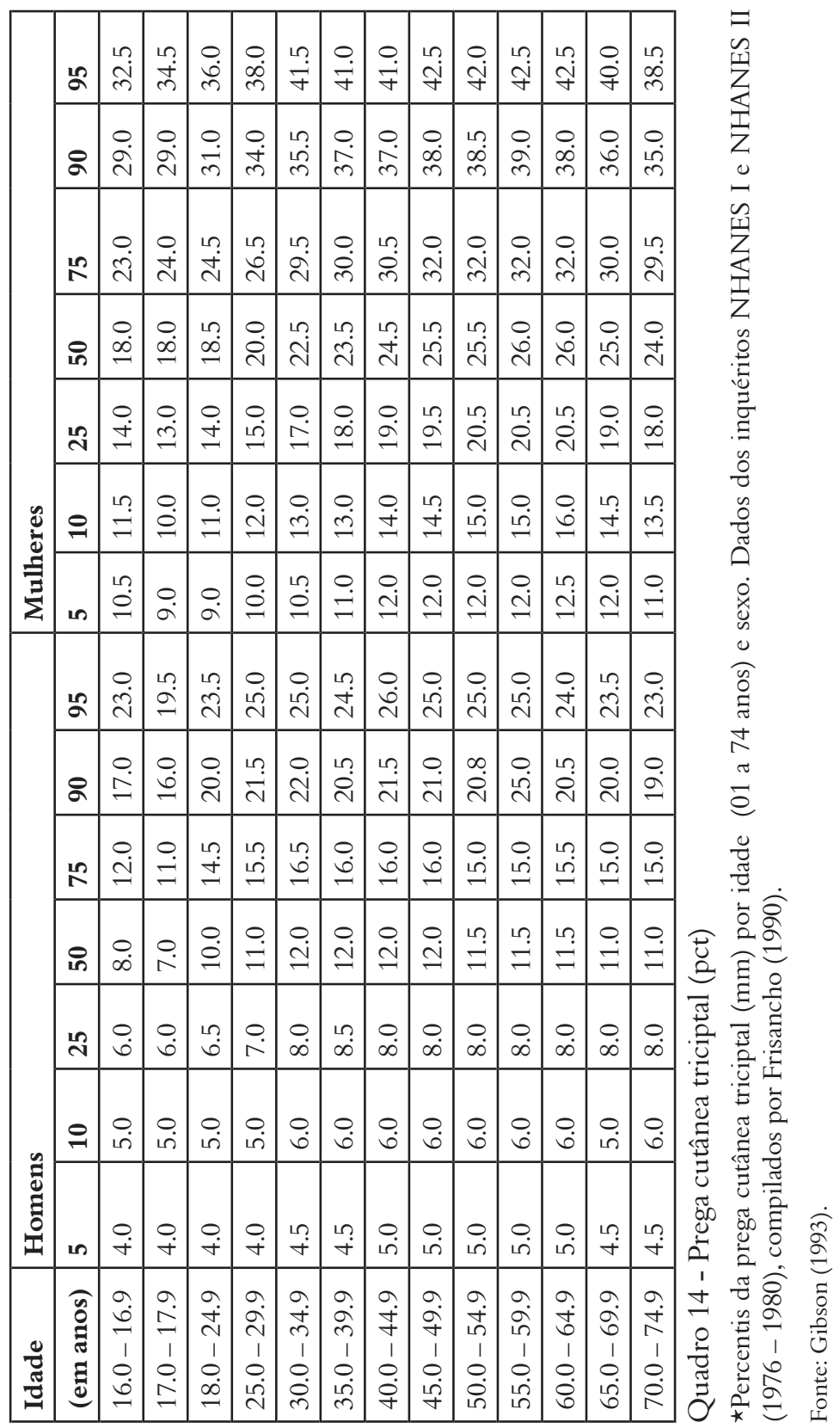




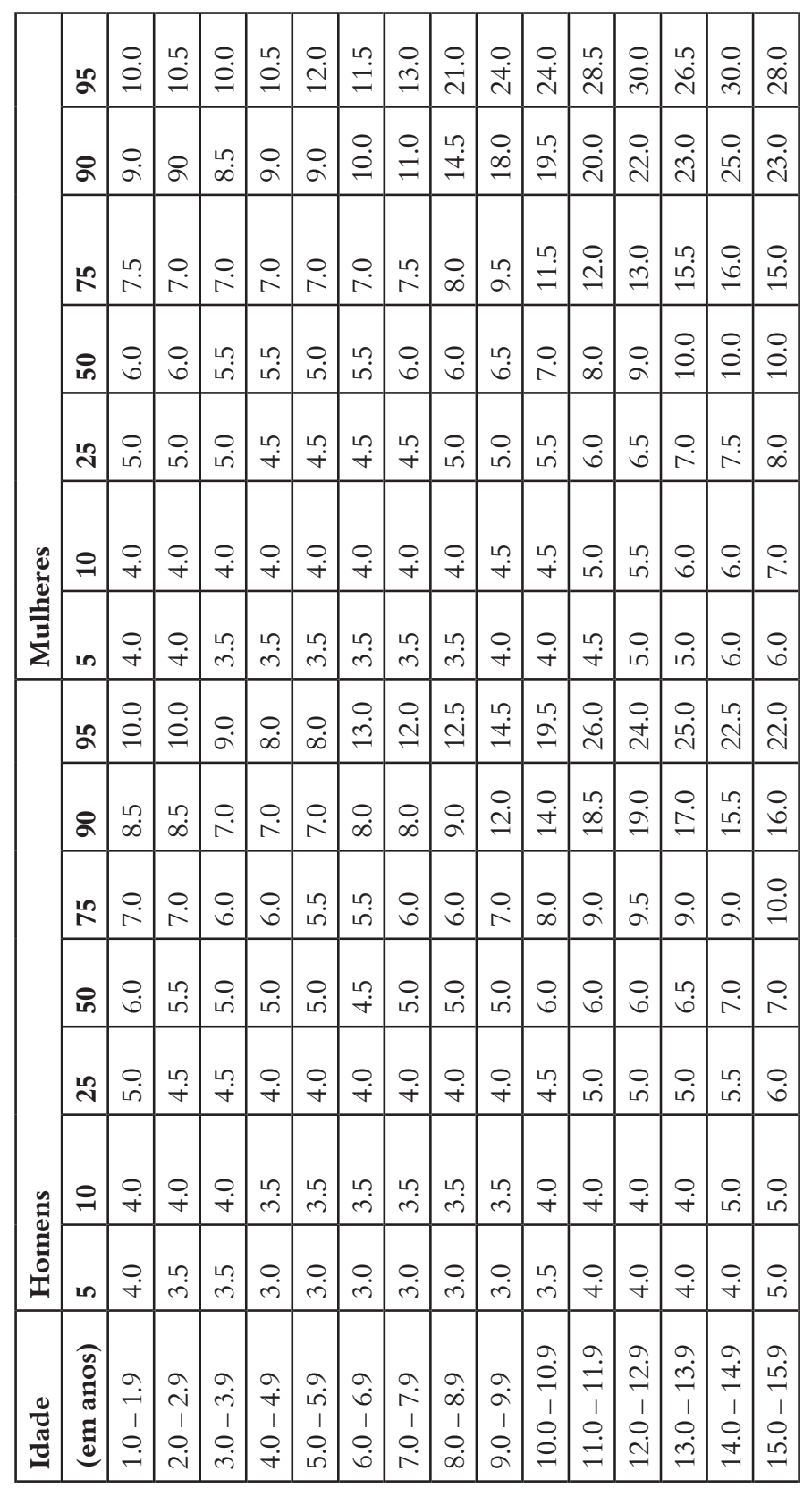




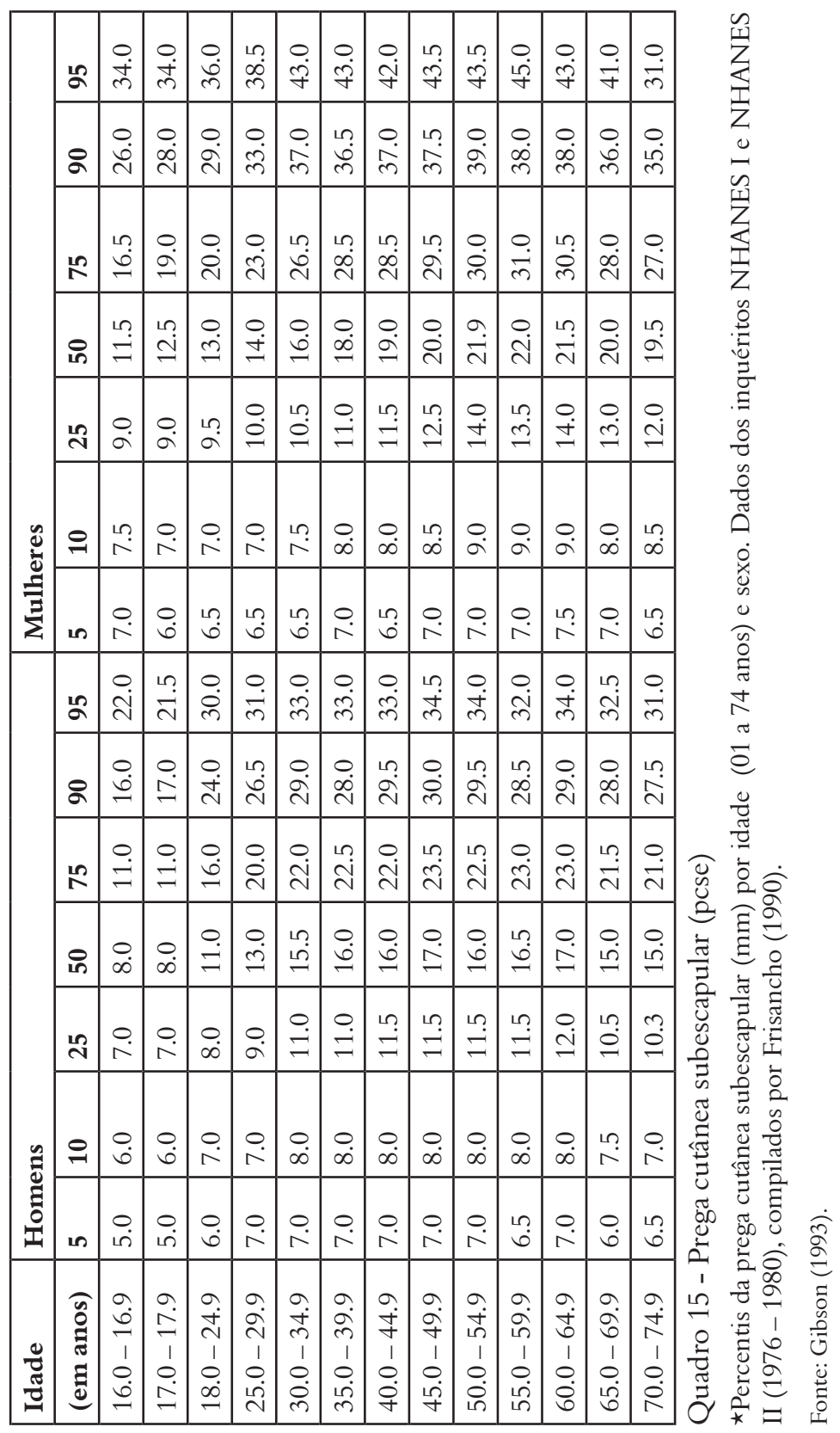




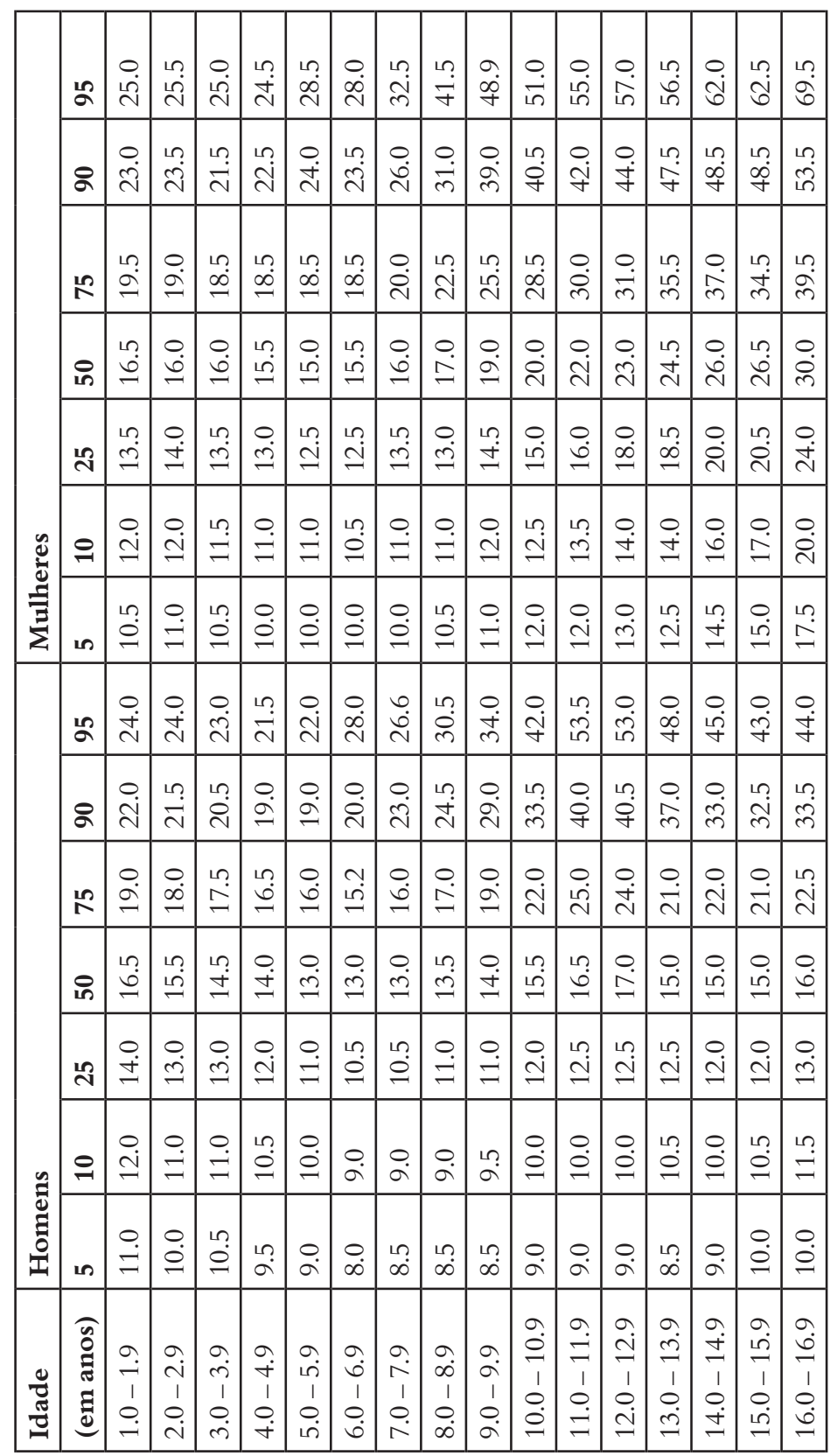




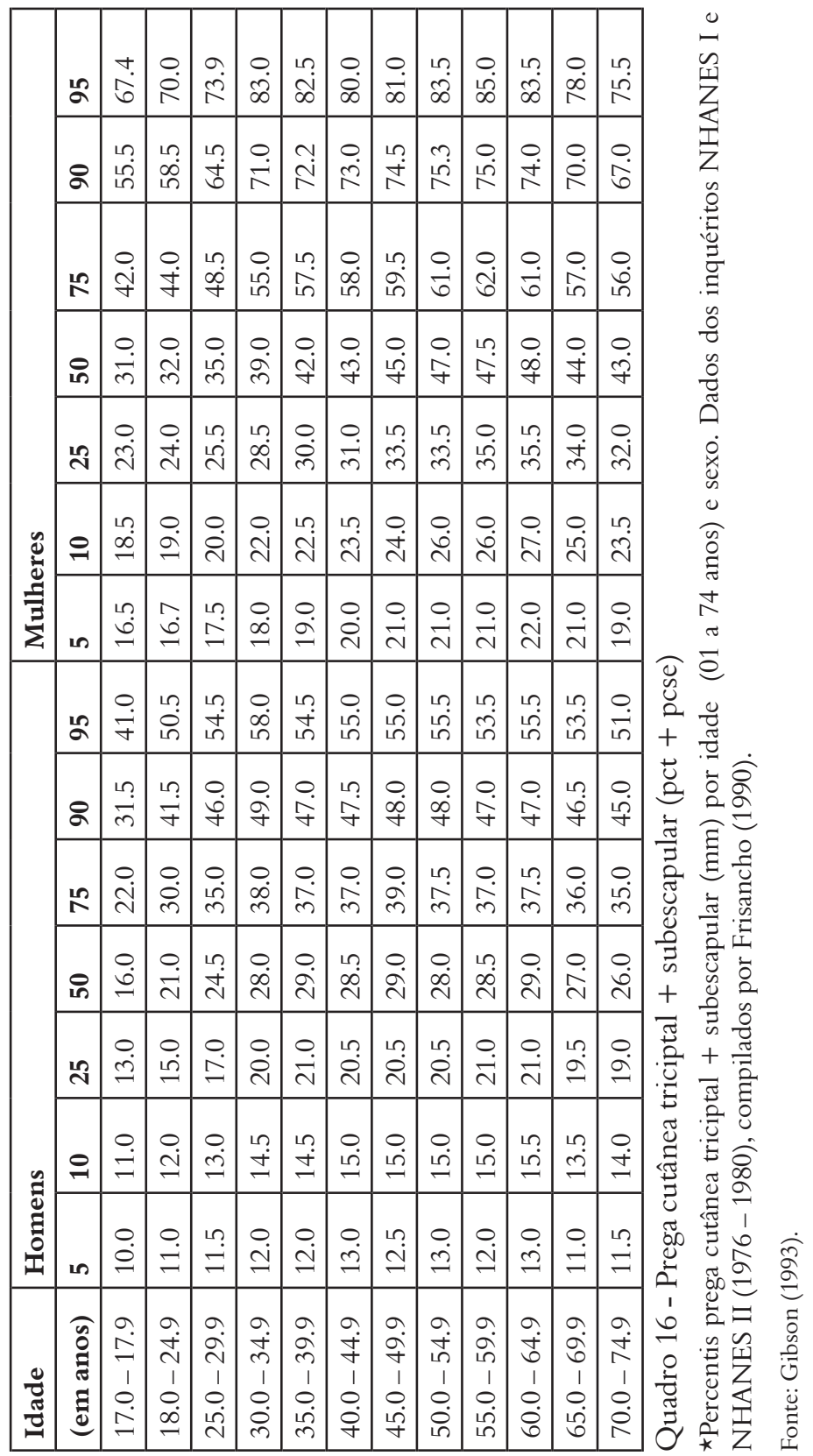




\begin{tabular}{|c|c|c|c|c|c|c|c|c|c|c|c|c|c|c|c|c|c|}
\hline \multirow{7}{*}{ 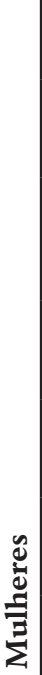 } & น̊ & 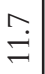 & $\begin{array}{l}0 \\
\stackrel{\sim}{i}\end{array}$ & $\underset{ָ}{\stackrel{v}{\sim}}$ & $\begin{array}{l}\infty \\
\stackrel{\sim}{\sim}\end{array}$ & $\stackrel{\llcorner}{ \pm}$ & $\stackrel{n}{6}$ & $\stackrel{0}{2}$ & 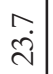 & ヘ? & $\stackrel{\partial}{\grave{\jmath}}$ & $\begin{array}{l}\infty \\
\dot{0} \\
m\end{array}$ & $\begin{array}{l}0 \\
\dot{m} \\
m\end{array}$ & $\stackrel{\infty}{\dot{\leftrightarrow}}$ & $\underset{+}{\stackrel{f}{+}}$ & $\stackrel{?}{\stackrel{9}{f}}$ & $\begin{array}{l}0 \\
\dot{b}\end{array}$ \\
\hline & ฉ̊ & $\stackrel{+}{\bullet}$ & $\begin{array}{l}\infty \\
\stackrel{0}{0}\end{array}$ & $\stackrel{\infty}{0}$ & $\stackrel{?}{=}$ & 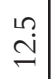 & $\ddot{n}$ & $\stackrel{\Xi}{ \pm}$ & $\begin{array}{c}0 \\
\infty \\
-1\end{array}$ & 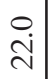 & $\stackrel{?}{\mathrm{n}}$ & $\begin{array}{l}N \\
\infty \\
N\end{array}$ & $\begin{array}{l}+ \\
\stackrel{े}{~}\end{array}$ & ๙ิ่ & $\begin{array}{l}0 \\
\dot{d}\end{array}$ & ڤે & ㅇ. \\
\hline & $\mathfrak{N}$ & $\begin{array}{l}0 \\
\infty \\
\infty\end{array}$ & $\stackrel{\circ}{\circ}$ & $\stackrel{N}{a}$ & $\tilde{a}$ & $\begin{array}{l}\infty \\
\stackrel{0}{0}\end{array}$ & $\stackrel{0}{0}$ & $\stackrel{0}{=}$ & $\stackrel{?}{?}$ & 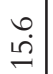 & $\underset{\infty}{0}$ & $\stackrel{a}{\sigma}$ & $\begin{array}{l}\infty \\
\stackrel{\sim}{\sim}\end{array}$ & $\vec{\vartheta}$ & 돔 & $\begin{array}{l}\stackrel{+}{+} \\
\stackrel{+}{v}\end{array}$ & $\begin{array}{l}0 \\
\infty \\
\stackrel{N}{N}\end{array}$ \\
\hline & in & $\neg$ & ?ִ & $\begin{array}{l}\sigma \\
\sim\end{array}$ & 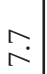 & $\stackrel{\infty}{\sim}$ & $\underset{\infty}{\circ}$ & $\begin{array}{l}\infty \\
\infty \\
\infty\end{array}$ & $\begin{array}{l}\infty \\
a\end{array}$ & $\stackrel{n}{=}$ & $\underset{\Xi}{\Xi}$ & $\ddot{\ddot{g}}$ & $\begin{array}{l}\infty \\
\dot{ \pm} \\
-\end{array}$ & $\stackrel{n}{0}$ & $\stackrel{\curvearrowright}{ح}$ & $\underset{\infty}{\infty}$ & $\begin{array}{l}10 \\
\stackrel{\overbrace{}}{\sim}\end{array}$ \\
\hline & $\stackrel{10}{\sim}$ & $\begin{array}{l}0 \\
\dot{1}\end{array}$ & $\overrightarrow{6}$ & $\overparen{6}$ & ִָ & ?ִ & ত্ & $\stackrel{0}{\circ}$ & $\stackrel{N}{N}$ & $\underset{\infty}{\circ}$ & $\underset{\infty}{+}$ & $\stackrel{\infty}{a}$ & $\stackrel{\infty}{\stackrel{0}{0}}$ & $\stackrel{\theta}{=}$ & $\stackrel{+}{\stackrel{J}{~}}$ & $\begin{array}{l}\infty \\
\stackrel{\bigcup}{\sim}\end{array}$ & $\stackrel{a}{\underline{0}}$ \\
\hline & $\stackrel{\ominus}{-}$ & $\begin{array}{l}0 \\
\dot{+}\end{array}$ & $\begin{array}{l}0 \\
\end{array}$ & $\begin{array}{l}0 \\
\dot{1}\end{array}$ & $\stackrel{\vartheta}{\forall}$ & $\begin{array}{c}0 \\
0\end{array}$ & $\begin{array}{l}0 \\
\text { ㅁ. }\end{array}$ & n? & $\stackrel{\sim}{\circ}$ & তִ & $\overrightarrow{0}$ & !n & $\stackrel{\circ}{\infty}$ & $\stackrel{\curvearrowright}{\Lambda}$ & $\begin{array}{l}0 \\
a\end{array}$ & $\stackrel{0}{0}$ & $\begin{array}{l}\infty \\
\stackrel{J}{J}\end{array}$ \\
\hline & in & 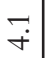 & $\underset{\forall}{+}$ & $\stackrel{?}{+}$ & 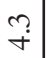 & $\underset{\forall}{+}$ & $\stackrel{10}{+}$ & $\stackrel{\infty}{+}$ & $\stackrel{N}{n}$ & $\stackrel{+}{\dot{H}}$ & $\overparen{6}$ & $\begin{array}{l}0 \\
\dot{0}\end{array}$ & $\widetilde{\theta}$ & $\stackrel{\sigma}{\sigma}$ & $\stackrel{m}{\infty}$ & $\begin{array}{c}0 \\
\infty\end{array}$ & $\stackrel{?}{=}$ \\
\hline \multirow{7}{*}{ 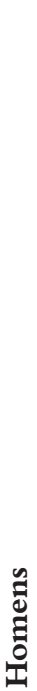 } & ㄴ & 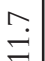 & $\begin{array}{l}0 \\
=\end{array}$ & $\stackrel{\infty}{\underset{\Xi}{\beth}}$ & $\stackrel{+}{\Xi}$ & $\stackrel{\widehat{c}}{\mathrm{C}}$ & 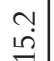 & $\begin{array}{l}n \\
10 \\
10\end{array}$ & $\begin{array}{l}0 \\
\infty\end{array}$ & $\stackrel{\curvearrowright}{\sim}$ & $\stackrel{0}{0}$ & ก & 0 & $\vec{\sim}$ & $\underset{\sim}{\infty}$ & $?$ & $\stackrel{n}{2}$ \\
\hline & 으 & $\stackrel{?}{\varrho}$ & $\begin{array}{l}0 \\
\stackrel{0}{0}\end{array}$ & $\begin{array}{l}0 \\
\stackrel{0}{0}\end{array}$ & $\stackrel{0}{0}$ & $\stackrel{\varrho}{0}$ & $\stackrel{\sim}{=}$ & $\begin{array}{l}\infty \\
\stackrel{\sim}{\sim}\end{array}$ & $\begin{array}{l}0 \\
\stackrel{0}{0}\end{array}$ & $\stackrel{\substack{0 \\
\infty}}{\infty}$ & $\stackrel{n}{\sim}$ & $\begin{array}{l}0 \\
\dot{v} \\
v\end{array}$ & $\stackrel{?}{N}$ & $\stackrel{+}{\stackrel{\leftrightarrow}{\Delta}}$ & $\begin{array}{l}\stackrel{n}{\sim} \\
\stackrel{n}{\sim}\end{array}$ & 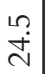 & $\begin{array}{l}\infty \\
\dot{d}\end{array}$ \\
\hline & ณ & $\stackrel{\sigma}{\infty}$ & $\begin{array}{l}0 \\
\infty\end{array}$ & $\begin{array}{l}\infty \\
\infty \\
\infty\end{array}$ & $\stackrel{n}{\infty}$ & $\ddot{\infty}$ & $\begin{array}{l}0 \\
\infty\end{array}$ & $\begin{array}{l}0 \\
\ddot{a}\end{array}$ & $\stackrel{+}{\circ}$ & $\stackrel{\infty}{=}$ & $\stackrel{\searrow}{ \pm}$ & $\vec{\sigma}$ & $\begin{array}{l}\infty \\
\stackrel{n}{n}\end{array}$ & $\underset{\Xi}{\Xi}$ & 官 & $\begin{array}{l}0 \\
\stackrel{ \pm}{ \pm}\end{array}$ & $\begin{array}{l}0 \\
\stackrel{0}{0}\end{array}$ \\
\hline & 오 & ざ & $\stackrel{?}{\Upsilon}$ & $\stackrel{N}{N}$ & $\overrightarrow{0}$ & $\widetilde{\sigma}$ & $\widetilde{\sigma}$ & 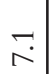 & $\stackrel{0}{r}$ & 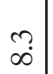 & $\begin{array}{l}\infty \\
a\end{array}$ & $\stackrel{+}{\circ}$ & $\stackrel{?}{=}$ & $\stackrel{\rightleftarrows}{\circ}$ & $\stackrel{ }{\circ}$ & $\begin{array}{l}0 \\
a\end{array}$ & $\stackrel{?}{0}$ \\
\hline & $\stackrel{12}{\sim}$ & $\begin{array}{l}\sigma \\
\dot{0}\end{array}$ & $\begin{array}{l}\infty \\
\dot{1}\end{array}$ & $\vec{a}$ & $\vec{\circ}$ & மִ & ํ. & $\dot{t}$ & $\begin{array}{l}\infty \\
\dot{1}\end{array}$ & $\overrightarrow{0}$ & $\tilde{\theta}$ & $\stackrel{?}{\sim}$ & $\begin{array}{l}0 \\
\sim \\
-1\end{array}$ & $\stackrel{0}{N}$ & $\stackrel{+}{\sim}$ & $\stackrel{?}{\sim}$ & $\infty$ \\
\hline & 윽 & $\stackrel{\sigma}{\sigma}$ & $\begin{array}{l}\infty \\
\dot{+}\end{array}$ & $\begin{array}{l}0 \\
\dot{1}\end{array}$ & $\stackrel{\sim}{\dot{\sigma}}$ & 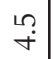 & $\stackrel{?}{+}$ & $\stackrel{?}{+}$ & $\begin{array}{l}\infty \\
\dot{\sim}\end{array}$ & $\stackrel{\infty}{+}$ & ?ִ & nִ & $\begin{array}{l}0 \\
\dot{1}\end{array}$ & $\vec{r}$ & $\begin{array}{l}0 \\
0 \\
0\end{array}$ & $\overparen{6}$ & $\overrightarrow{6}$ \\
\hline & in & $\stackrel{n}{+}$ & $\stackrel{+}{+}$ & $\stackrel{n}{+}$ & 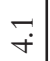 & $\underset{\forall}{\stackrel{O}{*}}$ & $\vec{\sigma}$ & $\begin{array}{l}\infty \\
\dot{r}\end{array}$ & 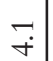 & $\stackrel{\sim}{+}$ & $\stackrel{\sim}{+}$ & $\stackrel{q}{+}$ & 今 & テ & $\stackrel{\bullet}{\dot{f}}$ & $\begin{array}{l}0 \\
\dot{0}\end{array}$ & $\underbrace{b}$ \\
\hline $\begin{array}{l}\frac{0}{\tilde{Z}} \\
\frac{\pi}{\tilde{C}} \\
\end{array}$ & 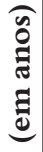 & $\begin{array}{l}\sigma \\
1 \\
0 \\
0 \\
-\end{array}$ & $\begin{array}{c}\hat{\sim} \\
\text { vi } \\
1 \\
0 \\
\stackrel{v}{v}\end{array}$ & $\begin{array}{c}a \\
\dot{\gamma} \\
1 \\
0 \\
\dot{m}\end{array}$ & $\begin{array}{l}\sigma \\
\dot{+} \\
1 \\
0 \\
\dot{+}\end{array}$ & $\begin{array}{c}a \\
i n \\
1 \\
0 \\
\dot{10}\end{array}$ & $\begin{array}{l}a \\
0 \\
1 \\
0 \\
0\end{array}$ & $\begin{array}{c}\Omega \\
\cdots \\
1 \\
0 \\
\end{array}$ & $\begin{array}{c}a \\
\infty \\
1 \\
0 \\
\infty\end{array}$ & $\begin{array}{l}a \\
a \\
1 \\
0 \\
a\end{array}$ & $\begin{array}{l}\mathfrak{a} \\
\stackrel{0}{1} \\
1 \\
0 \\
\dot{0}\end{array}$ & $\begin{array}{l}a \\
= \\
1 \\
0 \\
\vdots \\
=\end{array}$ & $\begin{array}{c}a \\
\mathfrak{I} \\
1 \\
0 \\
\mathfrak{d}\end{array}$ & $\begin{array}{c}a \\
\stackrel{2}{2} \\
1 \\
0 \\
\ddot{g}\end{array}$ & $\begin{array}{l}9 \\
\dot{ \pm} \\
1 \\
0 \\
\dot{ \pm} \\
\dot{J}\end{array}$ & $\begin{array}{c}a \\
\stackrel{0}{n} \\
1 \\
0 \\
\dot{1} \\
\dot{1}\end{array}$ & $\begin{array}{l}a \\
\underline{0} \\
-1 \\
0 \\
0 \\
0 \\
-1\end{array}$ \\
\hline
\end{tabular}




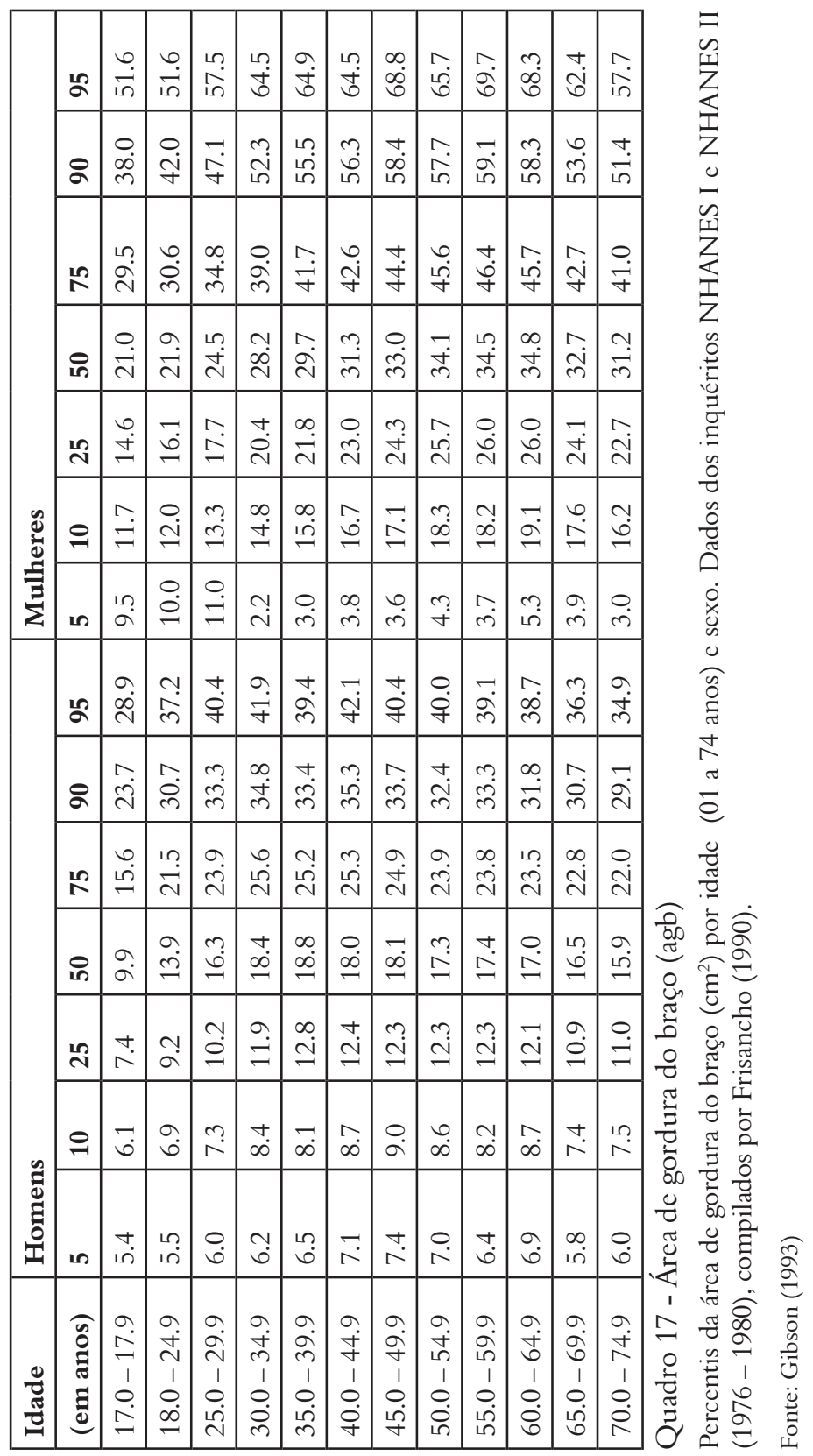




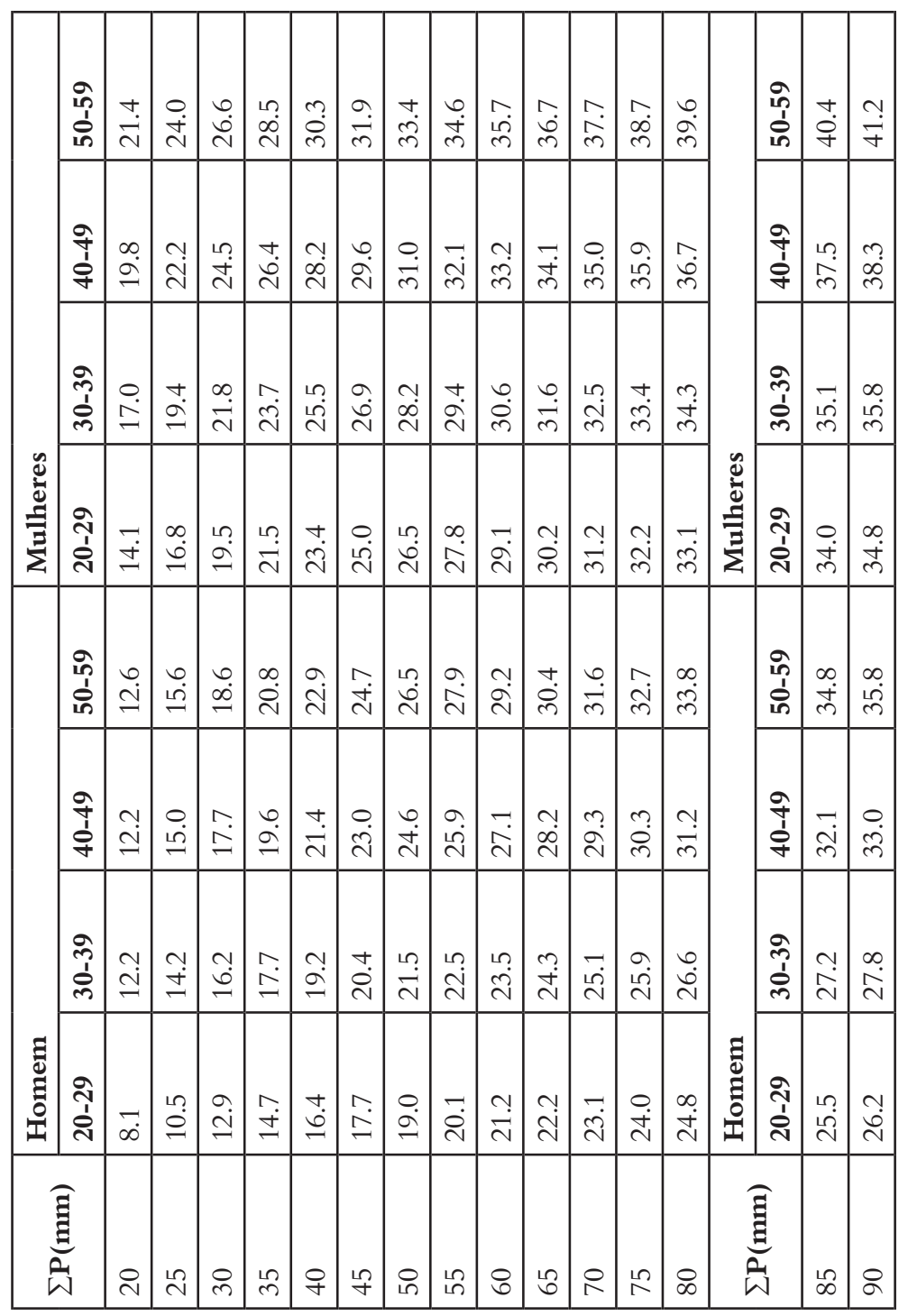




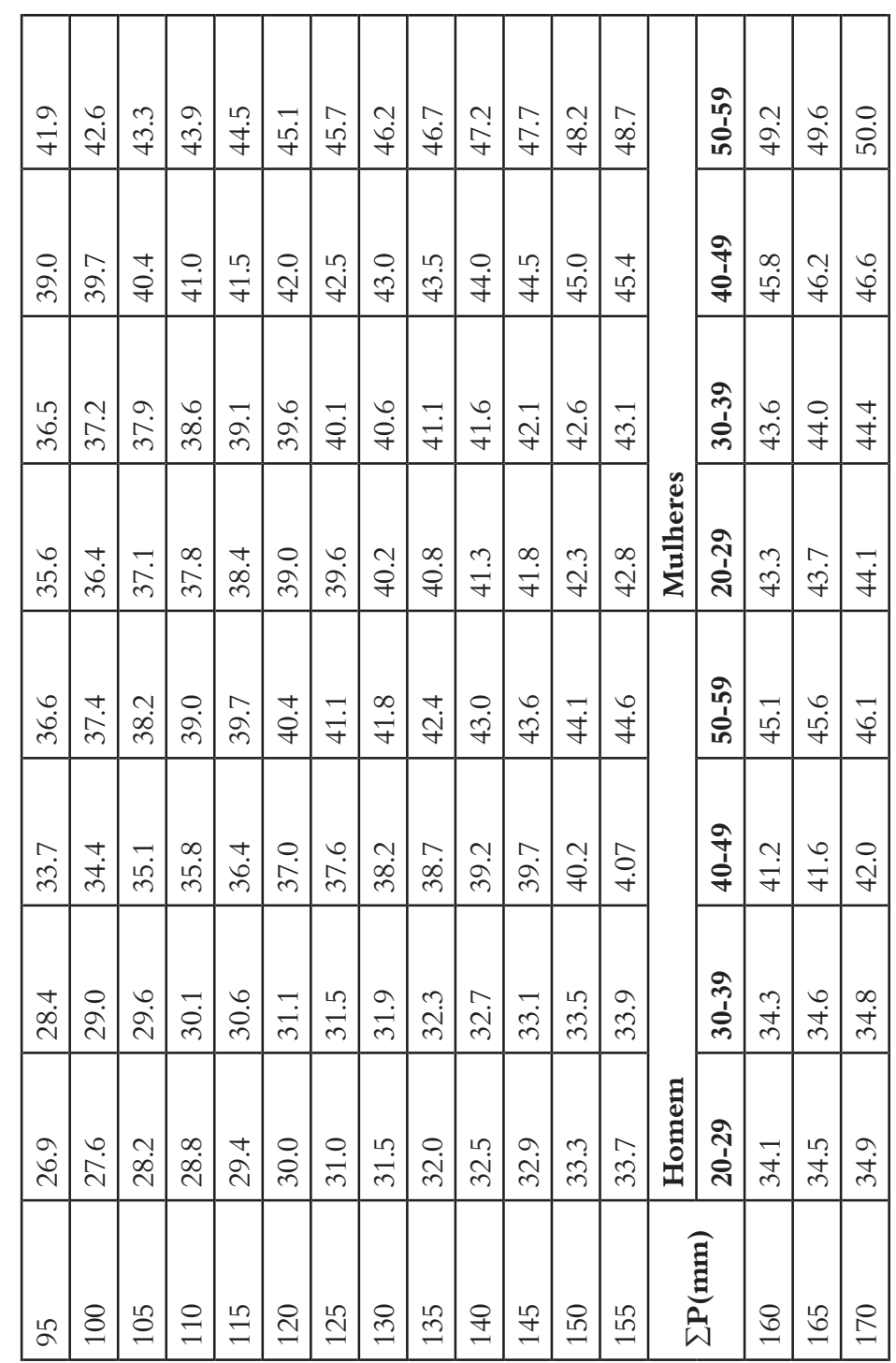




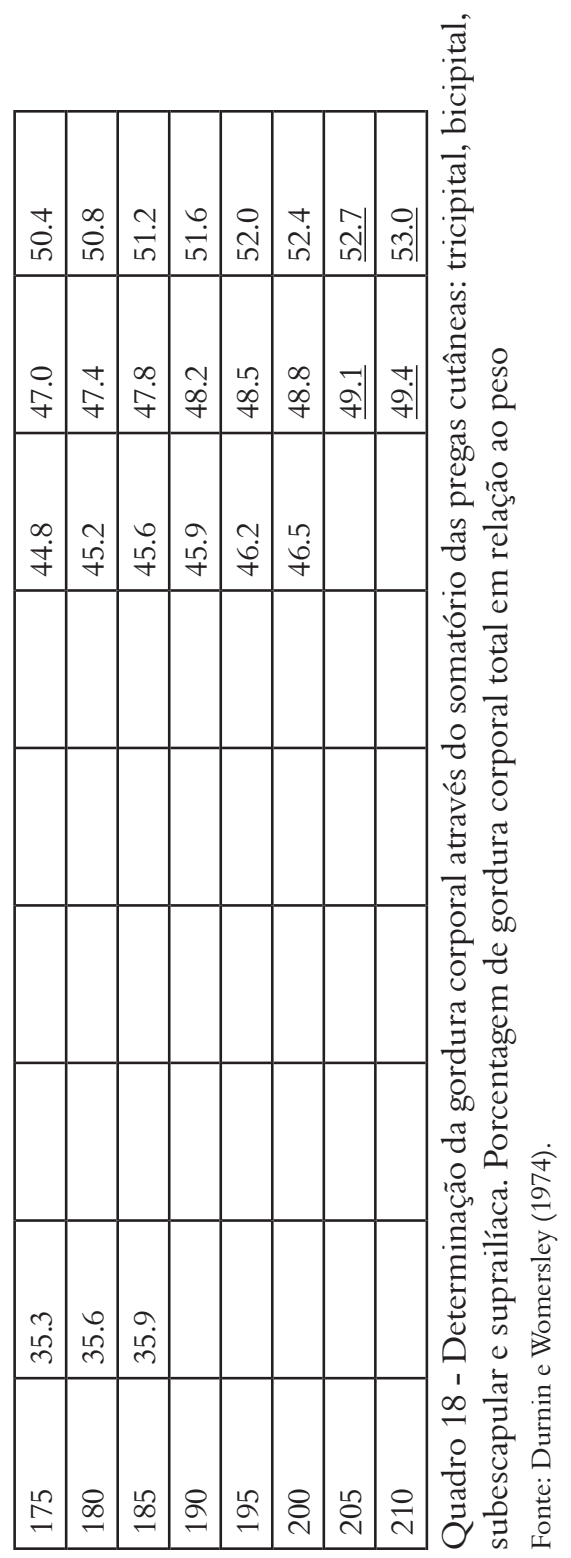




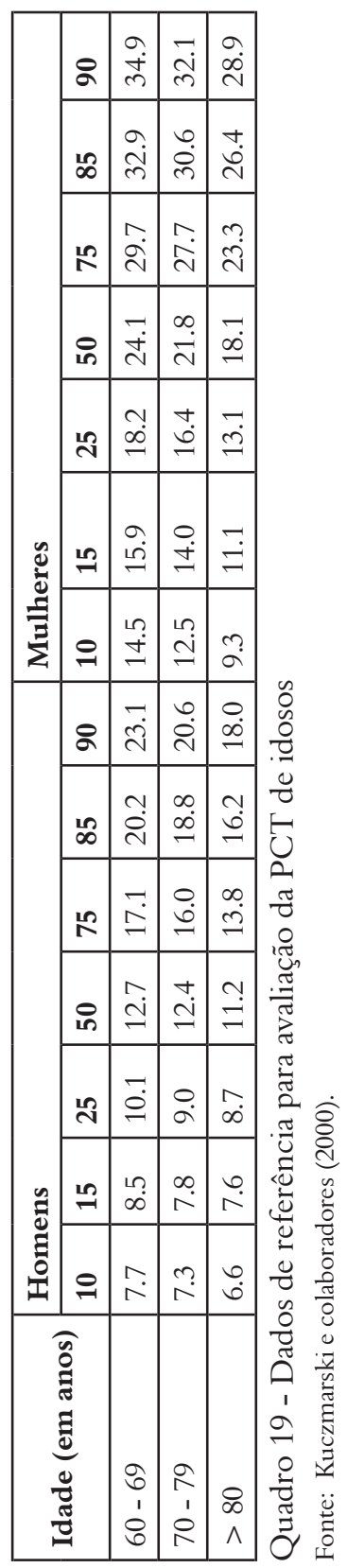

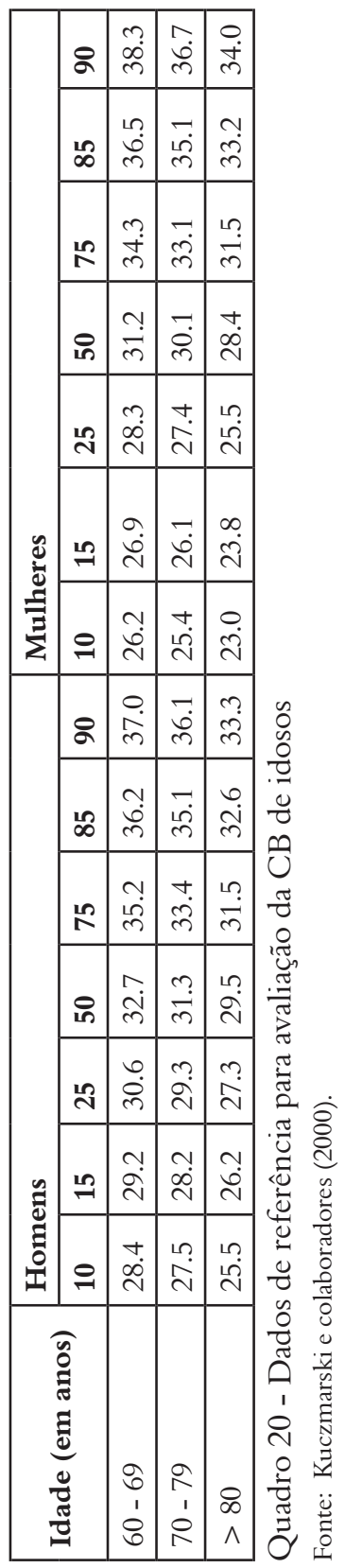




\begin{tabular}{|c|c|c|c|c|}
\hline \multirow{7}{*}{$\frac{\tilde{d}}{0}$} & ㅇ & $\stackrel{+}{\stackrel{\Delta}{N}}$ & $\stackrel{0}{\hat{N}}$ & $\begin{array}{l}0 \\
\stackrel{\leftrightarrow}{0}\end{array}$ \\
\hline & $\infty$ & $\begin{array}{l}0 \\
\dot{\sigma} \\
\sim\end{array}$ & ֶి & $\stackrel{+}{\stackrel{\leftrightarrow}{v}}$ \\
\hline & $\stackrel{10}{x}$ & $\stackrel{+}{\stackrel{\sim}{d}}$ & $\begin{array}{l}\infty \\
\stackrel{+}{\sim}\end{array}$ & $\stackrel{i n}{\stackrel{\sim}{d}}$ \\
\hline & 오 & ஸे & $\stackrel{\circ}{\grave{\jmath}}$ & $\begin{array}{l}0 \\
\stackrel{1}{N}\end{array}$ \\
\hline & $\stackrel{\stackrel{2}{N}}{ }$ & $\frac{\sigma}{\sim}$ & $\stackrel{0}{\stackrel{0}{N}}$ & $\stackrel{\tilde{\delta}}{\tilde{\delta}}$ \\
\hline & $\stackrel{10}{\sim}$ & $\stackrel{\overbrace{}}{\overparen{C}}$ & $\stackrel{\infty}{\stackrel{\leftrightarrow}{\sim}}$ & $\stackrel{0}{\stackrel{1}{0}}$ \\
\hline & $\stackrel{ }{ }$ & $\begin{array}{l}\stackrel{0}{\sim} \\
\stackrel{\sim}{0}\end{array}$ & $\stackrel{?}{\stackrel{1}{2}}$ & $\stackrel{n}{\varrho}$ \\
\hline \multirow{7}{*}{ 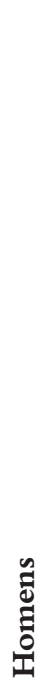 } & ฉ̊ & $\underset{⿱ 亠}{\dot{m}}$ & $\stackrel{\text { !n }}{\stackrel{2}{0}}$ & $\begin{array}{l}\infty \\
\infty \\
\stackrel{0}{N}\end{array}$ \\
\hline & $\infty$ & 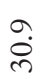 & O. & $\begin{array}{l}\stackrel{N}{\infty} \\
\stackrel{\infty}{N}\end{array}$ \\
\hline & $\stackrel{10}{x}$ & $\stackrel{0}{\stackrel{0}{0}}$ & $\begin{array}{l}a \\
\stackrel{\infty}{d}\end{array}$ & $\stackrel{n}{\sim}$ \\
\hline & in & $\begin{array}{l}\stackrel{+}{\sim} \\
\stackrel{\infty}{0}\end{array}$ & $\stackrel{N}{N}$ & $\stackrel{\sim}{\stackrel{N}{1}}$ \\
\hline & $\stackrel{1}{\sim}$ & $\stackrel{\sim}{\sim}$ & $\begin{array}{l}\vec{\omega} \\
\stackrel{\mathrm{N}}{\mathrm{N}}\end{array}$ & $\begin{array}{l}0 \\
\dot{d}\end{array}$ \\
\hline & $\stackrel{n}{\rightarrow}$ & $\begin{array}{l}0 \\
\stackrel{\leftrightarrow}{\sim}\end{array}$ & $\begin{array}{l}\infty \\
\dot{d}\end{array}$ & 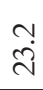 \\
\hline & $\stackrel{ }{ }$ & 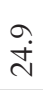 & $\underset{⿱}{\stackrel{+}{d}}$ & $\begin{array}{l}0 \\
\stackrel{N}{N}\end{array}$ \\
\hline \multicolumn{2}{|c|}{ 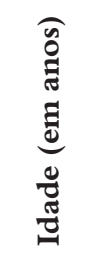 } & $\begin{array}{l}\text { oे } \\
\text { ' }\end{array}$ & 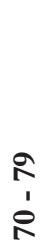 & $\begin{array}{l}\infty \\
\wedge\end{array}$ \\
\hline
\end{tabular}




\begin{tabular}{|c|c|}
\hline & Colofão \\
\hline Formato & $15 \times 21 \mathrm{~cm}$ \\
\hline Tipologia & $\begin{array}{l}\text { Aldine } 401 \mathrm{BT} \\
\text { Castle T e Castle T Ling }\end{array}$ \\
\hline Papel & $\begin{array}{l}\text { Alcalino } 75 \mathrm{~g} / \mathrm{m}^{2} \text { (miolo) } \\
\text { Cartão Supremo } 250 \mathrm{~g} / \mathrm{m}^{2} \text { (capa) }\end{array}$ \\
\hline Impressão & EDUFBA \\
\hline Capa e Acabamento & Cartograf \\
\hline Tiragem & 400 exemplares \\
\hline
\end{tabular}

